\title{
WestVirginiaUniversity
}

THE RESEARCH REPOSITORY @ WVU

Graduate Theses, Dissertations, and Problem Reports

2015

\section{A Descriptive Study of NCAA Life Skills Programs in the Big Ten Conference}

Marc Joseph Williams

Follow this and additional works at: https://researchrepository.wvu.edu/etd

\section{Recommended Citation}

Williams, Marc Joseph, "A Descriptive Study of NCAA Life Skills Programs in the Big Ten Conference" (2015). Graduate Theses, Dissertations, and Problem Reports. 6956.

https://researchrepository.wvu.edu/etd/6956

This Dissertation is protected by copyright and/or related rights. It has been brought to you by the The Research Repository @ WVU with permission from the rights-holder(s). You are free to use this Dissertation in any way that is permitted by the copyright and related rights legislation that applies to your use. For other uses you must obtain permission from the rights-holder(s) directly, unless additional rights are indicated by a Creative Commons license in the record and/ or on the work itself. This Dissertation has been accepted for inclusion in WVU Graduate Theses, Dissertations, and Problem Reports collection by an authorized administrator of The Research Repository @ WVU.

For more information, please contact researchrepository@mail.wvu.edu. 
A Descriptive Study of NCAA Life Skills Programs in the Big Ten Conference

Marc Joseph Williams, M.S.

Dissertation submitted

to the College of Education and Human Services

at West Virginia University

in partial fulfillment of the requirements for the degree of

Doctor of Education in

Department of Curriculum and Instruction and Educational Leadership

\author{
Sam Stack, Ph.D., Chair \\ Dana Brooks, Ed.D., Co-Chair \\ Jay Cole, Ph.D. \\ Neal Shambaugh, Ph.D. \\ Fernando Rivera, Ph.D. \\ Department of Curriculum and Instruction
}

\title{
Morgantown, West Virginia \\ 2015
}

Keywords: ncaa, life skills, big ten conference

Copyright @ 2015 Marc Joseph Williams 


\begin{abstract}
A Descriptive Study of NCAA Life Skills Programs in the Big Ten Conference
\end{abstract}

Marc Joseph Williams

The purposes of this study were: (1) To determine if Life Skills Programs exist in all of the 14 Big Ten Schools, (2) To determine if the NCAA Division I-A Life Skills Commitment Statements were utilized at all the Big Ten Schools and (3) To determine how Big Ten administrators perceived Life Skills Programs are across all 14 Big Ten Universities.

It was anticipated that all Big Ten colleges had a Challenging Athletes' Minds for Personal Success Life Skills Program on their campus. All Big Ten Life Skills administrators perceived their programs to be effective.

A written questionnaire based on the literature was constructed to answer the three research questions posed by the researcher. Upon IRB approval, the questionaire was emailed to the Big Ten administrators of the Life Skills Programs. The following universities located within the Big Ten conference were requested to participate: Indiana University, Michigan State University, Northwestern University, Ohio State University, Penn State University, Purdue University, Rutgers University, University of Illinois, University of Iowa, University of Maryland, University of Michigan, University of Minnesota, University of Nebraska, and University of Wisconsin.

The questionnaire consisted of two parts; each part took approximately 20 minutes to complete. The researcher made follow up phone calls if the subjects did not respond to the emailed questionnaires after two weeks. Ten of the fourteen Big Ten administrators participated in the study. The researcher found that all ten $(n=10)$ schools offered Life Skills Programs, All ten $(n=10)$ schools provided five of the Life Skills Commitment Statements and all ten $(n=10)$ schools reported their Life Skills Programs were effective. 


\section{WEST VIRGINIA UNIVERSITY}

The Undersigned Faculty Committee Approves the

Dissertation of

Dr. Marc Joseph Williams

A Descriptive Study of NCAA Life Skills Programs in the Big Ten Conference

Submitted by Marc Williams in partial fulfillment of the requirements for the degree of Doctor of Education specializing in Education Leadership. Accepted on behalf of the Faculty of the Graduate School by the dissertation committee.

\begin{tabular}{c}
\hline Sam Stack, Ph.D., Chair \\
\hline Dana Brooks, Ed.D., Co-Chair \\
\hline Neil Shambaugh, Ph.D., \\
Jay Cole, Ph.D., \\
Fernando Rivera, Ph.D., \\
Approval Date
\end{tabular}




\section{DEDICATION}

This study is dedicated to the two people most responsible for my success in life-my parents. Thank you for all the love, guidance, patience, and support. You believed in me when I did not believe in myself. You are my heroes. You provided the vision, the blue print for all my siblings' successes. To my mother, who is battling cancer: you are a warrior. You are the most fearless person I have ever met. I appreciate all of your love and the sacrifices you made for me. Know that I GOT YOU, and I promise to find a way to work to find a cure for this disease you are conquering. Dad, you are the smartest man I know. I am grateful that you NEVER compared me to my siblings or anyone else. You always told me that I could be anything and to "stay in my lane" and I would be okay. I promise to carry on your legacy of being a champion of education. I now realize where I get the love for collaborating with others and ability to be comfortable with any human being on the planet. I get my swagger and gift of speech from you, and I get my love for mankind and sensitivity from Mom. Thank you for never giving up on me. Everything I am and will be is because of you both. I love you both!

To Grandma Opal: The profound effect you had on our family in your 93 years on this planet is beyond remarkable - what an inspiration you are. I would have never been able to pursue my undergraduate degree if it were not for the empathy, love, and support you provided. I will never forget you opening your home to me when I became a man, grew up, and decided to finish my undergraduate degree. Most of all, I have become a dedicated man of faith because of the example you provided to me, my siblings, and my parents. Thank you for gracing all of us with your presence, I will always love and respect you. Can you believe your little "Marky" will be Dr. Marc Joseph Williams? 


\section{ACKNOWLEDGEMENTS}

I would be remiss if I did not first acknowledge my creator for blessing me with remarkable parents; amazing siblings; and the gifts of passion, hard work, and the determination to be excellent. My brilliant brother Sanford, thank you for never giving up on me and showing me how to live with purpose and integrity. My Sister Kori, one of the smartest women I know, I admire your tenacity, work ethic, and love for education and your family. Thank you to my brother Ben for always encouraging me and letting me know that my greatest days are ahead of me.

Dr. Lapchick, it is truly an honor to know you. Over twenty years you have been a mentor, friend, colleague and father figure. I love you my friend, thank you for always believing in me.

I thank my Uncle Fred for always being so positive and encouraging me through my doctoral journey. To Kyle, Sherice, and your wonderful kids for your consistent support and always opening your home to me. Thanks to my all my amazing nieces and nephews who continue to impress Uncle Marc. Kiara, Johnathan, Nia, DJ, and Kendall, what great parents you have, you are all equipped with the blue print provided by your parents, it is now up to you! To my sister-in-law and brother-in-law, Anastasia and Darrell, thank you for holding my siblings down, being great spouses to them, and opening your home to me. I am honored to be related to you both. To Momma and Father Bayardelle, thank you for always supporting me, giving me words of encouragement, and most of all feeding me beans and rice when I came to visit. To John, I am proud of you. I am confident you will find that special something where your light will shine. Your relentless work ethic showed me how much harder I needed to work on my writing. 
I thank the McCloud family for your support. Most of all thank you Henry McCloud for being a great example and serve as my first educational and career mentor. You were instrumental in setting the foundation for my journey in education. I will never forget all that you have done for me personally and professionally.

I want to express my sincere appreciation to Dr. Dan Hursh. I had the honor of taking three of my doctorate classes with him, and he ultimately became my Chair. Unfortunately he had to retire from the University and cut his distinguished career short due to an unexpected battle with cancer. He is a true survivor and inspiration. You fought the battle of your life and you WON! I admire this man; he never let his illness be an obstacle. He continued to keep in touch with me and worked tirelessly to ensure that I was staying the course. He would not let me give up in spite of the many obstacles I faced. I love him for that, and I pray I will grow to become half the man and educator he is - a true inspiration. Thank you!

To all of the Big Ten administrators who took the time out of their schedules to participate in this study, I will always remember each of you and we will forever be connected. It was truly an honor and privilege to get to know you all on a personal and professional level. The time and feedback you have provided was invaluable. The information you shared with me will help future administrators and the NCAA with identifying unique programming for their future.

A special thank you to my dissertation committee. Dr. Stack, I learned so much from you by taking three of your classes, I never imagined you would eventually serve as my dissertation chair. I am forever grateful to you for stepping in and chairing my committee. I am very appreciative of your honesty and the confidence you had in me. I will never forget you, I appreciative of everything you did for me. 
I want to thank Dana Brooks, who recruited me seven years to pursue my doctorate at West Virginia University. I would never have imagined in my wildest dreams after leaving corporate America that I would pursue a doctorate - let alone at West Virginia University. I am deeply humbled and honored that you chose to be my co-chair of my committee. I am still blown away by your commitment as a dean, that you took countless hours to counsel me, critique me, humble me, and teach me to be a better writer, educator, and human being. Words cannot express the pride I feel knowing that you supported me and believed in me. Thank you for believing in me and encouraging me to be the best I can be.

Dr. Jay Cole, Chief of Staff at WVU, words cannot express how I feel when I think of how you took an interest in me and created the administrative fellowship for me. You have been an inspiration to me, and it warms my heart to know that you among a few others who stood by my side throughout my journey. I appreciated all of the words of encouragement you have given me and that you always maintained the notion I would make a great university president one day_-if I decided to pursue that route. It is quite humbling hearing that encouragement from someone of your stature. You kept me focused when there were days when I wanted to leave and transfer. You helped keep my sanity and focus, thank you!

Dr. Neil Shambaugh, thank you for stepping in, supporting me, and joining my committee. I am forever grateful for your feedback, knowledge, and honesty you provided me. I want to thank Dr. Louisa Colon for all of her hard work, dedication, and belief in me. I sincerely appreciated all of your edits and tireless hours you spent working with me. Dr. Dooley, I am, and have been, in awe of you since I met you four years ago. I have never met a women with such purpose, wisdom, spirituality, and education than this woman. I am forever grateful for all that you have done for me. Although we did not interact a lot, the time you have given me to learn 
from you has been invaluable. Lastly, you stepping in to sit in on my defense is something I will never forget. Thank you.

While Dr. Ernest Goeres was not on my committee, his leadership ensuring that I selected the right committee members and that I was moving forward will never be forgotten. I am humbled by all of your help and your positive energy that fueled me each time I interacted with you. I will always be grateful to the tireless energy you dedicated to ensure that I was on the right track. Thank you.

I want to thank the Department of Education and Human Services for giving me a home to pursue my doctorate. Thank you to all of WVU professors in the College of Education and Allen Hall, who challenged me to be the best I can be.

Most of all I thank Dr. Sorber and Dr. Fierstein, who challenged me to not be afraid to write and live up to my potential. I appreciate the lessons you taught me, and will be eternally grateful to you. Because of Dr. Dick Walls, a legend in his field and a true honor to learn from, I learned to have fun in my journey because of his wonderful engaging spirit. I also want to thank all of the administrative assistants who went above and beyond for me, always had a welcoming smile, and consistently cheered me on. Kimberly Mooniack, Rosemary Hirblan, and Eva Taylor.

Most importantly, I thank Connie Miranov for keeping me on task and challenging me to meet all of my deadlines. I will never forget how you stepped in and stepped up to see that I followed each step with meeting all of my doctoral requirements. Every doctoral student needs a person like you - thank you so much! Special thanks to the professors who I was not fortunate to take classes with in the College of Education but who always gave me words of encouragement and a pat on the back each time I saw them. Dr. Charline Barnes Rowland, I appreciate all the 
golden nuggets you shared with me and taking an interest in my development as a man and a student.

Dr. Chapman, it was you who accepted me into the College of Education and gave me the blue print to succeed while pursuing my Doctorate. I realize you put your neck out for me, and I am thankful to you for giving me the opportunity to attend WVU. I am eternally grateful to you, and I will never forget all the lessons you taught me. I promise to justify the faith you put in me; please know I learned my lessons, and I will always be a vessel and symbol for educators around the world. I am here to stay! Thank you.

Dr. Constinia Charbonnette, it brings tears to my eyes when I think of all the sacrifices you have made to provide me such wonderful opportunities at WVU. If not for you, I would never have been able to afford school. I thank you and the Office of Graduate Studies for providing me with a fellowship to attend graduate school. There is nothing like having a person cheering you and always encouraging you through the good and bad. When I decided to finally listen to you and your words of wisdom, I learned to fly. Thank you my friend. I will always be here for you anytime you call upon me. Thank you.

Michael Ellington, thank you for believing when others did not. You have been a great mentor, friend, and confidant. I am forever grateful to you; it was truly an honor to learn from you. I pray you will continue to be supportive of me. I learned a great deal from you. Thank you. I also want to thank members of the WVU Residence Life community who allowed me to be a "live-in resident." Ralph Schmitt and Kevin Hall provided a place for me to live for the past four years.

I would also like to thank David Durham, Career Services, Office of Admissions, College of Physical Activity and Sport Sciences; and Dr. Jack Watson, Dr. Valerie Wayda, and Karen 
Blaney - I am grateful to all of you for consistently championing me and giving me the platform to work with your students. Thank you Kim Cameon for your consistent and unwavering support of me.

Special thanks to Nita Shippy, my editor and friend. Thank for reading every word of this document, you are remarkable and your attention to detail was invaluable. Thank you!

To my Nebraska family: Dr. Tom Osborne, my career would not have begun in sports if it was not for you, and for this I will always be eternally grateful to you! What an honor to have a man of your stature trust me and endorse me to your staff and your 1995 National Championship team.

Keith Zimmer, thank you for believing in my vision and supporting me over the past twenty years. The topic of this dissertation would not have been possible if it were not for your belief in me. It is truly an honor and blessing to learn from the man that is the standard for Life Skills. More importantly, I love your integrity, empathy and dedication to the development of student athletes.

To the greatest College Football punt returner of all time, Mr. Johnny Rodgers. It has been a privilege to know you. I love you much, you are a true friend.

To my Alpha Phi Alpha Brothers; Jay Harris, Dr. James Davis, Dr. Howard Bartee, Donnie Brooks, James Payne (JP) and Dr. Leon Prieto. I love all of you Brothers, let's continue to provide: Manly deeds, Scholarship, and Love for all mankind! 06!

It is my profound honor to thank my mentor and dear friend Dr. Deirdre Royster. It was you that told me in 2010 that I should consider pursing my Doctorate in Education, it was the best decision in my life- thank you! 
Dr. Elton Briggs, thank you for always encouraging me and staying focused. I know there were days when you were thinking I was unfocused-perhaps I was. Thank you for being there and becoming a friend.

To my Umass Sport Management Graduate School Brothers. Thank you Brother Ted Dalton, my dear friend of sixteen years. You have been my man, my friend, my supporter--you are a rock star! The Boston Celtics are blessed to have you. Brother Chris Salani, a man of a few words but when you speak, your words are heart felt. I thank you for your support of me, I will never forget the things you have done for me.

William Paterson University, thank you for giving me a wonderful platform to showcase my talents, educating me and allowing me to network with the amazing people. Thank you Robert and Eleanor Taylor for embracing me like I was one of your own. I thank Dr. Parrillo for being a great mentor. I thank the Department of Sociology, Dr. Flint and Dr. Baumgartner for encouraging me. Thank you to the University of Massachusetts at Amherst Sport Management Program for giving me a chance to excel and your patience.

To those great Basketball coaches that believed in me and gave me access to their student athletes. John Calipari, I am grateful to you and proud of everything you have accomplished. James Bruiser Flint, thank you for believing in me when nobody else did and providing me access. You are and have been always be an inspiration to me. Larry Harrison, you have been such a friend and always supporting me in all my endeavors. Thank you for the love you have shown me and advocating for me-you are a true friend. Bob Huggins, thank you for always being accessible and trusting me with your student athletes. Coach Lewis Jackson, from the $1^{\text {st }}$ day I met you, I loved your energy, spirit and kindness you have shown me. Thank you for trusting and believing in me. Brenda Nichols, thank you for your friendship and trust in me to 
provide leadership to your players. To Semeeka Randall, one of the greatest college basketball players of all time! It is an honor to call you "friend."

To my George Mason University family, thank you Dr. Wiggin, Craig Esherick, Dr. Gorell. Dr. Baker, words can’t express my thanks for you taking a chance on me to give me my first teaching opportunity at a University. My experience at George Mason prepared me for the academy, I will never forget you, thank you. Thank you for believing in me and taking a chance on me. Craig, I can never repay you and your Wife for your selflessness- I am forever indebted to you guys.

I want to thank the athletic directors and administrators that invited me to their campuses to speak to their student athletes about life skills, leadership and their personal brand. Thank you Bridgett Woodruff, Dr. Elizabeth Tovar, Keith Davidson, Penny Semaia, Lynn Thompson, Peyton Owens, Dr. Tanya Foster, Erica Nelson, Kathy Kaler, Dr. Sue Sherburne, Angela Montie, Lisa Franz, Eric Wood, Kevin Clark, Sherryta Freeman and Shawn Tucker.

Franklin Meredith, Alfreeda Goff, Kelly Vaughn, Bob Beaudine, Jay Crawford, Harvey Catchings and Wendy Lewis, thank you for your encouragement and friendship.

To the legendary Olympians who loved, supported and nurtured me. Ron Freemanthank you for always getting me to think more globally. I love you so much and honored that you always provided me with guidance, grace and wisdom. I am appreciative of you introducing me to your Olympian brothers from the tremendous 1968 track team and especially Larry James.

To Larry James, one of the greatest Olympians, Quarter milers, Athletic Directors, Husbands, Fathers and Mentors. Honored to know you and Cynthia. You set such a high standard, you are truly missed my dear friend. 
Johnny Gray, the baddest 800 meter runner the United States has ever seen, proud to call you my friend. Thank you for always believing in me. Harry Carson, you are the standard for excellence, so happy you made the NFL Hall of Fame!

To Rick Barry, one of the greatest NBA athletes of all time, I am proud to call you friend. I will never forget the patience and belief you had in me, I owe so much to you. To man Ray Lewis, future first ballot hall of famer. Thank you for your encouragement and friendship.

To Rocket Ismial, I never met a man so spiritually connected and such a genuine love for mankind. You have been a brother and spiritual advisor to me. I appreciate all the love you have shown me.

To three young Black male educators in their early 30's making a difference and inspiring young Black men across our great nation. Dr. Jamil Northcutt, Dr. Justin Ballenger and Daron Roberts---my man coached in the NFL, College and has a Harvard Law degree! You Brothers inspire me and we need to continue to motivate, inform and inspire these young people. Thank you for all you do to provide direction on empowering our youth, student and professional athletes. Thank you for coming in my life, I look forward to continue to build with each of you.

A special thank you to Robert Vowels who believed in me enough to give me an NCAA grant for two years to empower student athletes at Historically Black Colleges. I appreciate you and your belief in me, I can't thank you enough.

Thank you Floyd Kerr for allowing me to work with your student athletes at Morgan State University. Thank you for always encouraging me and being a great role model to me! Eric Hart, you have been an amazing cheerleader and support to me. Thank you Dr. Dennis Thomas for providing me the platform to meet all of your athletic directors, I am eternally grateful to you. 
To My Alabama State University Family, thank you! I appreciate Melvin Hines and Jaunelle White for their willingness to buy-in to our "Striving for Excellence" program for student athletes. Dr. Grandison, your friendship and support will never be forgotten. Thank you for all of your words of wisdom. I salute the entire athletic staff, coaches, administration and the profound student athletes at Alabama State University.

Very grateful to Jaclyn Small for believing in me. The impact you have on student athletes, young women and the human race is uncanny. A special thanks to Kyle Locke, thank you for believing in me, I look forward to working on the same campus as you one day, I love you Brother.

To three University Presidents that I love, respect and admire. Dr. Jim Clements, Dr. Wilson Bradshaw and Jim Collins. Thank you for taking an interest in me, encouraging me and consistently building me up. You have been inspiring and provided me a wonderful blue print in how to govern and lead. I pray we will continue to build in the years to come and most of all, thank you for believing in my vision to educate young people---especially student athletes. Thank you for your courage, boldness and vision-I Love all of you!

Wesley Mallette, thank you for your counseling and educating me how to protect my brand. Cal Berkeley and the student athletes are fortunate to have you. Thank you for being a great example of what it means to be a responsible man. Thirty three years and still counting!

The popular 1980's television shows; The Cosby Show and A Different World inspired me. The shows depicted a successful African American family and young African American's attending college and pursuing graduate degrees. I thank my favorite artist Jay $\mathrm{Z}$ for inspiring me. His music, business savvy and pursuit of excellence is unmatched I thank him for showing young African American men they can aspire to be anything they want. "The motivation for me 
is them telling me what I could not be.” These words fueled me each time someone said or suggested that I was wasting my time pursing my doctorate degree.

I thank my Mother for instilling in me that I am fearless and can do anything when I try. I thank my Father for telling me to "stay in my lane" and run my own race. The song "Black Butterfly" by Denise Williams played major role in my life and I listened to her words weekly in my pursuit of the highest degree in academia. Below are the profound lyrics:

Morning light, silken dream to flight

As the darkness gave way to dawn

You've survived, now your moment has arrived

Now your dream has finally been born

Black Butterfly, sailed across the waters

tell your sons and daughters

what the struggle brings

Black Butterfly, set the skies on fire

rise up even higher

so the ageless winds of time can catch your wings

While you slept, the promise was unkept

But your faith was as sure as the stars

Now you're free, and the world has come to see

Just how proud and beautiful you are

Let the current lift your heart and send it soaring

Write the timeless message clear across the sky

So that all of can read it and remember when we need it

That a dream conceived in truth can never die

Butterfly

Now that you're free and the world has come to see

Just how proud and beautiful you are

To all the future graduate students pursing the doctoral journey. I encourage you to identify your support network, a supportive committee, learn to relax, smile a lot and never give up!

Keep God first, pray each morning and be thankful for your wonderful blessings and opportunities. Time to spread your wings, you can do it! 
Table of Contents

Page

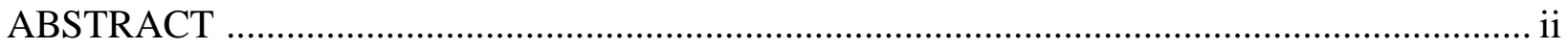

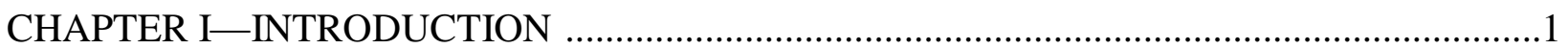

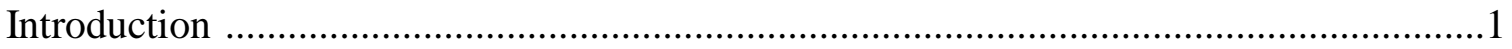

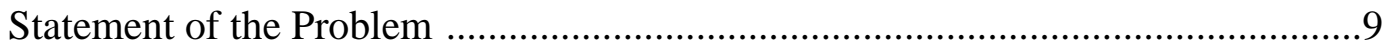

Significance of the Problem .......................................................... 9

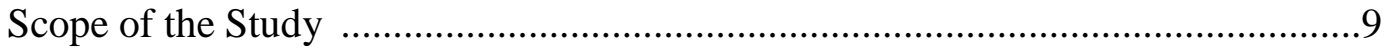

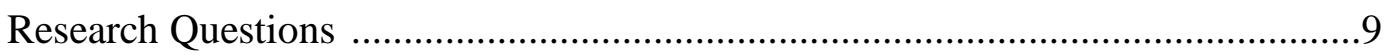

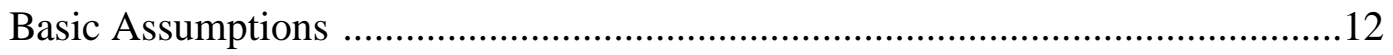

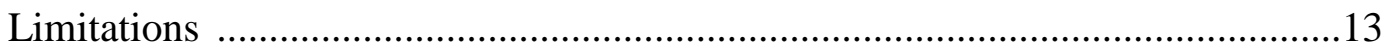

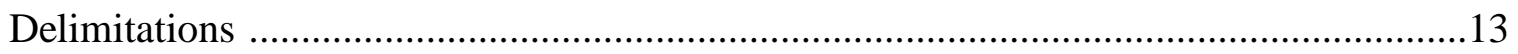

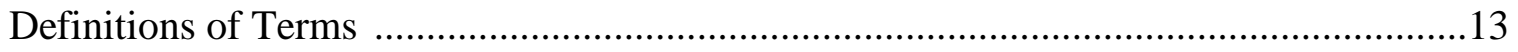

CHAPTER II-REVIEW OF THE LITERATURE .......................................................... 16

Overview of the History of College Athletics ...........................................................16

The African American Athlete and Coach in the late 1800s-1920s .......................17

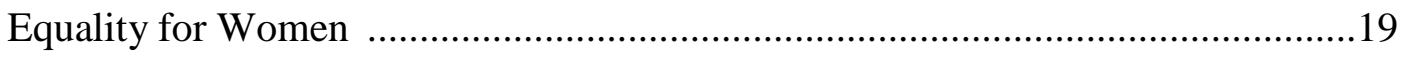

Graduation Rates ......................................................................................21

The Beginnings of Controversial Legislation .........................................................22

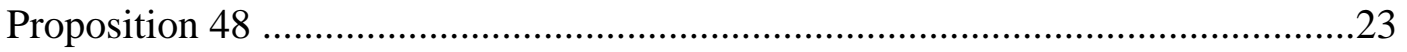

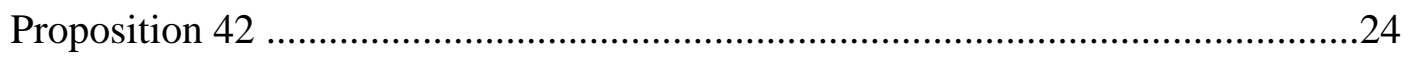

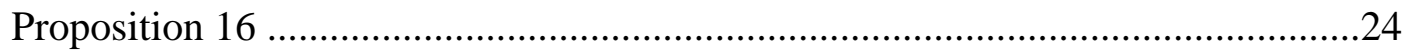


Table of Contents (Continued)

Page

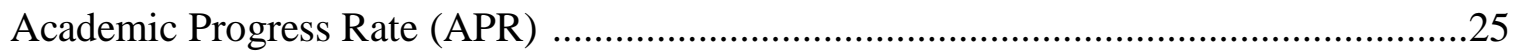

APR and Historically Black Colleges and Universities (HBCUs) ...................................26

Acceleration Academic Success Program .................................................................2

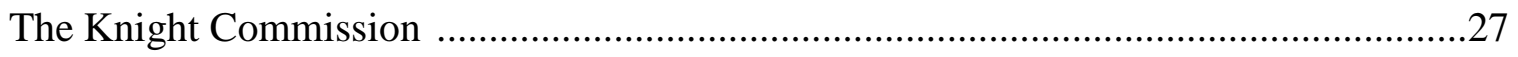

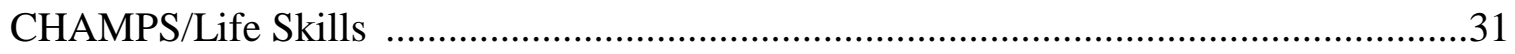

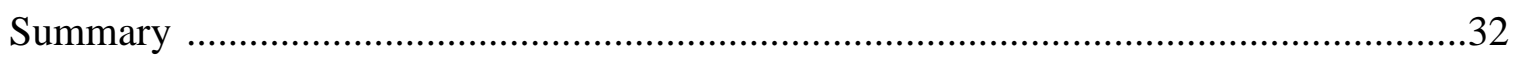

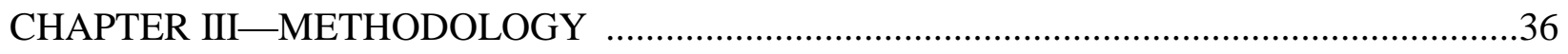

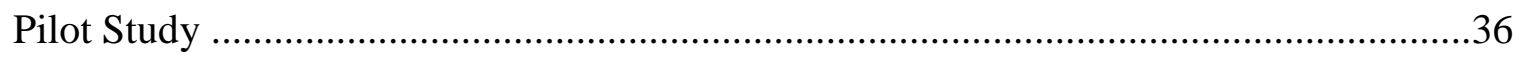

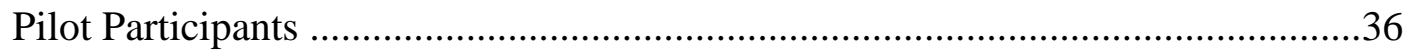

Ethnicity Composition of the Pilot Sample ………………………….......37

Amount of Life Skills Experience ……………………….......................37

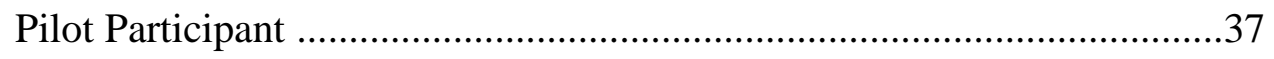

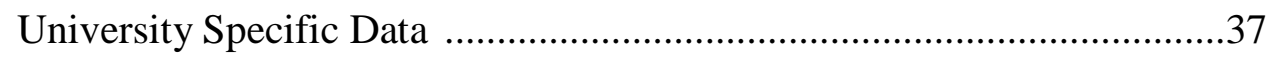

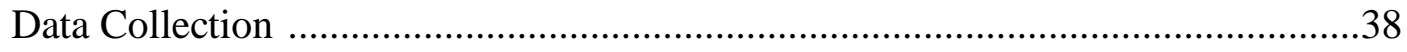

Perceptions about Clarity of Questions ………………........................................38

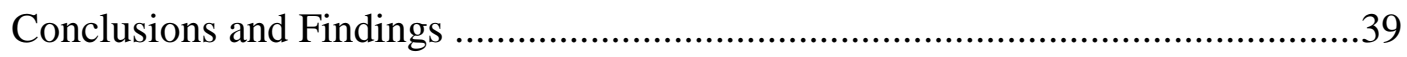

Concerns about the Life Skills Program …………………………….......41

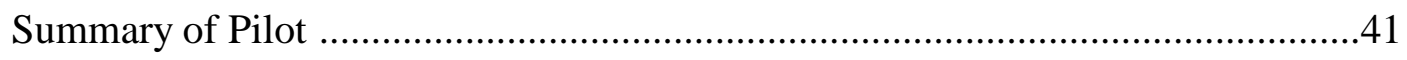

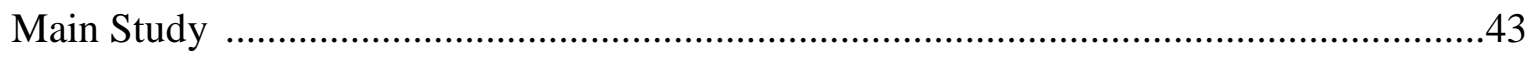

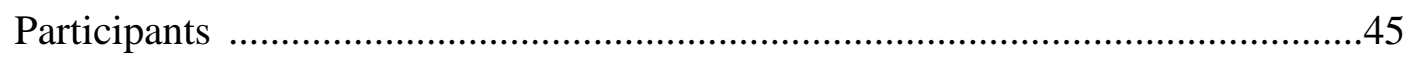

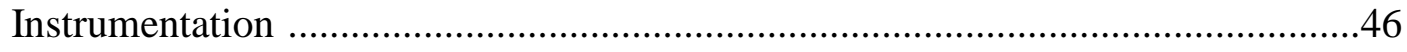


Table of Contents (Continued)

Page

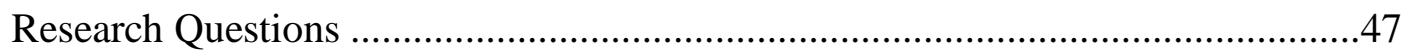

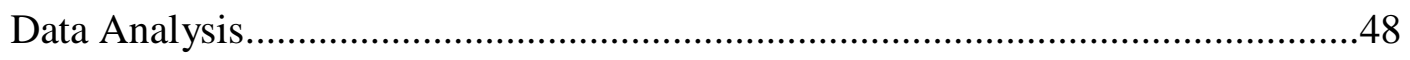

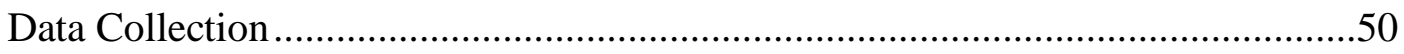

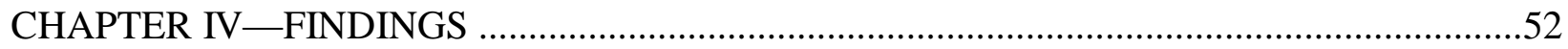

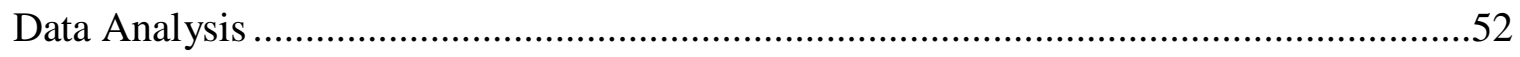

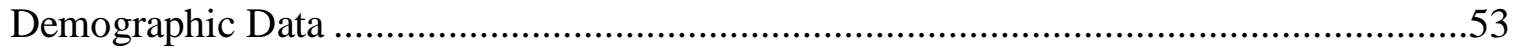

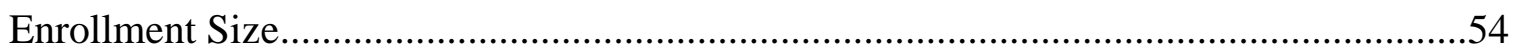

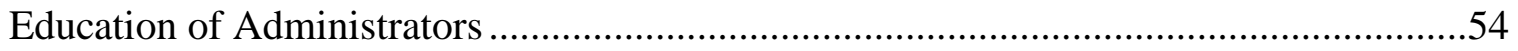

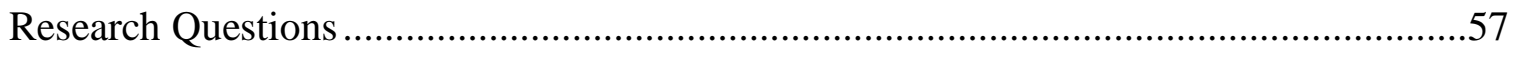

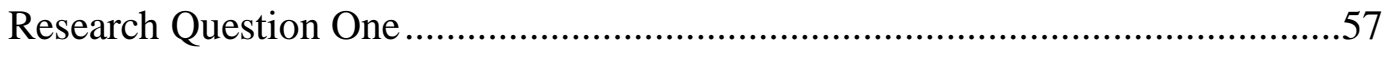

Research Question Two ..........................................................................57

Research Question Three ..............................................................................57

Quantitative Results of Effectiveness .........................................................................58

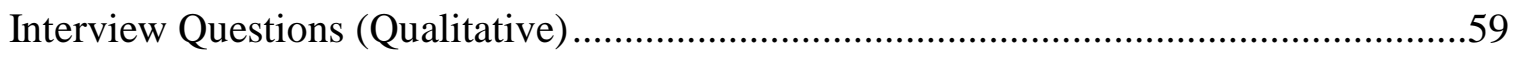

Common Strengths Reported by Big Ten Administrators Service .....................................60

Fully Comprehensive Program ...........................................................................61

Geographic Location and Career Enrichment.........................................................63

Athletic Director Support..............................................................................64

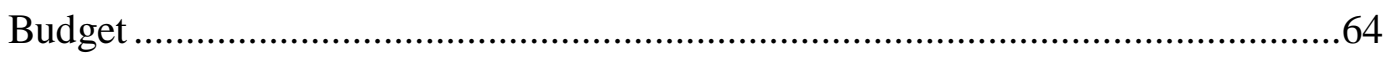

Programming that Focuses on Cultural Diversity ..................................................64 
Table of Contents (Continued)

Page

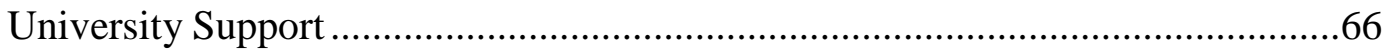

Influence of Being on the Senior Management Team ...........................................67

Mandatory vs. Non-Mandatory Attendance.......................................................68

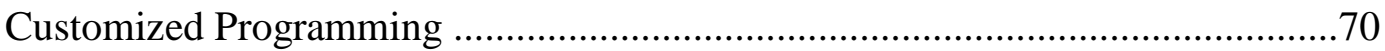

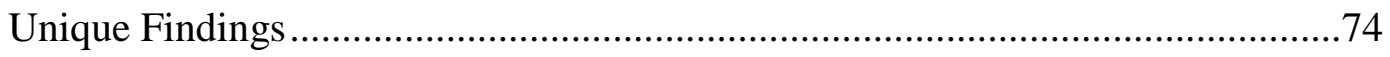

Leadership among African American Student-Athletes ..............................75

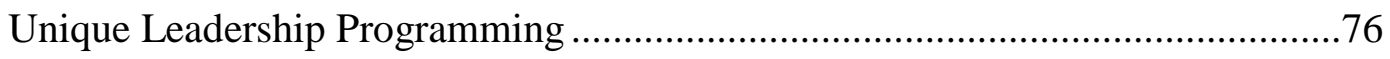

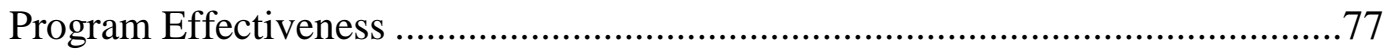

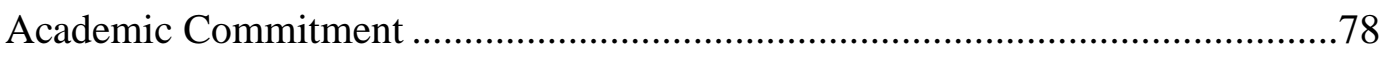

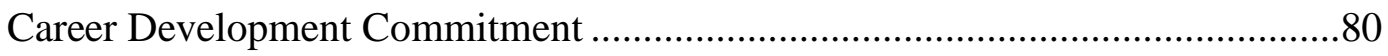

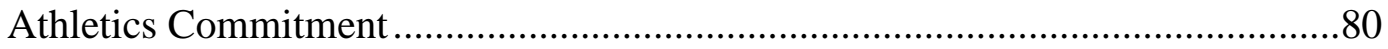

Personal Development Commitment ..................................................................81

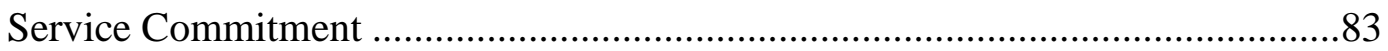

CHAPTER V—CONCLUSIONS AND RECOMMENDATIONS ……………….....................

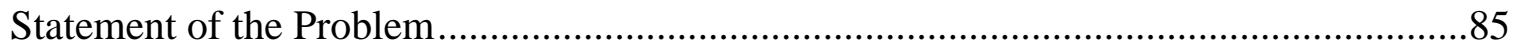

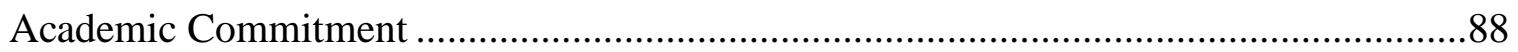

Career Development Commitment ..................................................................................

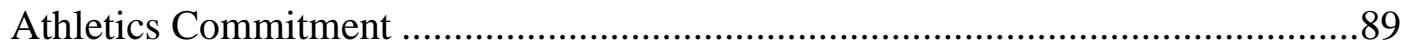

Personal Development Commitment....................................................................90

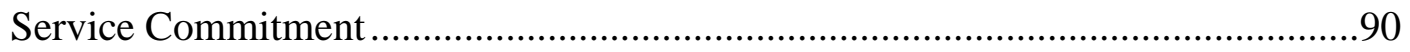


Table of Contents (Continued)

Page

Interview Questions ................................................................................ 90

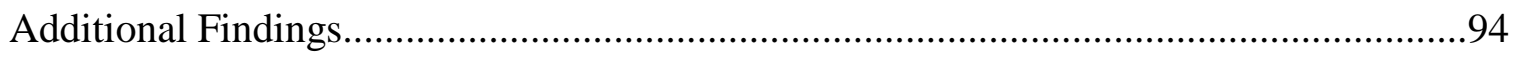

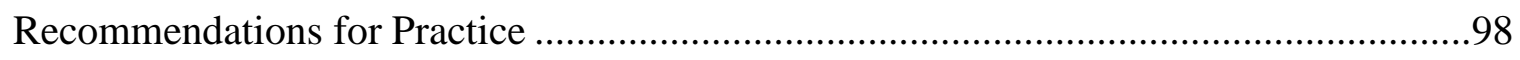

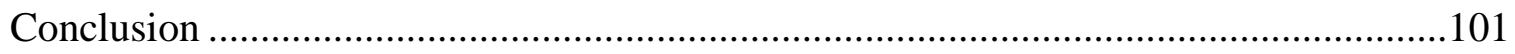

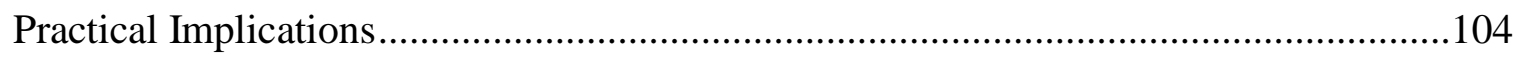

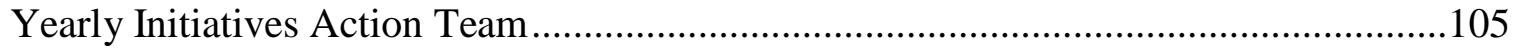

NCAA Life Skills Academy Action Team .........................................................106

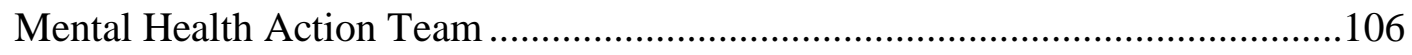

Recommendations for College Athletic Administrators........................................107

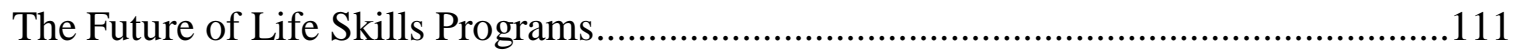

Job Title of the Life Skills Program Administrator .......................................112

Budget for Future Life Skills Programs ....................................................112

Organizational Structure of the Life Skills Program .................................................113

Commitment Statements for Life Skills.................................................115

Additional Recommendations for Athletic Directors .............................................115

Recommendations for Further Research..........................................................116

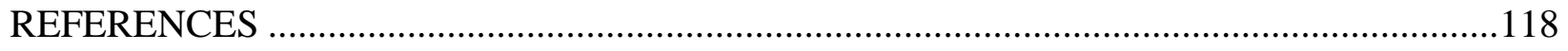

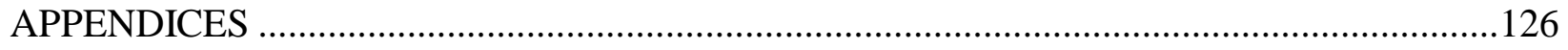

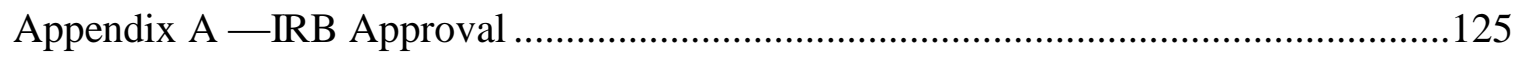

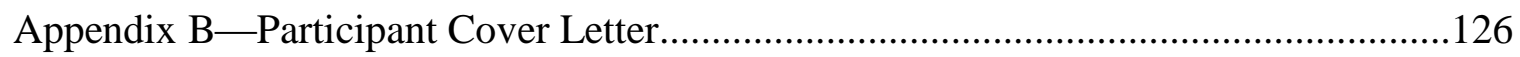


Table of Contents (Continued)

Page

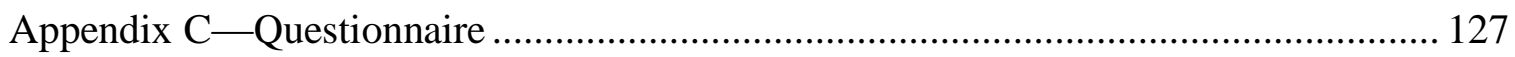

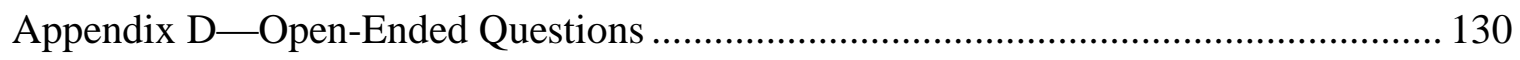

Appendix E —Best Practices Questionnaire …………………….................................. 131

Appendix F—Life Skills Questionnaire Answers ........................................................ 135

Appendix G—Recommended Life Skills Organizational Chart ..................................... 139 
Table 1. CHAMPS/Life Skills Commitment Statement .......................................................4

Figure 1. Big Ten Gender Demographic Data ..................................................................53

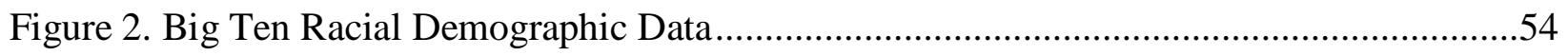

Figure 3. Big Ten Education Demographic Data.............................................................55

Table 2. Big Ten Administrators: Job Title, Program Budget, Race, Gender, Graduation Success Rate, and Reporting Structure ......................................56

Table 3. Common Strengths of Big Ten Administrators ..................................................67

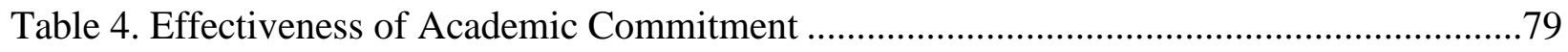

Table 5. Effectiveness of Career Development Commitment …........................................... 80

Table 6. Effectiveness of Athletic Commitment..............................................................81

Table 7. Effectiveness of Personal Development Commitment ..............................................83

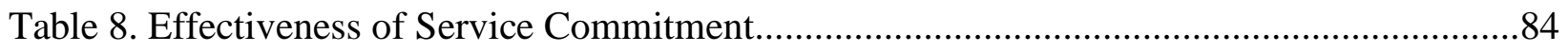




\section{CHAPTER I-INTRODUCTION AND STATEMENT OF THE PROBLEM}

\section{Introduction}

In 1989, the Knight Foundation formed the Knight Commission on Intercollegiate Athletics. The commission's goal was to improve the state of intercollegiate athletics through a reform agenda encouraging, among other things, greater focus on the welfare of student-athletes (Hesburgh \& Friday, 1991). The Knight Foundation was concerned that abuses (e.g., gambling, professionalization, and commercialization) in National Collegiate Athletic Association (NCAA) Division I-A college football and basketball threatened the integrity of higher education (Hesburgh \& Friday, 1991). In 1991, the Knight Commission on Intercollegiate Athletics published their first report, Keeping Faith with the Student athlete. The report recommended the goals and principles set forth by the department of intercollegiate athletics be a derivative of the university mission. The report suggested that NCAA Division I university presidents exercise control over athletics on their campuses. The report suggested academic integrity should include the principle that student-athletes would not be admitted to the university unless they show promise of being successful in courses that would lead to a degree. The commission demanded that universities and their athletic departments put "principles into action" by moving reform from "rhetoric to reality" (Hesburgh \& Friday, 1991, p. 35). As a result of recommendations offered by the Knight Foundation, the NCAA Foundation and Division I Athletic Directors' Association created the CHAMPS/Life Skills Program for student-athletes in 1991.

In 1994, after several years of development, the CHAMPS/Life Skills Program was launched for NCAA members. Over 50 NCAA institutions participated in the inaugural orientation session for administrators from around the country. These campus programs were encouraged to partner with other offices on campus such as the career center, counseling center, 
multicultural affairs, and residence life, among others, to create meaningful, relevant Life Skills Programming for student-athletes centered on a commitment to academic excellence, athletic excellence, career development, personal development, and community service.

The CHAMPS/Life Skills Program was initially proposed to member schools without requiring a fee for the NCAA providing the program material to member schools (Wright, 2002). According to the NCAA CHAMPS/Life Skill pamphlet, NCAA member institutions committed to starting a CHAMPS/Life Skills Program should adhere to four conditions when implementing the program (2005). First, there needed to be support from campus administrators. Second, there needed to be involvement from a student-athlete advisory committee with the purpose of evaluating the needs of the student-athlete. Third, an on-campus advisory team comprised of interested faculty staff and administrators was needed. The fourth suggested condition was creating a method for tracking the needs (e.g., academic, social, spiritual) of the student-athletes through focus groups and surveys (NCAA CHAMPS/Life Skill pamphlet, 2005).

Schools were expected to deliver the CHAMPS/Life Skills Programming through classes, seminars, workshops, speakers, social events, community service activities, and/or orientations. Schools were required to take responsibility for funding and implementing various programs. The NCAA encouraged schools to provide funds to send a representative to the annual Orientation and Continuing Education Conference (NCAA CHAMPS/Life Skill pamphlet, 2005). The purpose of the conference for various CHAMPS/Life Skills administrators is to share information and knowledge about issues facing CHAMPS/Life Skills Programs across the country.

Chickering and Reisser's (1993) Theory of Identity Development served as a foundation for the CHAMPS/Life Skills Program. The authors feel that it takes mastering content, gaining 
intellectual sophistication, and building a wide variety of skills for the student. The Identity Theory focuses on seven vectors of development which contribute to the development of the identity. These vectors are: Developing Competence, Managing Emotions, Moving through Autonomy toward Interdependence, Developing Mature Interpersonal Relationships, Establishing Identity, Developing Purpose, and Developing Integrity.

Student athletes who identify more with their athlete role are said to have a higher athletic identity (Brewer, Petitpas, \& Van Raalte, 1993). Ferrara (2014) indicated that studentathletes in revenue producing sports had higher athletic identities than athletes in non-revenue producing sports (Murphy, Petitpas, \& Brewer, 1996). Murphy and Ferrara $(1996,2014)$ also found that student-athletes with higher athletic identities displayed less career maturity. Based on the overall development of the student-athlete and Chickering's Theory of Identity, the NCAA created five distinct commitments that provide a framework for enhancing the quality of the student-athlete experience.

The CHAMPS/Life Skills five distinct commitments are:

1. Commitment to Academic Excellence

2. Commitment to Athletic Excellence

3. Commitment to Personal Development

4. Commitment to Career Development

5. Commitment to Service

It was the belief of the NCAA leadership and governing boards that the implementation of the five commitment areas of emphasis would assist student-athletes during their tenure on and off campus, and would assist in their transition from college to life after school (see Table 1 for the CHAMPS/Life Skills Commitment Statements). 
Table 1. CHAMPS/Life Skills Commitment Statements

\begin{tabular}{|c|c|}
\hline Commitment to Academic Excellence & $\begin{array}{l}\text { A commitment to academic excellence is to } \\
\text { support the academic accomplishments and } \\
\text { intellectual development of each student-athlete. } \\
\text { This includes study skills, goal setting, time } \\
\text { management, academic counseling and advising, } \\
\text { monitoring academic progress, registration, } \\
\text { curriculum, awards, honors and academic } \\
\text { recognition. }\end{array}$ \\
\hline Commitment to Athletic Excellence & $\begin{array}{l}\text { A commitment to athletic excellence will } \\
\text { encourage sportsmanship, fairness, and equity. } \\
\text { The program should provide facilities, staff, } \\
\text { support services that are dedicated to the success } \\
\text { and welfare of the student-athletes. }\end{array}$ \\
\hline Commitment to Personal Development & $\begin{array}{l}\text { A commitment to personal development focuses } \\
\text { on health, wellness, leadership, goal setting, } \\
\text { decision-making, time management. Personal } \\
\text { development might also include specific areas } \\
\text { such as nutrition, development of self-esteem, } \\
\text { understanding diversity and fiscal responsibility. }\end{array}$ \\
\hline Commitment to Career Development & $\begin{array}{l}\text { A commitment to career development places a } \\
\text { priority on developing student-athletes for life } \\
\text { after college. This might include: setting } \\
\text { career/life goals, career assessment, planning, } \\
\text { internships, summer employment. }\end{array}$ \\
\hline Commitment to Service & $\begin{array}{l}\text { A commitment to service encourages student- } \\
\text { athletes to give back to their campus and } \\
\text { surrounding communities. Student athlete may } \\
\text { individually, or with a team, take part in a } \\
\text { community service project such as reading at } \\
\text { local elementary schools. }\end{array}$ \\
\hline
\end{tabular}

Note. From Wisdom, T. (2006). Assessing the effectiveness of the NCAA CHAMPS/Life Skills Program model at meeting the developmental and psychological needs of Division I studentathletes. (Unpublished doctoral dissertation). University of Northern Colorado, Greeley.

According to the NCAA CHAMPS/Life Skill pamphlet (2005), each member school was required to have a full-time staff member to manage the CHAMPS/Life Skills Program. It was the responsibility of athletic programs at Division I schools to hire program directors/coordinators who would be able to implement a CHAMPS/Life Skills Programs for 
their student-athletes. Goddard (2004) reported the CHAMPS/Life Skills Program at the University of North Texas, called the Resources and Preparation: Tomorrow is Our Responsibility (RAPTOR) program, used the five Commitment Statements in their programming. Many of the core ideas of the CHAMPS program were implemented in the classroom, but the focus remained on the development of leadership skills. Most schools only had one person administering the CHAMPS/Life Skills Program and limited budgets. Some schools had CHAMPS/Life Skills budgets of $\$ 25,000$, though most managed the program on $\$ 2,500$ or less (Goddard, 2004).

A successful CHAMPS/Life Skills Program that addresses each of the five areas of commitment should lead to greater total development for student-athletes (Wisdom, 2006). The more experienced athletic department administrators, as well as administrators from larger institutions, tended to report higher institutional effectiveness in implementing the NCAA's CHAMPS/Life Skills Program's instructional resources/strategies (Murdock, 2010). Athletic departments may benefit from retaining individuals who are familiar with and have participated in a given school's CHAMPS/Life Skills Program for a longer period of time, as opposed to hiring individuals with little or no experience with that specific institution's programming (Murdock, 2010).

Over the past twenty-three years, the title CHAMPS/Life Skills was initially used by NCAA Division I schools to define the CHAMPS/Life Skills Program and its components. The NCAA is currently evaluating the future name of the program because the title does not clearly represent or define services rendered by the various CHAMPS/Life Skills programs across the country, according to Jason Paysinger, Assistant Director of Leadership for the NCAA, (personal communication, July $\left.10^{\text {th }}, 2014\right)$. Many schools have different names for their CHAMPS/Life 
Skills Program, but they all utilize the original 1991 CHAMPS/Life Skills statements. A common feature of the CHAMPS/Life Skills Program is the flexibility offered to member institutions (Wisdom, 2006). However, with that flexibility there has been inconsistency in programming offerings, depending on the varied mission and priorities from school to school. While there are differences in programming, funding, and resource availability at each institution, all CHAMPS/Life Skills follow the basic program model and seek to implement services that features the CHAMPS/Life Skills Commitment Statements (Wisdom, 2006).

Over the past 20 years, there has been an influx in the number of students going to college. According to the U.S. Department of Education, National Center for Education Statistics (2013) enrollment in degree-granting institutions increased by $43 \%$ between 1991 and 2011. The enrollment from 2001-2011 increased 32\%, from 15.9 million to 21.0 million. This has also increased the number of student-athletes, which leads to the increase in student-athletes cost and revenue generated by college team sports. While record television contracts continue to ripple through the nation's five major college sports conferences, students continue to help pay the bills for many of the largest athletic departments (Dodd, 2014).

In 2013, college athletics experienced the biggest revenue producing year since the inception of college sports in 1852. Men and women sports combined $\$ 12.6$ billion in revenue (Smith, 2014). Smith reported the NCAA had a 14-year, \$11 billion TV deal with CBS and Turner Broadcasting for the NCAA Tournament, and ESPN will soon pay $\$ 470$ million per year just for the new college football playoff. A large percentage of that money subsequently gets funneled to the nation's collegiate athletic departments via their conferences (Smith, 2014). Most of the time, the size of the payout corresponds with how well a conference's teams perform on the football field or basketball court, which in turn means that the biggest checks get sent to the 
nation's power conferences. Those conferences - the ACC, Big Ten, Big 12, Pac-12 and SECwill collect a combined $\$ 311$ million just from bowl games and NCAA Tournament payouts this year (Smith, 2014).

Many schools lack the resources to create a well functioned program. A successful CHAMPS/Life Skills Program takes the support and commitment of dedicated athletic directors, coaches, and student-athletes, according to Morgan State University Athletic Director Floyd Kerr (personal communication, June 3rd, 2014). In 2014, the NCAA Leadership Development unit provided personal and professional developmental opportunities for student-athletes, coaches, and administrators throughout Division I, Division II, and Division III colleges, according to Paysinger (Personal communication, July 10 $\left.{ }^{\text {th }}, 2014\right)$. Paysinger's responsibilities in his position at the NCAA is to administrator four of the major student-athlete programs: Student Athlete Leadership Forum, NCAA-AFCA Future Football Coaches Academy (FFCA), NFL-NCAA Summit (there are four programs within the summit), and Life Skills (NCAA, 2014).

To reiterate, since the establishment of the CHAMPS/Life Skills Program in 1991, the universities had no programming established for student-athletes. There was no mandatory programming for the universities to follow as they attempted to implement the NCAA CHAMPS/Life Skills Program. The researcher evaluated the lack of original programming at the universities and considered the university's various missions, anticipating that the CHAMPS/Life Skills Program implemented by the university would be based on the needs of the student-athletes at each school.

To date, few scholars have systematically analyzed CHAMPS/Life Skills Programs located at NCAA Division I-A schools. Since the NCAA's inception of CHAMPS/Life Skills Program in 1991, there has been limited research on the successfulness of the various 
CHAMPS/Life Skills Program. Farrell (1996) was one of the first to systematically critique CHAMPS/Life Skills Program perceptions of student services by athletic administrators at NCAA Division I-A CHAMPS/Life Skills schools. In addition, Wright (2002) focused on analyzing Division I-A CHAMPS/Life Skills Programs. Several scholars (Wright, 2002; Goddard, 2004; Murdock 2010) investigated perceived effectiveness of the CHAMPS/Life Skills Program. All three researchers found that CHAMPS/Life Skills Programs were effective, met the developmental/psychological needs of student-athletes, and that effective instructional strategies were implemented.

Wright (2002) analyzed the status of the CHAMPS/Life Skills Programs during 20002001. Major findings revealed the range length of employment as a program coordinator was one to three years, and indicated they frequently or very frequently spent time administering other programs in addition to CHAMPS/Life Skills. The NCAA CHAMPS/Life Skills Programming continues to change. Farrell's (1996) research was limited to 180 CHAMPS/Life Skills Programs, of which only 103 responded. Wisdom's (2006) study discovered CHAMPS/Life Skills Programs varied heavily across member NCAA Division I-A institutions, making it difficult to determine the most commonly used practices of a typical program. The response rate in the study was minimized based on the time involved in responding to the survey and lack of interest by the student-athletes to participate in the survey (Wisdom, 2006). The survey response rate was highly skewed towards a Caucasian freshman student-athlete population. After the researcher spoke to five leading Division I Life Skills Directors, the original "CHAMPS/Life Skills" name changed numerous times since 1991. The researcher will use the term "Life Skills" when referring to CHAMPS/Life Skills since it is the preferred term, based on the researchers conversations with the Life Skills Directors. 


\section{Statement of the Problem}

The purposes of this study were:

1. To determine if Life Skills Programs exist in all 14 Big Ten Schools.

2. To determine if the NCAA Division I Life Skills Commitment Statements were utilized at all of the Big Ten Schools.

3. To determine how Big Ten administrators perceived Life Skills Programs across all Big Ten universities.

Significance of the problem. Today administrators, coaches, and the general public are concerned with the overall well- being of college student-athletes. To date, few empirical research studies have been conducted to analyze the effectiveness of the NCAA Life Skills Programs on college campuses across the United States. In 1991, the NCAA CHAMPS/Life Skills program was developed to enhance student-athletes' personal and professional development. The results of this study will provide a descriptive analysis of Life Skills Programs at NCAA Big Ten schools.

\section{Scope of the Study}

All of the 2014 Big Ten colleges offering Life Skills Programs $(n=14)$ were asked to participate in this study. The Best Practices of the Life Skills Program Survey developed by Murdock (2010) was used to answer the three research questions posed by this study.

\section{Research Questions}

The research questions included:

1. Do Life Skills Programs exist at all Big Ten schools?

2. Are the 5 Life Skills Commitment Statements being enforced at all Big Ten schools?

3. Are Life Skills Programming effective at all Big Ten schools? 
There were two reasons for developing research questions one and two. First, the researcher found that by doing a Google search it was easy to find out if all schools in the Big Ten offered a Life Skills Program by what they stated on their websites. Based on the researcher's pilot study (2014) examining Life Skills Programs from six NCAA Division I conferences, the researcher reported some schools advertise on their websites that they have a Life Skills Program. After speaking to the Life Skills administrators, two of the six schools did not offer such a program. Some of the reasons the schools did not offer Life Skills Programs varied. "Not having personnel" and "inadequate budgets" were the most common reasons given.

The second reason for developing the questions one and two was that schools from the researcher's pilot study also suggested the schools advertising Life Skills Programs on their websites did not enforce the five Commitment Statements. Reasons explaining why some schools did not enforce the five Commitment Statements included lack of budgets and their athletic department's emphasizing one Commitment Statement over another.

In this current study, the researcher wanted to find out from Life Skills administrators from the Big Ten Conference if the Life Skills Programs advertised on their websites actually existed. The researcher also wanted to know if all the Life Skills Commitment Statements were used in their programming for student-athletes.

Upon IRB approval, a questionnaire was emailed to the administrators of the Life Skills Program. The following universities located within the Big Ten conference were requested to voluntarily participate: Indiana University; Michigan State University; Northwestern University; Ohio State University; Penn State University; Purdue University; Rutgers University; University of Illinois; University of Iowa; University of Maryland; University of Michigan; University of Minnesota; University of Nebraska; University of Wisconsin. 
The questionnaire consisted of two parts. Each part took approximately 20 minutes to complete. The researcher made follow up phone calls if the subjects did not respond to the emailed questionnaires after two weeks.

The current project expanded on Murdock's (2010) study by adding questions based on the written feedback received from athletic administrators of Life Skills Programs who worked in college athletics ten years or more and who had a personal relationship with the researcher. Based on the feedback, some additional questions were added to Murdock's (2010) original question:

1. What is the participation of your revenue generating sports in your Life Skills Program?

2. What is the male/female ratio in participation in the /Life Skills Program?

These questions were added to gain an understating of what programs make Life Skills Program attendance mandatory for the student-athletes. The researcher chose the Big Ten Conference of the NCAA for several reasons:

1. The Big Ten is the oldest conference in the NCAA and has a stellar reputation for academic excellence and quality academic programs. It is also a national leader in broadbased programming, student-athlete welfare, gender equity, and innovation. In 2007, they became the first national conference-owned television network.

2. The University of Nebraska-Lincoln's Life Skills Program is one of the first programs established in the country — considered by many to be the best — and is a model program for other universities in the United States. The administrator for Life Skills at the University of Nebraska-Lincoln Keith Zimmer is considered to be the leading expert on developing elite Life Skills Programming. In addition, the University of Nebraska- 
Lincoln also leads the nation with more academic All-Americans than any university in the country since 2000 .

Nebraska's rich tradition of academic excellence is solidified on the national level through the University's dominance of the CoSIDA/Capital One Academic All-American awards. University of Nebraska student-athletes from all sports teams combined far exceed any other school in the country. Nebraska had a nation-leading total of 315 CoSIDA/Capital One Academic All-Americans (as of March 11, 2015).

3. Two of the Life Skills Directors in the Big Ten conference were selected to serve on the NCAA's action team because of their expertise on their past experiences developing well respected Life Skills Programs at their respective universities. The 18 member action team is charged with defining the profession of Life Skills, bettering the emerging lives of NCAA student-athletes, and supporting membership professionals, as well as providing both student-athletes and administrators with tools to be successful. The members were chosen based on their leadership and reputation for having elite Life Skills Programming at their institutions. The Big Ten had the most representatives from a conference on the action team and the researcher felt they would be able to gain better insight of the NCAA's direction of Life Skills in the future for college athletics.

\section{Basic Assumptions}

The following were the basic assumptions:

1. All participants will answer all questions completely, openly and honestly.

2. All participants will have knowledge about their Life Skills Program.

3. At least $50 \%(n=7)$ of participants will participate in this study. 


\section{Limitations}

The limitations of the current study include:

1. The generalizability of findings. The participants were directors of CHAMPS/Life Skills Programs in the Big Ten Conference. Having participants from one conference can provide the researcher with a glimpse into CHAMPS/Life Skills Programs. However, the findings from this study may not be generalizable to Life Skills Programs nationwide.

2. The data collected reflected the status of the Life Skills Programs offered during the period of the investigation in the Big Ten Conference, which was the 2014-2015 academic year.

3. Big Ten institutions vary by mission, location, student population size and mission.

4. Since the respondent schools vary, the results make it difficult to determine the most common practices of a typical CHAMPS/Life Skills Program in the Big Ten Conference.

\section{Delimitations}

The study was limited to Big Ten CHAMPS/Life Skills Program administrators on their campuses who had access to the questionnaire.

\section{Definitions of Terms}

For the purposes of this study, the following terms were utilized:

Academic Progress Rate (APR): the annual academic progress rate. The NCAA agreed the terms of the APR rate below .930 (equivalent to a $50 \%$ graduation rate) are subject to penalties. The rate captures scholarship student-athletes entering the institution and calculates eligibility, retention, and graduation. The "snapshot" is calculated for every sports team during the academic school year. Each student-athlete receiving athletics aid on a team has the ability to earn two points for every term of full time enrollment. One point is awarded if the student-athlete 
is academically eligible to compete the following regular term, and one point if the studentathlete is retained by the institution (Satterfield, 2004).

Career Transition: The movement and selection of a student-athlete from college career to career. According to the NCAA Life Skills instructional materials, it is the enhancement of skills in career development during freshman-senior years and post-college.

CHAMPS/Life Skills: (Challenging Athletes Minds for Personal Success): Its mission is to provide services and support to the members, public, and media to develop and enhance the life of the student-athlete through educational programs and resources focusing on gender equity, student-athlete welfare, and life skills. The five program Commitment Statements are: Commitment to Academic Excellence, Commitment to Athletic Excellence, Commitment to Service, Commitment to Professional Development and Commitment to Career Development (NCAA, 2002).

CHAMPS Program of Excellence Award: An award given by the Division I Athletic Directors Association to institutions that exhibit a high level of excellence in the implementation of the CHAMPS program. The CHAMPS Program of Excellence award is awarded by the Division I Athletic Directors' Association based on criteria that programs have demonstrated proven excellence in all five commitment areas of CHAMPS.

CoSIDA All-American: College Sports Information Directors of America (CoSIDA) was founded in 1957 and is a 3,000+ member national organization comprised of the sports public relations, media relations, and communications/information professionals throughout all levels of collegiate athletics in the United States and Canada. It is the second oldest management association in all of intercollegiate athletics. 
Life Skills: An active way to prepare students and student-athletes for success in their academic and athletic college careers and beyond. It is a means to provide transferable skills to young people.

Life Skills Director/Coordinator: A staff member designated at each institution to help implement and deliver CHAMPS/Life Skills Programming. This person oversees the Life Skills Program at the university.

National Collegiate Athletic Association (NCAA): A non-profit association that regulates athletes of 1,281 institutions, conferences, organizations, and individuals, and organizes the athletic programs of many colleges and universities in the United States and Canada. The primary purpose of the association is to maintain intercollegiate athletics as an integral part of the educational program and the athlete as an integral part of the student body. It is headquartered in Indianapolis, Indiana (NCAA, 2002a).

NCAA Division I Institutions: An educational institution designated as a Division I member must sponsor at least seven sports teams for male students and seven for female students. Among many other criteria for Division I designation are the number of contests played against other Division I teams and the number of home games played during the season (Howard-Hamilton \& Watt, 2001).

Student Athlete Advisory Committee (SAAC): A committee made up of student-athletes assembled to provide insight on their experience. The SAAC also offers input on the rules, regulations and policies that affect student-athletes' lives on NCAA member institution campuses (NCAA Publications, 2014). 


\section{CHAPTER II-REVIEW OF THE LITERATURE}

The purpose of this chapter is to:

1. Describe the literature relating to the history of college athletics and the NCAA legislation and reform.

2. To describe the development of Life Skills at all the Big Ten schools and NCAA Division I colleges/universities.

\section{Overview of the History of College Athletics}

A brief overview of the history of college athletics in America (from the first recorded college event in 1852) suggests contradictions and conflicts in the use of the term "studentathlete." In 2014, the debate still continued on the use of the term "student-athletes" by college administrators, the lay public, and the NCAA. The term "student-athlete" was deliberately ambiguous. College players were not students at play (which might understate their athletic obligations), nor were they just athletes in college (which might imply they were professionals). That they were high-performance athletes meant they could be forgiven for not meeting the academic standards of their peers, and that they were students meant they did not have to be compensated, ever, for anything more than the cost of their studies. "Student athlete" became the NCAA's signature term, repeated constantly in and out of courtrooms (Branch, 2011).

Inter-collegiate sports in the United States began in 1852 when crews from Harvard and Yale met in a challenge race in the sport of rowing. As other sports emerged, the public outcry for greater oversight of college sporting events emerged by the beginning of the $19^{\text {th }}$ century. For example, during the 1905 season alone, records indicated 18 college and amateur players died during games. President Theodore Roosevelt met with 13 football representatives in college sports at the White House. The purpose of the meeting was to reach a consensus regarding the 
need to reform college sports to improve the safety of the student-athletes. The meeting led to the formation of the Intercollegiate Athletic Association of the United States (IAAUS). This organization was the governing body for college sports. One year later, in 1906 the IAAUS changed its name to the National Collegiate Athletic Association (NCAA).

\section{The African American Athlete and Coach in the late 1800's-1920}

It should be noted that during this time period, the role of the African American athlete and coach was taking shape in America. The first Black college coach was Abram Molineaux Hewlett. He was the first director of physical education at Harvard University from 1859 through 1871 (Harrison, 1999). The first Black college football game was played on Thanksgiving Day, 1892 between Johnson C. Smith University and Livingstone College of Salisbury, both in North Carolina. J.C. Smith won 4-0 (Harrison, 1999). William H. Lewis, considered by many authorities as the finest football player of the decade, played for Amherst College in Massachusetts from 1890-1893. He later became a football coach at Harvard (Harrison, 1999). There were other Black football heroes in the 1890s. W.T.S. Jackson was an outstanding runner at Amherst, and a teammate of William H. Lewis. George A. Flippin was a halfback for the University of Nebraska in 1892, 1893, and 1894. William L. Washington played for Oberlin College in Oberlin, Ohio, in 1897, 1898, and 1899 (Harrison, 1999).

Two of the greatest football players of all time made their appearance on American gridirons during the second decade of the century. The first was "Fritz" Pollard. Pollard became the first African American to play in the Rose Bowl in 1917. The second was Paul Robeson. He was named All-American in 1917 and 1918. Robeson also starred in basketball, baseball, and track, and was an exceptional student. He was one of ten men in Rutgers University's history 
who won four varsity letters as an undergraduate. He was also a member of Phi Beta Kappa honorary scholastic society (Harrison, 1999).

Although there were some successful African American's in college sports during this time period, in the 1920s the NCAA focused its energies on two significant issues that faced the association. The first was governance issues, and the second was developing rules, policies, and procedures for NCAA sports. However, during this time period the NCAA spent little time on academic success issues facing the student-athletes, including graduation rates, college entrance standards, issues of race and race relations, and gender issues. Nonetheless, college sports expanded in scope, increasing the number of participants and revenue generated through the college sports enterprise. Once again the term "student-athletes" came to the forefront. The NCAA soon realized college sports was becoming a big business and needed to be regulated to ensure overall student success. In 1948, the NCAA passed a set of regulations called the Purity Code (later renamed the Sanity Code) which permitted student-athletes free tuition and meals, but required that part-time jobs be legitimate with commensurate pay for their work (Brown, 1999).

The NCAA was entering a new era in which its enforcement authority was increased. However, the need to support the funding for coaches' salaries, facility expansion, equipment purchases, and stipends to support student-athlete scholarships continued to escalate. One example of this escalation was the NCAA negotiating its first television contract with an access of one million dollars (Smith, 1987).

By the 1950s, the NCAA was concerned with protecting student-athletes from organized gambling. According to Thelin (1994), the revelation of connections between organized crime and college basketball existed heavily in society, specifically within intercollegiate athletics. 
There were several noted legal cases focused on point shaving in college basketball (Killinger, 2012). In 1951, less than $1 \%$ of students enrolled at predominately White schools (PWI's) were African American (Shulman \& Bowen, 2001). However, the 1954 Brown v. Board of Education Supreme Court decision marked the beginning of a dramatic increase in African American enrollment at PWI's, according to Allen (1992). This was also a time period when segregation policies were dissolving, but was still commonplace as a social practice.

During the 1960s, many African American student-athletes began transitioning to predominately White campuses. This was also a watershed decade in U.S. history. Many citizens responded strongly to the Civil Rights Movement, making aggressive, widespread efforts to address many of the wrongs imposed on African Americans for centuries. Increased Black access to higher education was seen as one major solution to the problem of racial inequality; thus, the decade witnessed the beginning of dramatic increases in the number of African American students attending predominantly White colleges and universities. One area of difficulty was that of the future of the African American male student-athlete (Harrison, 1999). Many African American male student athletes focus was to play professional sports, while Dr. Edwards was concerned about their education and them graduating with college degrees. As Dr. Harry Edwards stated in many personal interviews over the years, "sport merely recapitulates society" (Edwards, 1992).

\section{Equality for Women}

Policies such as Title VII in the 1964 Civil Rights Act mandated equity in employment opportunities and decisions. However, further efforts are required to tackle the existing problems of exclusion in college athletics hiring practices which — despite hiring policies — remain at the forefront of these issues (Lapchick, 2008). Data from these reports provide a systematic measure 
of the outcomes of hiring policies and practices. Title VII made it "illegal for an employer to discriminate against individuals on the basis of their race, sex, national origin, or religion, unless it is a necessary and bona fide occupational qualification" (Baez, 2002). In 1972, educational institutions were included in and covered by Title VII (Cooper, Kane, and Gisselquist, 2001). Since then, educational institutions have a duty to make certain that their hiring practices reflect the availability of women and minorities in the labor populations from which their employees are selected (Busenberg and Smith, 1997).

By 1973, only approximately one-fourth of African American college students attended HBCUs, while the majority attended PWIs instead (Allen, 1992), a trend that continues today. Although African American enrollment at PWIs has increased significantly, African American students at these colleges still encounter obstacles that sometimes lead to academic failure. African American student-athletes are allowed access to predominately White institutions because their athletic prowess helps generate revenue (Northcutt, 2013). Harrison and Lawrence (2003) stated "one out of nine African American students on predominately White campuses is a student-athlete on athletic scholarship, compared to one out of fifty White American students on an academic scholarship.

In the early 1970s, university and college presidents were becoming more directly concerned with the operation of the NCAA and graduation rates among their student-athletes for three major reasons:

1. Enrollment began to drop, and expenses were increasing in athletics.

2. They personally came to understand their reputations as presidents were often tied to the success of the athletic program, and they were becoming fearful of the NCAA's enforcement authority. 
3. They wanted to find ways to attract the African American student-athletes to create a winning athletic program.

By the 1980s, university presidents increasingly found themselves caught between the pressures applied by influential members of boards of trustees and alumni-who often demanded winning athletic programs — and faculty and educators—-who feared the rising commercialization of athletics and its impact on academic values (Smith, 1988). Many presidents were determined to take an active, collective role in the governance of the NCAA, so they formed the influential Presidents Commission in response to these pressures (Smith, 1988).

Noted sports sociologist George Sage witnessed an increase in college sports commercialization and the public's demand to win in big time college athletics. Sage eloquently wrote about the perceived athletic and academic tensions between the goals and integrity of higher education and economic interest and values of big time sports (Sage, 1993). The desire of college administrators to generate funds for supporting the college mission was particularly apparent during the 1980s. One of the biggest issues college athletics was facing during this time period was the role of graduation rates. Many young men and women continued to be exploited for their free labor, then turned out with no degree or meaningful improvement in their life skills. This was a very real tragedy and national scandal. Academic disclosure-the power to gain widespread support via a visceral connection with the public and Congress-is a way to stop this exploitation (Splitt, 2009).

\section{Graduation Rates}

Graduation rates of Division I college athletes have been tracked since 1983 (Watt \& Moore III, 2001; Northcutt, 2013). While not perfect, graduation rates are one of the best indicators of academic success in college. In most cases, consideration for a professional job 
requires a college degree. Many researchers (Beamon; 2008; Donnor, 2005; Harper, 2012; Harper, Williams, \& Blackman, 2013; Harrison \& Lawrence, 2003; Northcutt, 2013) noted that some student-athletes are academically unprepared for college, and a gap exists in the graduation rates of African American student-athletes compared to Caucasian student-athletes.

In 2006 the NCAA reported that African American football players graduated from Division I institutions at a rate that was $13 \%$ lower than that of their Caucasian teammates (62\% for Whites and 49\% for African Americans) (Northcutt, 2013). There were also significant differences in the graduation success rates of African Americans and Caucasians. In 2011, Lapchick reported that at schools participating in college football bowl games in the 2011-2012 season, the average graduation success rate was $81 \%$ for Whites and $61 \%$ for African Americans. While both African American and Caucasian football student-athletes graduated at higher rates than their male non-athlete peers in the student body (40\% and 60\%, respectively), a gap between African American and Caucasian students still remains (Lapchick, 2011).

\section{The Beginnings of Controversial Legislation}

In 1984, the President's Commission asserted its authority, and the NCAA introduced some controversial legislation, beginning with Proposition 48, which immediately passed. The proposition focused on the need to provide academic entrance to ensure student success because there was a growing need for college presidents to enacting various propositions resulting in mandated academic eligibility requirements for freshman varsity athletes. Proposition 48 required student-athletes to have a minimum SAT score of 700 or an ACT score of 17 and a minimum GPA of 2.0 in at least 11 courses in core subjects. In 1985, the President's Commission took dramatic action by exercising their authority to call a special convention to be 
held in June of 1985. This quick assertion of power led one sports writer to conclude that there was no doubt who runs college sports; it's the college presidents (Smith, 1988).

Presidents were initially involved in a number of efforts to change the rules, particularly in the interest of cost containment. These efforts were not all successful. Over time, however, the presidents gained a better understanding of the workings of the NCAA, and they were beginning to take far more interest in the actual governance of intercollegiate athletics (Smith, 1998).

\section{Proposition 48}

The first policy enacted by the NCAA that altered admission requirements for studentathletes was Proposition 48. Previously, only a 2.0 high school GPA was required for students to be eligible to participate in inter-collegiate athletics. Proposition 48 included standardized test scores to determine initial eligibility. By meeting these standards, students became eligible to practice, compete, and receive athletic financial aid. While the focus of Proposition 48 was to establish a national standard of admissions based on indicators of college success, requiring a benchmark score on the SAT may be a disadvantage for minorities more so than for Whites.

Dr. Harry Edwards and Dr. Richard Lapchick, two renowned sports sociologists, supported Proposition 48. However, Edwards felt that academic standards were too low (1983). This communicated to a generation of Black athletes that they were expected to perform academically as well as athletically (Lapchick, 1988). Proposition 48 required that incoming freshmen have at least a 2.0 grade point average and a minimum SAT score of 700 or 15 on the ACT in order to be eligible to play. Some believed the standardized tests are biased against members of minority groups and the poor. After pressure from numerous high profile coaches, such as Georgetown Men’s Basketball Coach John Thompson and Arkansas Men's Basketball 
Coach Nolan Richardson, the NCAA introduced a less stringent proposition but to strengthen eligibility rules and enforced Proposition 42.

\section{Proposition 42}

In 1989, the NCAA strengthened initial eligibility rules through Proposition 42. This proposition eliminated partial qualifiers, which the NCAA estimated at 1,800 prospective student-athletes over the last three years. It kept Proposition 48 requirements of a 700 SAT/17 ACT score and a GPA of 2.0 in core courses (Rosen, 2001). There continued to be growing debate among coaches and athletic directors about student-athlete eligibility. As a result, the NCAA proposed and enforced Proposition 16.

\section{Proposition 16}

In 1996, the NCAA enacted Proposition 16, which increased the admission standards for freshman student-athletes at Division I schools, in an effort to improve graduation rates (Rosen, 2001). Results indicated that Proposition 16 increased graduation rates significantly for Black student-athletes, and had no significant impact on graduation rates for White student-athletes (Rosen, 2001). Results also indicated that graduation rates declined for Black student-athletes at Division II schools, which may have been driven by students transferring to Division I (Rosen, 2001). As a result of the higher admission standard, Division I schools changed recruiting patterns and relied less on freshman student-athletes - particularly Black student-athletes - to fill scholarships. Even though fewer Black freshman student-athletes enrolled in Division I schools, the overall number of Black student-athletes did not change, suggesting a greater proportion of transfer students into Division I schools were Black (Rosen, 2001). During the ten years of increasing academic standards, the NCAA implemented the Academic Progress Rate (APR), another proposition to increase academic success and graduation rates among student-athletes. 


\section{Academic Progress Rate (APR)}

In 2005, the NCAA introduced the APR, and was described by the NCAA as a measurement that provides a "real-time view" of a team's academic success by tracking the progress of scholarship athletes on a semester-by-semester basis during the school year (Bartlett, 2012). It was created to help provide a clearer picture of a team's academic culture than considering graduation rates (one of the preexisting measurements) alone.

The APR is calculated by allocating points for eligibility and retention. Each scholarship player on a roster earns a maximum of two points per term, one for being academically eligible, and one for staying with or graduating from the institution (NCAA). A team's APR is the total points of a team's roster of scholarship athletes at a given time, divided by the total points possible, and multiplied by 1,000. A perfect APR score is 1000. Programs that fail to achieve an APR score of 930 - equivalent to a $50 \%$ graduation rate — may be penalized with the loss of scholarships by the NCAA. Although academic and Life Skills support programs are provided to student-athletes, the motives for their existence raise concerns for faculty. Due to the NCAA legislation of Academic Progress Rate (APR), Division I institutions have become increasingly concerned with keeping their student-athletes eligible and their sports programs from incurring penalties (Northcutt, 2013).

The schools that have been mostly effected by the APR are HBCUs. In 2013, 15 of 18 teams penalized for insufficient academic progress were from HBCUs (that's three more than in 2012, and ten more than 2011). This statistic illustrates the extent to which those institutions which admit more first-generation and underprepared students than most universities, yet tend to have fewer academic advisers—-are being disproportionately affected (Grasgreen, 2013). 
Six schools from the Southwestern Athletic Conference will be banned from postseason competition in several sports in the 2015-16 academic season. Many Presidents at HBCUs assert that APR guidelines are imbalanced for institutions with limited academic development resources. Texas Southern University President and SWAC Council of Presidents Chairman John Rudley criticized the NCAA for holding HBCUs, and other limited resource institutions, to similar standards as BCS and power conference Division I schools with higher budgets for compliance and academic development. The average graduation rate for all students at HBCUs is $36 \%$. The NCAA's APR 50\% minimum student-athlete graduation rate requirement is such a high standard that most HBCUs and other limited resource institutions cannot meet that standard (Gray, 2014).

\section{APR and Historically Black Colleges and Universities (HBCUs)}

When the NCAA voted to raise academic standards in October 2011, it gave HBCUs and other "low resource institutions" an extra year to come into compliance (they have until 201617). The association also dedicated about $\$ 6$ million over the next several years to help those institutions meet the new standards (Grasgreen, 2013). In 2012, the NCAA Executive Committee approved $\$ 4.8$ million in funding over three years for a pilot program that will help Division I schools identified as "limited-resource institutions" develop enhancements and systems to increase their student-athletes' academic performance (Brown, 2012).

The funding is in addition to $\$ 4$ million allocated to the Division I Supplemental Support Fund, which was established in 2007, to assist student-athletes at limited-resource schools. The two funds extend the effort to help limited-resource institutions meet standards set within the Division I APR. The primary goal is to help schools develop sustainable plans to ensure all teams meet the 930 APR benchmark which will be in effect by 2016-17 for limited-resource 
schools. Additionally, the pilot includes reporting requirements to hold institutions accountable for properly using the funds and to better measure the initiative's success. Grants up to $\$ 300,000$ will be awarded annually to successful applicants for such uses as summer bridge programs for student-athletes, funding summer school attendance, paying for a fifth year of aid, or funding additional staffing, facilities and equipment.

\section{Accelerating Academic Success Program}

In August 2013, the NCAA Executive Committee approved the NCAA Accelerating Academic Success Program (formerly the NCAA Limited-Resource Institutions Grant Program Pilot). A total pool of $\$ 4.8$ million was available for the grant program. Institutions were eligible to receive up to a maximum of $\$ 300,000$ per year for three years (subject to a yearly renewal assessment). Thirty institutions were eligible for the pilot program; 24 institutions applied and six were awarded grants. In the 1980s, the NCAA was working diligently on legislation to increase academic standards and places a greater focus on the welfare of student-athletes. During this time, the Knight Commission was also interested in partnering with the NCAA to work on the reform of college athletics, particularly in regard to emphasizing academic values and policies that ensure athletic programs operate within the educational missions of their universities.

\section{The Knight Commission}

The Knight Commission on Intercollegiate Athletics was formed by brothers John and James Knight in October, 1989 in response to more than a decade of highly visible scandals in college sports (Splitt, 2009). The commission's initial goal was to recommend a reform agenda emphasizing academic values in an arena where commercialization of college sports often overshadowed the underlying goals of higher education. Since 1989, the Knight Commission on 
Intercollegiate Athletics has worked to ensure that intercollegiate athletics programs operate within the educational mission of their colleges and universities. As a result of the Commission's efforts, significant strides have been made to reconnect college sports with the educational mission of American colleges and universities. Among the Commission's recommendations to the NCAA were:

- Stronger academic standards for athletes leading to improved graduation rates.

- Presidential control and leadership over NCAA decisions and athletics conferences achieved through governance changes.

- Increased campus engagement and accountability through the NCAA's certification process.

Standards that require team accountability for academic performance by sanctioning teams with subpar retention and graduation rates (NCAA, 2008).As a result of recommendations from the Knight Foundation and efforts internally at the National Collegiate Athletic Association (NCAA), the NCAA Foundation and Division I Athletic Directors' Association created the Challenging Athletes' Minds for Personal Success (CHAMPS/Life Skills) Program for studentathletes in 1991. In 1994, the NCAA launched the program for their entire membership, with 46 initial participating institutions (NCAA, 2008). This program has grown to over 950 member institutions during the past 20 years. With a mission to ensure the integration of intercollegiate athletics in the campus educational program and enhance the quality of the student-athlete experience, the NCAA provides resources and support that enable member institutions to meet the needs of their student-athletes. Through speakers, workshops, community outreach efforts, and both academic and athletic services, the Life Skills Program promotes personal accountability, leadership skills, and a respect for diversity among student-athletes. 
Former NCAA President Cedric W. Dempsey, who served in that capacity from 1994 through 2002, was instrumental in proposing the program to the NCAA membership. Prior to him serving as president, former NCAA President Dick Schultz brand was instrumental in introducing the concept to the NCAA in the spring of 1988. The first two frameworks in which the NCAA worked with a handful of schools was focused on Academic Excellence and Career Development. When Dempsey became the NCAA president, he convinced the NCAA membership and 46 NCAA institutions to participate in the first orientation for administrators from around the country.

Many academic assistance programs do little or nothing to improve the GPAs or graduation rates of student-athletes (Bell, 2005). Researchers have reported current retention programs lack the cultural intervention necessary to increase student-athletes academic performance (Berry, 2001; Clow, 2000; Gaston-Gayles, 2009). In 2014, the NCAA reported 82\% of Division I athletes had graduated within a recent six-year period. That statistic went up from 74\% a decade before (Woverton, 2014). The University of Alabama football graduation rate was a dismal 39\% in 1998, and rose to $73 \%$ in 2006 (NCAA, 2014). In the early 1990s, when Jon Denver, Alabama's Director of Academic Services for Athletics, was hired, the university had only five academic-support staff members, including a secretary. In 2014, the department had 15 full-time employees. During the football season, the university hires up to 100 tutors, and the academic facilities for athletes have grown exponentially from about 2,000 square feet when Denver started, to approximately 40,000 in 2014 (Woverton, 2014).

One key factor is coaching turnover. Players often choose a college based on the coaching staff. When coaches leave, many players follow. If the players do not leave in good academic standing, colleges' graduation rates can be affected (Woverton, 2014). While there are 
programs which help to retain student-athletes, other programs such as Life After Sports encourage student-athletes to not lose sight of making plans for when their playing days are done. Such programming consists of transition preparation and career placement assistance at the University of Missouri.

As a result of recommendations from the Knight Foundation and internal efforts at the NCAA, the NCAA Foundation and Division I Athletic Directors' Association created the CHAMPS/Life Skills Program for student-athletes in 1991. In 1994, the NCAA launched the program for their entire membership with 46 initial participating institutions (NCAA, 2008). With a mission to ensure the integration of intercollegiate athletics in the campus educational program and enhance the quality of the student-athlete experience, the NCAA provides resources and support that enable member institutions to meet the needs of their student-athletes. Through speakers, workshops, community outreach efforts, and both academic and athletic services, the CHAMPS/Life Skills Program promotes personal accountability, leadership skills, and a respect for diversity among student-athletes. CHAMPS/Life Skills focuses on five basic areas: academic excellence, athletics excellence, personal development, career development, and service.

Additional problems universities faced within 2014 included life skills for the studentathletes, graduation rates, and academic performance and achievement. It is argued that these problems will remain intractable until the education of the student-athlete is fully addressed. There has been little research conducted on the impact Life Skills.

Since the inception of the CHAMPS/Life Skills Program, the NCAA did not make Life Skills mandatory for universities. This study evaluated college athletic programs that provide skills to encourage better leadership, self-esteem, character and networking skills that can enable student-athletes to better function in society. Some schools have Life Skills budgets over 
$\$ 100,000$ according to Paysinger, and many HBCU's operate with no budget (Personal communication, July $\left.10^{\text {th }}, 2014\right)$.

The researcher based these numbers on personal conversations with Life Skills program directors at Division I schools in the United States. Many of the Life Skills program directors want to ensure their student-athletes are prepared for life after college, and they work diligently on creating programming that focuses on the Five Life Skills Commitments.

\section{CHAMPS/Life Skills}

In 1994, the CHAMPS/Life Skills Program was launched to the NCAA membership. Over 50 NCAA institutions participated in the inaugural orientation session for administrators from around the country. Since then, approximately 1,050 member institutions have joined the CHAMPS/Life Skills Program. CHAMPS/Life Skills focuses on five basic areas: (a) academic excellence; (b) athletics excellence; (c) personal development; (d) career development; and (e) service. Schools tailor the program to fit the specific needs of the student-athletes on their campuses.

Farrell (1996) was one of the first scholars to examine the perceptions of student services by athletic administrators at NCAA Division I Life Skills schools. In addition, Wright (2002) examined NCAA Division I-A program coordinators' perceptions of cooperation and support of the Life Skills Program by head coaches and athletic administrator overseeing football and basketball teams. Goddard (2004) attempted to measure the extent to which student-athletes at the University of North Texas perceived their Life Skills program had value, and the extent to which the program equipped them with self-esteem and leadership/character building skills. Goodard sought to determine student-athletes' perceptions of the effectiveness of the Life Skills 
Program at UNT. Goddard concluded that student-athletes found value in the Life Skills Program at UNT (Goddard, 2004).

The data reported student-athletes who participated more than two years in the Life Skills Program found significantly more value in the program than those who were involved for less than two years. This result may have been due to those who are in the program longer get to experience the program in its entirety during their time at school.

Wisdom (2006) analyzed the effectiveness of the Life Skills Program by examining the development and psychological needs of student-athletes. Murdock (2010) identified effective instructional resources and strategies of the Life Skills Program based on the perceptions of program administrators. According to the NCAA, there are over 1,050 Division I-A NCAA institutions offering Life Skills Programs for student-athletes. There has been little formalized research conducted on the effectiveness, planning, or quality of Life Skills Programs. Although the NCAA provided guidelines for programming, institutions are left on their own to implement and meet the needs of the student-athletes by aligning the program with their particular institution's goals.

\section{Summary}

The literature review was broken down into time periods in college athletics, and focused on the important changes during each timeframe. The chapter begins describing the first college event in 1852. As college sports became more popular on college campuses and in society, due to adequate safety measures, many college and amateur players died during games. College sports were so popular that President Theodore Roosevelt was concerned with the need for reforming college to improve the safety of the student-athletes. This helped create the formation of the Intercollegiate Athletic Association of the United States (IAAUS). This organization was 
the governing body for college sports, and a year later the National Collegiate Athletic Association was born.

In the 1920s the NCAA focused its energies on governance issues, developing rules, policies, and procedures for NCAA sports. However, during this time period the NCAA spent little time on academic success issues facing the student-athletes such as graduation rates, college entrance standards, issues of race and race relations, and gender issues. By the 1940s, the NCAA passed a set of regulations called the Purity Code, later renamed the Sanity Code, which permitted student-athletes free tuition and meals, but required that part-time jobs be legitimate and their pay commensurate with the work.

The NCAA began to focus on finding support to fund coaches' salaries, facility expansion, equipment purchases, and stipends to support student-athlete scholarships escalated as well as the influx of college teams garnering million dollar television contracts. By the 1950s, the NCAA's big concern was protecting student-athletes from organized gambling. During the 60s, society responded strongly to the Civil Rights Movement, making aggressive, widespread efforts to address many of the wrongs imposed on African Americans for centuries. One of the ways colleges and universities tried to amend the wrongs was admitting African American student-athletes and they began transitioning to predominately white campuses. In the early 1970s and 80s, university presidents became interested in having winning athletic teams, took an active role in the governance of the NCAA, and formed the Presidents Commission.

The desire of college administrators to generate funds to support the mission of the college was particularly apparent during the 1980s. In 1984, the Presidents Commission became very concerned about high academic standards among its student-athletes, and the NCAA enacted a series of controversial legislation, including Proposition 48, Proposition 16 and 
Proposition 42. The propositions focused on the need to provide academic entrance to ensure student success and admission standards. Unfortunately, many of these legislative changes negatively affected African American athletes and athletes that came from disadvantaged backgrounds who did not have high academic standards in high school.

During the ten years of increasing academic standards, the NCAA implemented another proposition to increase academic success and graduation rates among student-athletes called APR in 2005. The APR was a measurement that provides a "real-time view" of a team's academic success by tracking the progress of scholarship athletes on a semester-by-semester basis during the school year (Bartlett, 2012). It was created to help provide a clearer picture of a team's academic culture than could graduation rates alone (one of the preexisting measurements). The schools that have been mostly affected by the APR are HBCUs. Many presidents at HBCUs assert that APR guidelines are unbalanced for institutions with limited academic development resources.

In order to gain balance in promoting overall wellness for student-athletes, the Knight Commission on Intercollegiate Athletics was in response to more than a decade of highly visible scandals and controversial legislation in college sports. The Commission's initial goal was to recommend a reform agenda that emphasized academic values in an arena where commercialization of college sports often overshadowed the underlying goals of higher education. As a result of the Commission's efforts, significant strides were made to reconnect college sports with the educational mission of American colleges and universities.

As a result of recommendations from the Knight Foundation and efforts internally at the NCAA, the NCAA Foundation and Division I Athletic Directors' Association created the Life 
Skills Program for student-athletes in 1991. The Life Skills Program promoted personal accountability and leadership skills. 


\section{CHAPTER III-METHODOLOGY}

In the first portion of this chapter, a listing of the research questions and a summary of the research design are presented. A synopsis of the pilot study follow, which includes an overview of the pilot study, an outline of the instrumentation, and a description of the participants involved. An explanation of data collection procedures, validity and reliability results, and conclusions drawn from the pilot study are included.

\section{Pilot Study}

After searching existing literature, the researcher used the best practices of the Life Skills Program Survey Instrument created by Murdock (2010) to adequately address the pilot study's three research questions. The purposes of this research pilot project were:

1. To determine if Life Skills Programs exist on the six selected Division I NCAA campuses.

2. To determine if the five NCAA Division I Life Skills Commitment Statements are utilized on the six college campuses.

3. To analyze the perceived effectiveness of the Life Skills administrators at their respective schools.

In order to begin the study, an application was completed and submitted to the West Virginia University Institutional Review Board (IRB). Once IRB approval was received, the pilot study began. A copy of the IRB approval form can be seen in Appendix A.

\section{Pilot Participants}

The researcher chose the six NCAA Division I schools of various geographic locations, school sizes, Historically Black Colleges and Universities (HBCUs), Ivy League schools, and 
large NCAA conferences. Schools selected were also Life Skills member institutions (as listed on their website) and had adapted their Life Skills Program.

In order to prevent bias, participants in the pilot study were not included in the main study. Only participants from select conferences in charge of Life Skills Programs were asked to complete the pilot survey. The sample for the current pilot study included six athletic administrators who oversaw Life Skills Programs at the following NCAA Division I-A conferences: American Conference; Big Ten Conference; Ivy League Conference; Mideastern Athletic Conference; Southeastern Conference; the Sun Belt Conference. All participants ( $n=6)$ that completed the questionnaire were male $(100 \%)$.

Ethnicity composition of the pilot sample. The demographic distribution of the pilot study participants, based on ethnicity, resulted in a total of $83 \%(n=5)$ African American/Black administrators. $17 \%(n=1)$ were Caucasian/White.

Amount of Life Skills experience. Participants were asked about the time of tenure in their current roles. In response, subjects could select from one of the following options: (a) one month to one year; (b) two years; (c) three years; (d) four years; (e) five or more years. Of the survey population, $50 \%(n=3)$ held their current positions five or more years in the university's Life Skills Program. 33\% of the respondents reported having one month to a year of experience. $17 \%$ of the respondents indicated they had participated in the program at least three years.

University-specific data. For the questionnaire, respondents were asked to identify their current job title at their university. None of the respondents' job titles were the same as the other respondents'. Titles were as follows: (a) athletic director; (b) assistant athletic director for peak performance; (c) associate athletic director of student-athlete development; (d) assistant director 
of compliance and student affairs; (e) associate athletic director for student-athlete services; (f) associate athletic director life-skills.

Respondents were asked to indicate the student population size of their respective schools. 33\% of the respondent schools had student populations of 1,000-10,000;33\% had student populations of $25,001-35,000 ; 17 \%$ of the schools had student populations of 15,001 25,$000 ; 17 \%$ had student populations of 35,001 or more. $100 \%(n=6)$ of the administrators had a master's degree. $83 \%$ of the respondents were former student-athletes, and $17 \%$ did not play a sport as an undergraduate. The average number of female athletes was 253 , and the average number of male athletes was 304.

\section{Data Collection}

The administrators responded to the open-ended pilot questionnaire by writing their responses on the form. From the open-ended/written responses provided by the administrators, the amount of time spent completing the pilot survey form ranged from 8 to 25 minutes. The majority of the respondents completed the survey in approximately 10 to 20 minutes. The most frequently identified completion time was 15 minutes, which included time ranges incorporating 15 minutes within the response. In total, four of the six participants included "15 minutes" in their answer. "Twenty minutes" was the next most frequent response, which was identified by two individuals.

\section{Perceptions about Clarity of Questions}

The majority of participants indicated the questions on the pilot survey form were sufficiently clear. These respondents provided no supplementary commentary. The majority of those who did provide additional comments were very positive about the clarity of the questions, pointing out that the questions seemed clear and understandable. One respondent stated they felt 
students from the Student Athletic Council should have the opportunity to provide feedback for future research.

\section{Conclusions and Findings}

The results of the pilot study found all schools $(n=6)$ had a Life Skills Program, they all incorporated the five Commitment Statements in their programming, and they all had effective Life Skills Programs for their student-athletes.

Question One: Do Life Skills Program exist on the six college campuses? If answered "yes" by the respondent, what is their current position, the staff size, budget and organizational structure?

Each school $(n=6)$ delivered all of the five areas of the NCAA required as part of the Life Skills Program. Only one of the schools called their program Life Skills, but they all had the NCAA Life Skills Commitment Statements of: academic, athletic, personal, and career and service development. A unique finding about the program resulted from question 6 on the questionnaire, which asked the respondents how many years they have been working in their current position. One respondent indicated they were in their position for 28 years. The average time in the current role from the other respondents was less than four years. Three of the programs had budgets over $\$ 100,000$, while the other three schools had budgets of $\$ 10,000$ or less. Three of the schools had a staff of five or more who managed various aspects of Life Skills, and the remaining three had one person who managed the Life Skills department. Question Two: Are the five NCAA Life Skills Commitment Statements utilized on the six college campuses?

All ( $n=6)$ schools provided five of the NCAA Life Skills Commitment Statements: Academic commitment, Athletic Commitment, Personal Development Commitment, Career Commitment, and Community Service Commitment. 
Question Three: How effective are the various CHAMPS/Life Skills Programs?

Three questions were posed to assess Life Skills effectiveness at each school:

1. Question \#23: What is the overall effectiveness of your Life Skills program?

2. Question \#28: What do you feel are the strengths of your Life Skills Program?

3. Question \#29 What concerns, if any, do you have about your school's Life Skills program?

The first item assessed the effectiveness of Life Skill program was question \#23. It asked respondents to identify the overall assessment of effectiveness of their Life Skills Program. The responses from each item included: (a) very effective; (b) somewhat effective; (c) effective; (d) ineffective; (e) very ineffective. Of the six respondents, four indicated their program was "very effective," one indicated "effective," and one was "ineffective."

The second items that measured the effectiveness of the Life Skills Program were question \#28 and question \#29. These items asked respondents about the strengths of the Life Skills Program and the concerns of the Life Skills Program at their schools. Question \#28 asked, "what do you feel are the strengths of your Life Skills Program?" Of the six administrators who responded to strengths of the Life Skills Program $100 \%(n=6)$ identified at least one strength of their school's Life Skills Program. There were three main themes that emerged from these responses: (a) commitment to the academic well-being of student-athletes; (b) involvement in the community; and (c) academics.

The strength most frequently identified by participating athletic department administrators was the commitment to the academic well-being of their student-athletes. All $(n=6)$ of the responding administrators offered positive comments concerning the academic component of their institution's Life Skills Program. Many of the administrators specifically 
pointed out that providing academic support for their student-athletes was a strong feature within their department.

Concerns about Life Skills Program. Of the six administrators who responded to the survey, all $(n=6)$ expressed concerns about their Life Skills Program. From the responses of the six administrators, two major themes emerged from three of the schools: (a) a lack of support and (b) insufficient finances and other resources. The most frequently mentioned concern about the Life Skills Program was lack of support from their athletic director, coaches, and studentathletes. Administrators reported this as a concern because they felt the athletic staff did not value the programming administered. Furthermore, they would not receive the financial support to provide adequate Life Skills Programming for student-athletes because it was not prioritized by decision makers. Out of the six athletic department administrators who expressed concerns about their program, three identified at least one problem related to support for their school's Life Skills Program.

\section{Summary of Pilot}

The pilot contributed to the growing body of literature about Life Skills Programming for student-athletes at NCAA Division I institutions. The pilot provided an analysis of Life Skills Programs at selected schools from various geographic locations in the U.S. Considering the input of administrators who participated in the pilot study, items used on the pilot survey were adapted for use in the questionnaire for this study. Consequently, the following changes were made to the instrument based on the results of the pilot study (see copy of pilot survey instrument in Appendix C):

1. The format for asking respondents about their annual budget changed. In the main study's instrument, the question "what is your annual budget for your CHAMPS/Life Skills 
Program? (a) less than $\$ 20,000$; (b) 21,000-\$50,000; (c) $\$ 51,000-\$ 99,000$; (d) $\$ 100,000$ and above" was added, as opposed to the answer being pre-selected by the researcher in the pilot study version.

2. The question "what is your ethnicity?" was added. Additionally, the "African American" and "Asian" responses were changed to "African American/Black" and "Asian/Pacific Islander," respectively. An "Other (please specify)" category was also added.

3. In the main study's version of the questionnaire, "how much total time have you been involved in the Life Skills Program at your institution?" was changed to "how many years as an administrator have you been involved in the Life Skills Program at your institution?"

4. In the pilots study's version of the questionnaire, the statement read, "please indicate size range of your institution." The main version of the questionnaire read: "please indicate student enrollment at your institution."

5. In the pilot study's version of the questionnaire, the question read, "what was the highest level of education attained?" The main version of the questionnaire read, "what is your highest level of education attained?”

6. In the pilot study's version of the questionnaire, the question read, "how many studentathletes are at your current institution?" The main version of the questionnaire read, "how many Student Athletes by gender are at your current institution?" The choices were "male" or "female."

7. In the pilot study's version of the questionnaire, the question read, "how often do you interact with student-athletes?" The respondent was given the following choices to answer: "never; seldom; sometimes; always." The main version of the questionnaire read, 
"on a weekly basis, how often do you have face to face interactions from your studentathletes?" with the following choices: "once a day; twice a week; three times a week; never; other (specify)."

8. In the main study's version of the questionnaire, responses to the question "do you attend student-athletes' practices?” The new changes listed these responses (e.g., “once a day; twice a week; three times a week; never; other (specify)").

9. In the main study's version of the questionnaire, responses to the question, "does your Life Skills Program include the five components?" was changed to include a list of the components (e.g., "commitment to academic excellence," "commitment to personal development," "commitment to career development," "commitment to athletic excellence," and "commitment to service). Respondents were then asked to choose "yes or no," in response to the above stated question.

10. In order to gain a better understanding of support for the Life Skills Program at each university, the researcher added the question "what is the 'buy in' (i.e. support) from the following? Check all that apply: coaches; athletic director; university president; other."

11. Follow-up questions concerning the utility of the instrument, which were used in the pilot study, were eliminated from the main study's instrument.

\section{Main Study}

Upon completion of the pilot study, the main study was initiated. Appropriate corrections were made to the best practices of the CHAMPS/Life Skills Program survey by Murdock (2010), and incorporated input from the pilot study participants and university experts. The questionnaire instrument was then converted from the pencil-and-paper format to an online format via Qualtrics software. All of the questionnaires used in the main study were completed and 
submitted online through Qualtrics.com. Approximately two weeks were allowed for data collection.

The purposes of this study were:

1. To determine if Life Skills Programs exist in all of the 14 Big Ten Schools.

2. To determine if the NCAA Division I Life Skills Commitment Statements were utilized at all the Big Ten Schools.

3. To determine how Big Ten administrators perceived Life Skills Programs across all 14 Big Ten Universities.

Murdock (2010) noted that pre-testing was the only way to detect, in advance, problems in a questionnaire and to address the question of instrument reliability. Murdock's best practices CHAMPS/Life Skills Program survey was used to answer the research questions of this study once IRB approval was obtained by the researcher. University administrators from the Big Ten NCAA Conference in the athletic departments of the following schools were invited to participate: Indiana University; Michigan State University; Northwestern University; Ohio State University; Penn State University; Purdue University; Rutgers University; University of Illinois; University of Iowa; University of Maryland; University of Michigan; University of Minnesota; University of Nebraska, and the University of Wisconsin. Only ten schools agreed to participate in this study.

The questionnaire consisted of two parts. Part one consisted of 29 Life Skills questions; part two had 45 questions that addressed the five Life Skills Commitment Statements. Each section took approximately 20 minutes to complete. Administrators had two weeks to respond to the invitation after contact was made by email from the PI between November 17th and December 1st, 2014. 


\section{Participants}

The sample for this study included directors from ten Life Skills Programs at NCAA Division I-A member institutions in the Big Ten Conference during the 2014-2015 academic year. These participants were identified for this study because of their involvement in Life Skills. The researcher chose the Big Ten Conference of the NCAA for several reasons:

1. The Big Ten is the oldest conference in the NCAA and has stellar reputation for academic excellence and quality academic programs. It is a national leader in broadbased programming, student-athlete welfare, gender equity, and innovation. In 2007, they became the first national conference-owned television network.

2. The University of Nebraska-Lincoln's Life Skills is one of the first programs of its kind established in the nation, and is considered by many to be the best, a model program for universities in the United States. The administrator for Life Skills at the University of Nebraska-Lincoln, Keith Zimmer is considered to be the leading expert on developing elite Life Skills Programming. In addition, the University of Nebraska-Lincoln also leads the nation with more academic All-Americans than any university in the country since 2000.

Nebraska's rich tradition of academic excellence is solidified on the national level through the University's dominance of the CoSIDA/Capital One Academic All-American awards. University of Nebraska student-athletes from teams in all sports combined far exceeded that of any other school in the country. As of March 11, 2015, Nebraska had a nation-leading total of 315 CoSIDA/Capital One Academic All-Americans.

3. Two of the Life Skills Directors in the Big Ten conference were selected to serve on the NCAA's Action Team for Life Skills. The18 member action team is charged with 
defining the profession of Life Skills, bettering the emerging lives of NCAA studentathletes, supporting membership professionals, as well as providing both student-athletes and administrators with tools to be successful. The members were chose based on their leadership and reputation for having elite Life Skills Programming at their institutions. The Big Ten had the most representatives from a conference on the NCAA action team, and the researcher felt they would be able to gain better insight of the NCAA's direction of Life Skills in the future for college athletics.

\section{Instrumentation}

Prior to any data collection, approval from the West Virginia University Institutional Review Board (IRB) had to be obtained. Following IRB approval, the Primary Investigator (PI) contacted Life Skills Directors via email. The email explained the study and invited the Life Skills Directors to participate. If the directors chose to participate, they contacted the PI to express their interest. Their rights as participants were then explained in a written letter. All instruments were administered to college administrators by the PI. Administrator participants received a research packet with the following documents:

1. Cover letter (see Appendix B) explaining the purpose of the study and rights as a participant.

2. Best practices of the Life Skills Program Survey (see Appendix C) by Murdock (2010).

The first section of the best practices of the Life Skills Program questionnaire constructed by Murdock (2010) asked participants to respond to demographic and background questions (i.e., gender; ethnicity; amount of personal experience in their current school's Life Skills Program; amount of time the school has participated in the Life Skills Program; size of the institution; job 
title). The first portion of the survey (see Appendix C) included other demographic prompts (completed by the researcher prior to dissemination) including a range of the institutions' graduation success rate, number of years the institution had been a participating member of the Life Skills Program, size range of the institution, and participant's job title.

The second section of the instrument included instructions for completing the 45 Likert scale questions. These questions were derived from the instructional resources and accompanying descriptions listed in the NCAA Life Skills Program 2008-

2009 brochure (NCAA, 2008a). The questions were adapted for use in the questionnaire to elicit quantified ratings concerning respondents' impressions about the effectiveness of the Life Skills Program practices at their institutions. Possible responses ranged from "1 'totally ineffective' through 5 'highly effective,"” or "N/A."

\section{Research Questions}

Based upon results from the pilot study and the results from the literature, the following research questions were developed:

1. Do NCAA Life Skills Programs exist at all Big Ten schools?

2. Are the five NCAA Life Skills Commitment Statements being enforced at all Big Ten schools?

3. Are NCAA Life Skills Programs effective at all Big Ten schools?

The researcher chose the research questions for the following reasons: After the researcher did a Google search to see if all schools in the Big Ten offered a Life Skills Program, they wanted to speak to the administrators to determine if each school actually provided Life Skills Programs at their universities. Based on the researcher's pilot study examining Life Skills Programs on six schools from six NCAA Division I conferences, the researcher reported some 
schools advertise on their websites they have a Life Skills Program. After speaking to the Life Skills administrators, two of the six schools did not offer such a program. Some of the reasons the schools did not offer Life Skills Programs varied. "Not having personnel" and "inadequate budgets" were the most frequently given reasons.

The researcher's pilot study also suggested schools which advertised Life Skills Programs on their websites did not enforce the five Commitment Statements. Some of the reasons why some schools did not enforce the five Commitment Statements were "the lack of budgets" and their "athletic department's emphasizing one Commitment Statement over another." For example, one school reported that it focused mostly on the Academic Commitment because of the APR penalties some of their teams suffered.

In this current study, the researcher wanted to find out from the Life Skills administrators if the Life Skills Programs being advertised on the websites were indeed the programs provided for their student-athletes.

\section{Data Analysis}

To address research question one, the researcher examined if all Big Ten schools had Life Skills Programs. Question \#7 asked, “does your athletic department have a Life Skills Program?” For research question two the researcher examined each Big Ten school athletic administrator's responses to determine the extent to which all five Commitment Statements were practiced at Big Ten schools. The PI will also refer to question \#20 on the questionnaire, “does your Life Skills Program include the five Commitment Statements?"

To answer research question two, the researcher examined five of the NCAA Life Skills Commitment Statements utilized by the Big Ten schools: Academic Commitment; Athletic Commitment; Personal Development Commitment; Career Commitment, and Community 
Service Commitment. To answer research question three, regarding the effectiveness of Life Skills, the researcher will refer to question \#29 on the questionnaire: "what is the overall effectiveness of their Life Skills Program?” Question \#1 under the qualitative portion of the study: "what do you feel are the strengths of your Life Skills Program?

In the third portion of the survey, four interview questions were presented. The first questions provided subjects an opportunity to express their opinions concerning the strengths of their school's Life Skills Program. The second question asked participants about the percentage of participation of revenue generating sports in their Life Skills Program. The third question elicited respondents' concerns about their program. The final question allowed participants to discuss new programs/initiatives that were not offered at their institutions. The interview questions requested participants to offer recommendations they believed could create a positive impact on the student-athlete experiences.

Each interview was digitally recorded. Recordings were kept in a locked home office located in Morgantown, West Virginia. Only the PI had access to the recordings from the interviews. Recordings will be destroyed six months after the conclusion of the study. After the completion of the qualitative research, the PI transcribed recorded sessions verbatim. According to Patton (2002), verbatim transcriptions are "the essentials of raw data for qualitative analysis" (p. 441), and completing this process allowed the researcher to get a better sense of the data. The transcript will be given to a panel of experts (two of which are experienced researchers from West Virginia University). The researchers read each transcription to gain a better sense of what participants were saying, the tone of their ideas, and to have a general impression of the overall interview (Murdock, 2010). The researcher examined emerging themes from the data and separated the codes into categories. 
The research team consisted of the PI, Marc Williams, a doctoral student at West Virginia University in the College of Education and Human Services; Dr. Luisa Velez-Colon from the College of Physical Activity and Sports Sciences at West Virginia University, and Dr. Oran Alston from the College of Business and Economics from West Virginia University. Both professors had experiences with qualitative data analysis. Members of the research team were asked to read each transcription to gain a better sense of what participants were saying and the tone of their ideas. All personal identifiable information was removed from the transcripts. The research team met to discuss emerging themes from the data and separate the codes into categories. If any discrepancies arose during this process, categories were debated until the group came to a consensus. Themes that emerged from the focus groups are presented in the "Findings" section.

\section{Data Collection}

The research design of this project was a cross-sectional, non-experimental design in which data was gathered at one point in time from Life Skills Program administrators. Crosssectional survey methodology was selected for collecting data since it allowed the researcher to gather data not directly observable, but self-reported, such as beliefs and opinions (Murdock, 2010).

On August $9^{\text {th }}, 2014$, the researcher located athletic department personnel's contact information through perusal of each institution's athletic department web site. The researcher emailed and called administrators to participate in the study. Once the researcher spoke to the administrator, the administrator informed the researcher which individual in the athletic department would be the most appropriate for completing the survey, clarifying issues related to survey participation, and for follow-up purposes. Contact information for the primary 
investigator was provided within the e-mail invitation message. Athletic department representatives at all 14 NCAA Division I-A Big Ten Life Skills Program institutions were provided with a link to the Qualtics.com software via e-mail so they could access the instrument and submit their survey responses online. Participants could return to their survey to edit their own responses using the same link.

The participants were instructed to call the researcher to take part in an interview within 24 hours of completing the survey. The phone interview consisted of four open-ended questions requiring a maximum of 20 minutes of their time. With permission of the participants, the interviews were audio recorded for a more accurate analysis of the data. Once the survey and the interviews were completed, the interviewer thanked the interviewees for their time and contributions. 


\section{CHAPTER IV-FINDINGS}

\section{Data Analysis}

Fourteen $(n=14)$ senior athletic administrators at Big Ten universities with Life Skills Programs were asked via email to complete the modified survey. Survey forms were completed and emailed back to the researcher by November 17th, 2014. The first part of the survey consisted of demographic questions for the respondents. The second section of the instrument included instructions for completing the 45 Likert scale questions. These questions were derived from the instructional resources and accompanying descriptions listed in the NCAA CHAMPS/Life Skills Program 2008-2009 brochure (NCAA, 2008a). The questions were adapted for use in the survey to elicit quantified ratings concerning respondents' impressions about the effectiveness of their academic institution's Life Skills Program practices. Possible responses ranged from " 1 = totally ineffective" through " 5 = highly effective," and "N/A (not applicable)."

The third portion of the survey was descriptive data, and consisted of five open-ended questions. The open-ended questions were derived from themes that emerged from interviews with participants. Three panelists discussed and agreed upon the themes. Two of the panelists were professors at West Virginia University with extensive backgrounds in qualitative research. The third panelist was the researcher. The panel of experts read the qualitative responses the researcher had recorded. Each expert discussed and agreed upon the most common themes from each of the qualitative responses.

The first questions asked was "what do you feel are the strengths of your Life Skills Program?" The second question asked was "what is the participation of your revenue generating sports in your Life Skills Program?" The third question asked was "what new programs or initiatives would you add that your program does not currently offer that would make a positive 
impact on your student-athletes?" The fourth question asked was "what concerns, if any, do you have about your school's Life Skills Program?" The fifth question asked was "what is the 'buy in' (i.e., support) from the following university officials?"

\section{Demographic Data}

Nine ( $n=9)$ administrators in the department of athletics and one respondent had been on the job two months, and were only able to provide demographic data and an outline of the new Life Skills Program that will be implemented in the fall of 2015. Seven $(n=7)$ of the participants were female and three $(n=3)$ were male (see Figure 1 for Big Ten gender demographic data). Figure 1. Big Ten demographic data. This figure depicts the gender ratios of Big Ten Life Skills administrators.

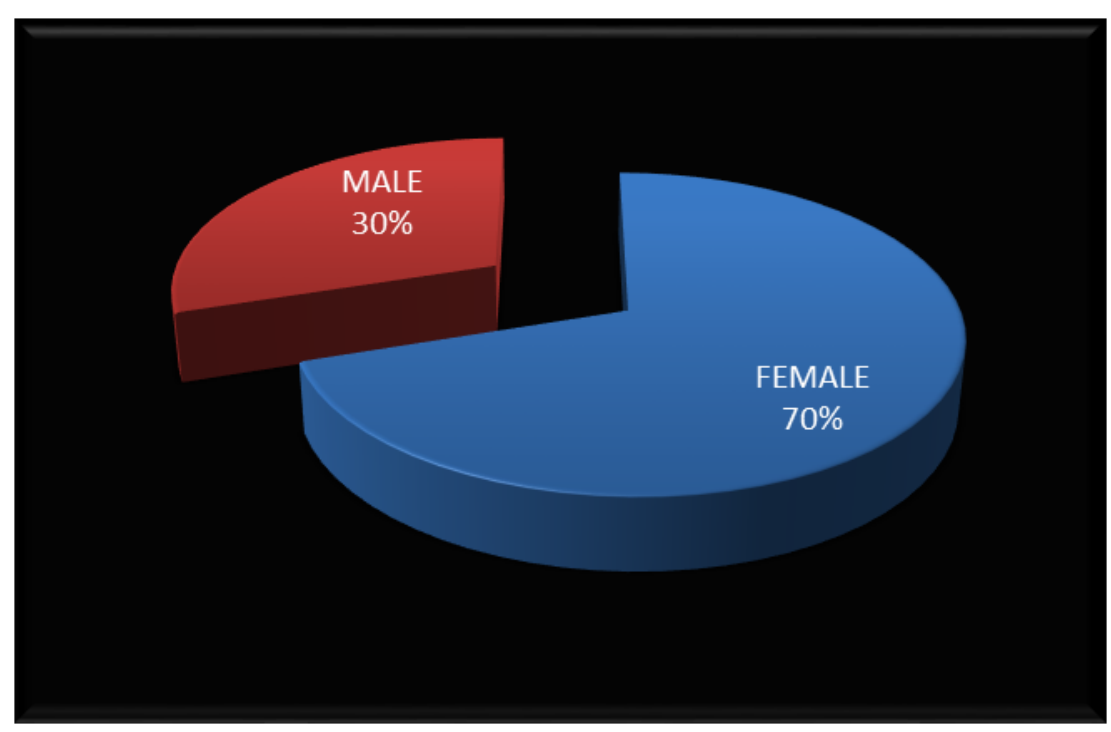

Seven of the participants were Caucasian/White and three were African American (see Figure 2 for Big Ten racial demographic data). Nine subjects reported an 80\%-100\% graduation success rate, and only one reported a 51\%-79\% success rate. Job titles of the Life Skills administrators varied among the participants. 
Figure 2. Big Ten racial demographic data. This figure depicts the racial ratios of Big Ten Life Skills Administrators.

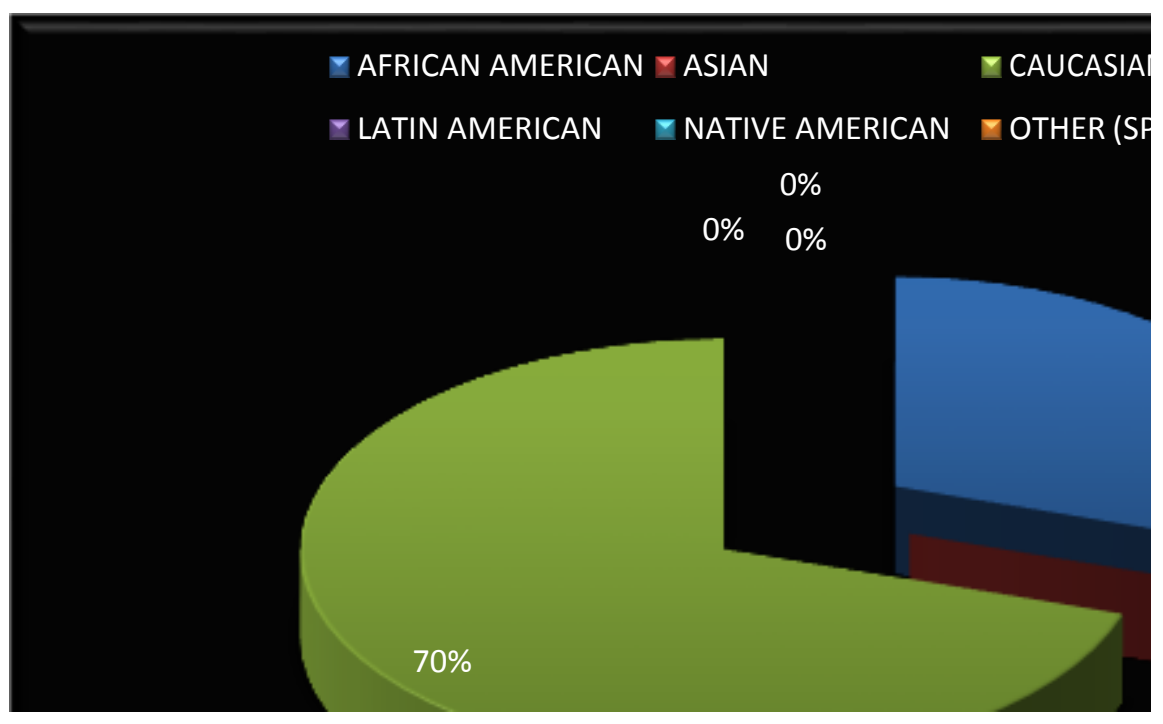

Data revealed a variation in number of years Life Skills administrators held their current positions. Three of the Life Skills administrators held their current positions for one to two years; two held their positions over 27 years; two held their positions three to five years; two held their positions less than a year; one held his position six to ten years.

\section{Enrollment Size}

Enrollment across the Big Ten universities ranged from 1,000-10,000 to 35,001 or more. Seven of the schools had student populations of 35,001 or more; two of the schools had student populations of 25,001-35,000; one had a student population of 15,001-25,000.

\section{Education of Administrators}

Six of the administrators $(n=6)$ held a master's degree, three had doctorate degrees, and one had a bachelor's degree (see Figure 3 for Big Ten education demographic data). Six administrators $(n=6)$ were former student-athletes and four had not played a sport as an undergraduate. Administrators had participated in various sports, including football, swimming, 
and gymnastics. One administrator played three sports: volleyball, basketball, and softball. The undergraduate majors of the administrators also varied. One administrator double-majored in Spanish and horticultural genetics, and one administrator double-majored in planning and public policy. The remaining majors reported were: counseling; business; kinesiology; psychology; physical education; telecommunications; athletic training; and sociology.

Figure 3. Big Ten education demographic data. This figure depicts Big Ten Life Skills Administrators' Highest Levels of Education.

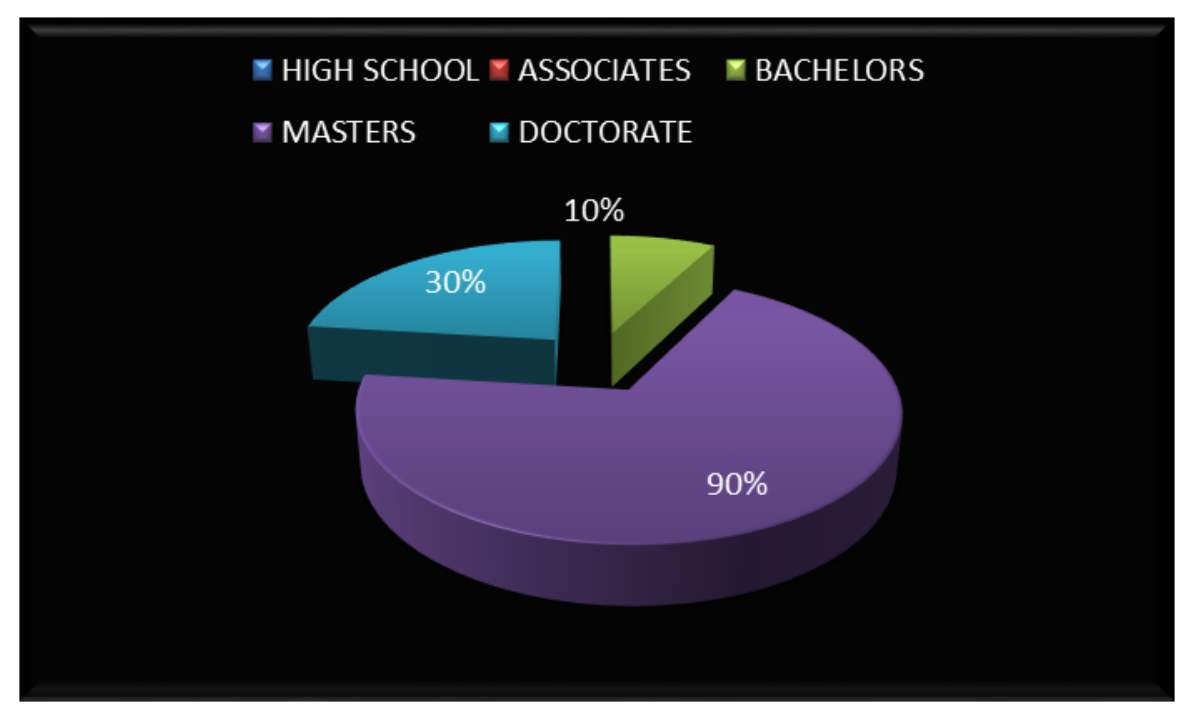

Respondents from each school were asked about the population of the student-athletes' gender. It was reported the average number of female athletes was 306 and the average number of male athletes was 337 .

Respondents were asked about the frequency of interactions with student-athletes. All ten respondents $(n=10)$ indicated they always interact with student-athletes. Respondents were asked how frequently they attended student-athlete practices. Two indicated twice a week, seven said several times a month, and one said rarely. Respondents were asked if they attended studentathlete home games Four indicated always and two indicated sometimes. Lastly, respondents 
were asked if they attended student-athlete away games. Three indicated sometimes, two indicated seldom, and one indicated never.

All ten $(n=10)$ institutions were asked to identify their school's Life Skills budget. Only one respondent reported they had no budget, and the athletic director had not identified an appropriate budget at the time of the interview with the administrator. Further budget analysis indicated that five had budgets of $\$ 100,000$ and above, two had budgets of $\$ 21,000-\$ 50,000$, one had a budget of $\$ 51,000-\$ 99,000$, and one reported he did not have a budget due to his new position. Five indicated their budgets increased, four indicated the budget stayed the same, and one indicated he did not have a budget because he just took on his position.

Subjects were asked where the Life Skills offices were located. All ten $(n=10)$ reported the Life Skills offices were located in the athletic department. Ten of the respondents indicated they were the person responsible for the Life Skills Programs at their university (see Table 2 for Big Ten administrators' profile summaries).

Table 2. Big Ten Administrators: Job Title, Program Budget, Race, Gender, Graduation Success Rate (GSR), and Reporting Structure.

BI G TEN AD MIN IS TRA TO RS: JOB TI TLE, PROGRA M B U DGET, RA CE, GEN DE R, GS R A ND REP ORTI NG

\begin{tabular}{|c|c|c|c|c|c|c|c|}
\hline Job Title & Program Title & Budget & Race & Gender & Education & $\begin{array}{r}\text { Graduation } \\
\text { Success Rate }\end{array}$ & $\begin{array}{l}\text { Reporting } \\
\text { Structure }\end{array}$ \\
\hline $\begin{array}{l}\text { Associate Athletic Director For Life } \\
\text { Skills }\end{array}$ & Life Skills Program & $\$ 100,000+$ & White & Male & Masters & $80 \%-100 \%$ & Reports to AD \\
\hline $\begin{array}{l}\text { Associate Director for Athletic } \\
\text { Academic Support/Life Skills }\end{array}$ & CHAMPS/Life Skills Program & $\begin{array}{l}\$ 21,000- \\
\$ 50,000\end{array}$ & White & Female & Doctorate & $51 \%-79 \%$ & $\begin{array}{l}\text { Reports to } \\
\text { Senior Admin }\end{array}$ \\
\hline $\begin{array}{l}\text { Director of Student Athlete } \\
\text { Development }\end{array}$ & CHAMPS/Life Skills Program & $\$ 100,000+$ & White & Female & Masters & $80 \%-100 \%$ & $\begin{array}{l}\text { Reports to } \\
\text { Senior Admin }\end{array}$ \\
\hline $\begin{array}{l}\text { Assistant Director of Academics, } \\
\text { Student athlete development }\end{array}$ & CHAMPS/Life Skills Program & $\begin{array}{l}\$ 51,000- \\
\$ 99,000\end{array}$ & White & Female & Masters & $80 \%-100 \%$ & $\begin{array}{l}\text { Reports to } \\
\text { Senior Admin }\end{array}$ \\
\hline Director of Leadership \& Life Skills & Excellence Academy & $\begin{array}{l}\$ 21,000- \\
\$ 50,000\end{array}$ & White & Female & Bachelors & $80 \%-100 \%$ & $\begin{array}{l}\text { Reports to } \\
\text { Senior Admin }\end{array}$ \\
\hline $\begin{array}{l}\text { Associate Athletic Director - Academic } \\
\text { Services }\end{array}$ & Life Skills Program & $\$ 100,000+$ & African-American & Female & Doctorate & $80 \%-100 \%$ & Reports to $A D$ \\
\hline Director, Student-Athlete Development & $\begin{array}{l}\text { Student Athlete Development } \\
\text { Program }\end{array}$ & $\$ 100,000+$ & White & Female & Masters & $80 \%-100 \%$ & $\begin{array}{l}\text { Reports to } \\
\text { Senior Admin }\end{array}$ \\
\hline $\begin{array}{l}\text { Assistant Athletic Director, Student- } \\
\text { Athlete Development }\end{array}$ & Life Skills Program & $\$ 100,000+$ & African-American & Male & Masters & $80 \%-100 \%$ & Reports to AD \\
\hline $\begin{array}{l}\text { Assistant Athletic Director, Student- } \\
\text { Athlete Development }\end{array}$ & Leadership Academy & $\$ 100,000+$ & African-American & Male & Masters & $80 \%-100 \%$ & Reports to $A D$ \\
\hline $\begin{array}{l}\text { Assistant Athletic Director for Life } \\
\text { Skills and Career Development }\end{array}$ & Brand $\mathrm{U}$ & $\begin{array}{l}\$ 51,000- \\
\$ 99,000\end{array}$ & White & Female & Doctorate & $80 \%-100 \%$ & \begin{tabular}{|l} 
Reports to \\
Senior Admin
\end{tabular} \\
\hline
\end{tabular}




\section{Research Questions}

\section{Research Question One}

The first question was "do NCAA Life Skills Programs exist at all Big Ten schools? All ten $(n=10)$ institutions offered NCAA Life Skills Programs.

\section{Research Question Two}

The second research question asked, "are the five NCAA Life Skills Commitment Statements being enforced at all Big Ten schools?" All ten ( $n=10)$ institutions provided five of the NCAA Life Skills Commitment Statements: Academic Commitment, Athletic Commitment, Personal Development Commitment, Career Commitment, and Community Service Commitment. Nine $(n=9)$ indicated their schools enforced the five Life Skills components.

Respondents were asked, "was it mandatory for student-athletes to attend the Life Skills seminars?" Eight $(\mathrm{n}=8)$ indicated it was not mandatory and two indicated it was mandatory for all student-athletes to attend Life Skills seminars.

Respondents were asked, "participants from which sports attend life skill seminars regularly?" Two indicated all of them and eight indicated it was not mandatory for athletes from all sports to attend.

Respondents were asked, "What sports were not required to attend Life Skills Programming?" All ten $(\mathrm{n}=10)$ responded the Life Skills Programs were mandatory for all teams.

\section{Research Question Three}

Research question three asked, "how effective are the various Life Skills Programs?" Program effectiveness was analyzed by measuring effectiveness through quantitative and qualitative responses. 


\section{Quantitative Results of Effectiveness}

Three items assessed Life Skills effectiveness at each school: (a) question \#29 on the questionnaire: "what is the overall effectiveness of their Life Skills Program?" The first item to assess the effectiveness of Life Skill program was question \#24. The possible responses from each item included: very effective, somewhat effective, effective, ineffective, and very ineffective. Of the ten respondents, four indicated their program was very effective, four indicated somewhat effective, and one was effective.

Community service was the strength most frequently identified by the participating institutions' athletic department administrators. All participants $(n=10)$ who offered positive responses to this open-ended question made comments concerning his/her program's service component. For example, several athletic department administrators noted the high amount of activity displayed by their community service program.

Other administrators mentioned the priority and focus they had on community service activities. Another respondent indicated their school completed community service hours through a community service competition between sports teams in the athletic department, which resulted in more community service hours being completed at that particular university than ever before. One administrator used "stellar" to describe their community service program. Some respondents identified community outreach, community involvement, or community/campus connections as particular strengths of their Life Skills Program. It is important to note that participants who were new to a school and had been at the institution less than three months were not able to answer all of the questions. 


\section{Interview Questions (Qualitative)}

The five interview questions that were asked to gain a more in-depth perspective about the Life Skills Programs were:

1. What do you feel are the strengths of your Life Skills Program?

2. What is the participation of your revenue generating sports in your Life Skills Program?

3. What new programs or initiatives would you add that your program does not currently offer that would make a positive impact on your student-athletes?

4. What concerns, if any, do you have about your school's Life Skills Program?

5. What is the "buy in" (i.e., support) from the following university officials?

The second and third items that measured the effectiveness of the Life Skills Program were questions \#1 and \#5 in the open-ended questions "what do you feel are the strengths of your Life Skills Program and the "buy in; of the Life Skills Program?" and "what concerns, if any, do you have about your school's Life Skills Program?”

In response to the first question, nine of the ten administrators $(n=9)$ were able to identify at least one strength of their school's Life Skills Program. While responses to this question varied, common themes emerged. The researchers identified the following as common themes regarding the strengths of the participating programs: involvement in the community, support from their athletic director, and a fully comprehensive program. A total of nine out of ten $(n=9)$ of the responding administrators offered positive comments about the support of the athletic director, senior team, the coaches, the campus community, the commitment to service, and a fully comprehensive program.

One administrator added that in his athletic department he had a great deal of personal contact with his student-athletes. Some of the schools' administrators highlighted the general 
emphasis on academics at their institution. Responses $(n=8)$ included acknowledgement of their

strong commitment to academics, and reported that academics were their program's biggest

strength. One administrator specifically outlined the academic achievements and awards earned

by their student-athletes, in which they are a national leader for the past 20 years in producing

Academic All-Americans.

\section{Common Strengths Reported by Big Ten Administrators Service}

The researchers all agreed that participants perceived community service emerged as the most important strength of the Life Skills. Every respondent stated that service was the most important strength of their programming. The total average amount of service hours their student-athletes devoted throughout the year was 10,000. Respondents 2, 4, 6, 7, and 10 offered positive comments about their commitment to service.

Life Skills Administrator \#3:

Student athletes perform 6,000-7,000 hours of community service per semester. They visit schools, nursing homes, hospitals, big brothers, big sisters, MLK Day70 student-athletes at five different events through the community. On Easter will have 150 events they can choose to be involved in.

Life Skills Administrator \#4:

Our community service is very big. We have a long-standing tradition where our student-athletes work in the community as well as the school system. We have a day of caring, student-athletes are placed with different business and volunteer for those companies. We have over 200 student-athletes that participate every year.

Life Skills Administrator \#6:

Our community outreach is what we stood on for years, we put a lot of emphasis on it and the student-athletes are excited to participate. We track the hours and time our student-athletes participate in community service events. We do between 60-80 events per year with our student-athletes in the community. For the past 10 years, every sport adopted a family during the holidays for the Salvation Army and bought toys and delivered them. We also do relay for life and individual request from the community. 
Life Skills Administrator \#7:

Our community service arm is also pretty major, we did over 15,000 hours of community service last year, and we have a strong commitment to service and giving back. We worked with an organization with kids with cancer. We put on our version of a state fair at our facility for the hope kids and the community. All of our student-athletes are at every station and getting the kids actively engaged. It has become our culture the past nine years.

We have visited Native American reservations, and we are exploring going to go to Thailand. Our big platform is our poster program: teaching schools about exercising, healthy eating, anti-bullying, oral hygiene, reading, and teaching them to make healthy choices. This is really woven in who we are.

Life Skills Administrator \#10:

Our service component is also very strong. We have annual competition for our student-athletes to see who has the most hours of community service and we reward them at our annual awards banquet for their service. It is definitely one of the three components of our leadership academy.

As a component of service, more schools are incorporating a travel abroad service project for their student-athletes to participate in and experience. For example, respondent \#1 reports a new international initiative his school will sponsor during the summer of the 2014-2015 academic school year.

Life Skills Administrator \#1:

This is the first year we are doing a service abroad program, and we are taking 18 student-athletes, two letter winner alumni student-athletes, two Life Skills staff members and the director of athletics — seven days in Guatemala, building a sports complex, an amphitheater.

\section{Fully Comprehensive Program}

The second largest strength reported was Life Skills programs having fully comprehensive programming featuring all five of the NCAA Life Skills components: service, academics, athletics, professional development, and career development. Respondents 1, 2, 3, and 9 reported on their school's fully comprehensive program. 


\section{Life Skills Director \#1:}

I think it is the depth, the comprehensiveness of our program. . . I feel we have a program that touches every level of the student-athlete, no matter where they are in their career and their development. We help them with transition issues into college, transition issues out of college, helping to feel more confident while they are in school. We also do a great job with sticking with our student-athletes beyond graduation, so we provide Life Skills Programs for life. We are rolling out some new things that are pretty exciting.

For example, post eligibility opportunities, longer and stronger commitment beyond their eligibility and their graduation. The depth and comprehensiveness and the complete commitment makes us unique.

\section{Life Skills Director \#2:}

We try to help the student-athlete with their overall development. We cover academic, personal development. Athletic, career development. We try to make sure we give everybody the opportunity to get involved and give back to our community. That is our primary focus for us. We also want to make sure we provide them with options, making choices. We want them to give thought on what they think they need, so we can have balance to our programming. We do have some mandatory programming and we bring 2 speakers in a year for all student-athletes. We offer 30-40 workshops a year on topics to mirror the NCAA 5 Commitments. They student-athletes buy into our programming because they have a choice in what seminars they can choose from. The student-athletes have can choose the number of seminars they attend, it is mandatory they choose one in every category and many actually attend more than the required amount.

\section{Life Skills Director \#3:}

Our comprehensive approach to the overall development of student-athletes is excellent. We focus so much on transitioning into college and transitioning out of college, most colleges we have transitioning seminars. We have a program we are slowly developing on is finding ways to provide student-athletes with internships, job shadowing opportunities, so our student-athletes can be afforded those opportunities.

\section{Life Skills Director \#9:}

The biggest strength is that we offer programming in various areas. We have four pillars: Leadership, Personal Development, Career Development, Diversity and Inclusion. We have four full time staff members so we have the resources to incorporate and implement these programs. The biggest strength is that we offer programming in various areas. We have four full time staff members so we have the resources to incorporate and implement these programs. 


\section{Geographic Location and Career Enrichment}

The location of the university seemed to influence what was valuable in a Life Skills program. For example, four of the ten respondents were located in rural areas and felt their school's program needed to improve on career development for their student-athletes. Though the Big Ten existed for nearly a century as an assemblage of universities located primarily in the Midwest, the conference now has a geographic footprint which spans from the state of Nebraska in the West to the Atlantic Ocean in the East. The schools classified to be in the rural areas were Indiana, Purdue, Iowa, and Nebraska. Schools that were in a more metropolitan setting valued career development more because of their geographic location. The Big Ten schools classified as metropolitan were Rutgers, Maryland, Minnesota, Illinois, Michigan State, and Wisconsin. Respondent \#10 provided an in-depth analysis of the program's focus on geographic location that attracts student-athletes.

Life Skills Director \#10:

Our geographic location first and foremost is probably our greatest strength. Our Life Skill program is centered around career enrichment. We have studentathletes that purposely come here because of our geographic location and they focus on their careers prior to them attending, and they feel our location provides them the best opportunity to get employed by the diverse number of companies that are in our proximity. We put a lot of emphasis on networking, resume building, and a number of events throughout the year.

We are very hands on. Each year we do a career assessment for all our studentathletes so that they are very much aware each year what the expectations are on campus. By the time they are done, they at least will have exposure to people from the industry of their choice and that will position them to land a full time job.

Our annual networking event in December and our welcome back barbecue are the only two events that are mandatory - kind of unspoken - We highly encourage it. The past six years we do these events, and it has been part of the culture. What is also very strong about our networking event is that we customize 
it to fit the student-athlete's career interest. For example, if you are a public health major, you will attend the public health panel because it is beneficial to you as it relates to what you want to do long term.

\section{Athletic Director Support}

A large number of the respondents indicated that their athletic directors supported and valued their program. As stated by respondent \#3:

Life Skills Administrator \#3:

The commitment our amazing AD has made to have a full time person to just primarily focus on life skills. The students are told rapidly that they are important and they can clearly see by the commitment from the AD, the coaches and the athletic staff that we are serious about them based on the facilities and the programs we have established to help them to become better all-around human beings.

\section{Budget}

Five out of the ten respondents reported they had a budget over $\$ 100,000$, as indicated by respondents \#6 and \#3.

Life Skills Director \#6:

The great thing is I am not given a specific budget. Administration typically supports the things we do. I would estimate our budget to be over $\$ 100,000$ based on some of the things we do. For example, I do a welcome back picnic, an annual banquet, and orientation. We do a speakers series in July for Men's \& Women's Basketball, Football, Hockey, and Volleyball and hit all the sports in August ... Sexual Assault, Drugs and Alcohol ... These along with the financial speaker is about $\$ 30,000$.

Life Skills Director \#3:

We had two years of budget increases to ensure that our programming and area was going to be able to prepare our student-athletes on and off their field.

\section{Programming that Focuses on Cultural Diversity}

Four of the ten schools cited that cultural diversity programming emerged as a strength as it pertained to programming for student-athletes. Interestingly, those schools averaged $2.6 \%$ total 
African American student populations. One of the unique aspects of the Big Ten is that they designate a diversity intern position to represent the Big Ten from each school. The goal of the Big Ten diversity internship is to:

1. Provide an individual with practical and well-rounded work experience and mentorship.

2. Increase the opportunities for underrepresented minorities and women within intercollegiate athletic administration.

3. Positively impact the university and its department of intercollegiate athletics.

Respondents \#4, 7, 8, 9, and 10 provided unique comments about their diverse programming for African American student-athletes and international students.

Life Skills Director \#10:

I love the Big Ten does this so they want to make sure minority students are best served-it is mandatory that each team has a representative. In addition, we do an exit interview with all of our senior minority student-athletes.

Life Skills Director \#7:

An example of what we are doing for students of color, we have our African Heritage night in February for Black History Month, living learning communities for African-American men, Black student union, VP equity and diversity, director equal opportunity, and affirmative action will join 250 kids from our local middle schools. We do have organizations for our international students, which is based on campus organizations, to continue with our collaboration with the campus community.

\section{Life Skills Director \#9:}

Our diversity and inclusion and beyond the game program are pretty advanced and a definite a strength. Beyond the game program - effort to discuss various career development paths for those who have aspirations to play in pro sports.... Having a parallel plan, what is your plan when you leave. Three courses they take. The specific population for beyond the game program is primarily focused on African-American males.

\section{Life Skills Director \#4:}

Something we are very excited about is what we do with our students of color. Since we are a predominantly White institution, we do as much as we can so that 
our minority students are as comfortable as possible. A well-respected employee established this program many years ago called the Minority Focus Group: They talk about issues that are relevant to student-athletes of color and international student-athletes. They get together three to four times a semester. They have mentors that meet with the student-athletes to help to prepare them for the community and life after school. We also pay attention to the hiring in our office, we work hard at actively recruit individuals who the student-athletes feel comfortable around.

\section{Life Skills Director \#8:}

We partner with the African American Studies Center and do an orientation. I oversee the international component, my fellow staff member and I partner with the LBGT community, making sure we are doing programming and educating our student-athletes. We are doing a two-day program in March of 2015.

\section{University Support}

Four respondents indicated the support of various stakeholders was a major strength at their universities, as stated by participant \#7.

Life Skills Administrator \#7:

The tremendous buy in from the valued campus community stakeholders that we serve. Internally from our senior administrators, student-athletes and coaches. Everyone sees us as being essential to their success that really diversifying their meaning in a way that is conducive for preparing them for life after sports. Everyone values it and they see it. The extension of that, our campus, and community stakeholders as well as our alumni. I can't say enough about how our alumni continue to give back and stay actively engaged in everything to career development, leadership development, and brand management to community outreach. They come back and stay engaged, and that speaks volumes to how much our area is woven into the fabric of the maroon and gold way and definitely look to how we look to embody excellence for our student-athletes. I say our marketing and promotional efforts we do a great job to make sure we have enough touch points to get our information out, from our newsletter, from our student athlete advisory committee, to being able to speak at unit director meetings, so that other units in athletics know what we are doing so they can support what we are doing, and more importantly we can support them. Working with student affairs, equal opportunity office, student union activities and making sure we are able to work actively be engaged with coaches and staying engaged with them. 


\section{Influence of Being on the Senior Management Team}

Three respondents $(n=3)$ cited the role of being on senior management helped influence

the importance of Life Skills and provided the staff a better understanding, and emerged as a common theme.

Life Skills Administrator \#10:

Me being on the senior administrative team carries a lot of weight and is major strength. Having a place at the table and a voice and what is best for the studentathlete experience. It is key and instrumental in the types of programs we do and having the executive staff. They value the work we are doing means a lot helps to foster consistency in what we do with the student-athletes.

Life Skills Administrator \#7:

Another strength is that in my position, I am part the senior management team in athletics; I sit at the table with all of our senior AD, the deputy AD and AD. We always want to make sure all of our efforts always are student-athlete centered and to make sure I am able to really articulate to those point to those that make those decisions.

Life Skills Administrator \#6:

Me being on the senior administrative team carries a lot of weight and is major strength. Having a place at the table and a voice and what is best for the studentathlete experience. It is key and instrumental in the types of programs we do and having the executive staff. They value the work we are doing means a lot helps to foster consistency in what we do with the student-athletes.

See Table 3 for summary of Big Ten Administrator strengths.

Table 3. Common Strengths of Big Ten Administrators

\begin{tabular}{|c|c|}
\hline \multicolumn{2}{|r|}{ Big Ten Common Strengths } \\
\hline Service & All ten respondents' indicated service as their number one strength of their lifeskills program \\
\hline Fully Comprehensive Program & $\begin{array}{l}\text { All ten programs in the Big Ten utilize the CHAMPS/Life Skills commitment statements: Academic } \\
\text { Excellence, Athletic Excellence, Service, Career Development and Personal Development }\end{array}$ \\
\hline Support & $\begin{array}{l}\text { Each Big Ten school receives 100\% support from their Athletic Directors and Senior Campus } \\
\text { Administrators }\end{array}$ \\
\hline Budget & Over half of the Big Ten schools have budgets over $\$ 100,000$ \\
\hline SeniorManagement Team & $\begin{array}{l}\text { More than half of the respondents reports their role on senior management team facilitates senior } \\
\text { management supporting the CHAMPS/Life Skills program }\end{array}$ \\
\hline Large Staff & Average staff size for Big Ten programs is 3.3, with the largest staff containing five individuals \\
\hline Career Enrichment & Half of the respondents indicated preparing student-athletes for careers is very important \\
\hline Diversity & $\begin{array}{l}\text { Unique aspect of the Big Ten is their diversity intern position, making it mandatory that each } \\
\text { school have a minority representative }\end{array}$ \\
\hline
\end{tabular}


There were varying responses to the second interview question, "what is the level of support from your revenue generating sports in your Life Skills Program?” Responses ranged from "getting full support from revenue generating sports" to "some of the programs at some institutions did not require mandatory programming," thus causing some revenue generating sports teams to not participate in all of the Life Skills Programs. Respondents \#1, 2 and 7 indicated the support they received from revenue generating sports.

Life Skills Director \#7:

They all participate, we never have any issues, and I am pleased with the support we receive from the non-revenue sports.

\section{Life Skills Director \#2:}

The revenue generating sports do a wonderful job at participating and they are just as excited as the non-revenue producing sports to participate. We put a lot of effort to make sure we have quality programming, and once they get there they see the benefit. We always do evaluations, and constantly getting feedback from them. If for some reason teams are traveling, we videotape the session so they can still get the same information. Although it may not be ideal, they still have the opportunity to get the knowledge.

\section{Life Skills Director \#1:}

All of the revenue generating sports participate in the Life Skills programs. As I mentioned before, teams get to choose the kinds of things they want to participate in but by and large when there are programs/events that are mandatory we get $100 \%$ support from all of the teams.

\section{Mandatory vs. Non-Mandatory Attendance}

One of the recurring themes that emerged from open-ended question \#2 was the relevancy of mandatory and non-mandatory attendance. The programs that appeared to be mandatory were programs for incoming freshmen and transfer student to get acclimated to the new university. Respondents \#1, 3, 9, and a few others reported they had mandatory seminars for freshman and transfer student-athletes. 


\section{Life Skills Director \#9:}

The requirement for freshman is basic skills academy in the 1 st semester. It is a one-credit course, a transition support course. The sophomore and junior requirements are not classes, it is a Life Skills intervention program for alcohol education, or fiscally fit, financial education workshop.

\section{Life Skills Director \#3:}

The only mandatory program is for all freshman student-athletes. They meet once a month, this year it is the 2nd Tuesday of each month.

\section{Life Skills Director \#1:}

There is a mandatory seminar that the 1st year/transfer students have to take. Transition seminar promotes responsible decision-making and adjustment to college life. They meet up on Sunday nights in the fall semester for 90 minutes. It is Pass or No pass and 0 credits. We feel strongly about this. The reason why we don't do it for a grade, because as an athletic department it could be an integrity issue, so that is why we do it for no credit or a grade. We make it interactive, activity based, theater productions, get to experience culture performances, alcohol awareness, bringing guest speakers. Make it fun. They look forward to it and we make it positive and enjoyable. Based on hot topics and societal issues and we do evaluations. We are always going to talk about relationships, social media, leadership, finances, personal brand, party behaviors and finance---they will always be priority. Educate them up front and hopefully their college experience can be focused on the positive, they worked hard to get there and we don't want them to fail and this is why we do this up front.

The two service projects per team, each student-athlete from a team has to meet individually with a Life Skills counselor once a semester, sometimes more. We have an open door policy. Some may come in once a week. We help them with their resume, provide them recommendations, and help them be more marketable. It is not about helping them to improve athletically, they have to improve that resume, and we don't want to have that door slam in their face.

Participant \#1 was very adamant about working hard to ensure he, along with his staff,

created a culture of "trust" with the student-athletes. He further stated the following:

Once you get the student-athlete to come in and they get to see they value what you do and see how you are trying to help them, if you treat them the right way, you have to be delicate, you don't want to squelch the athletic dreams of these young men and women. So you have to be very delicate in how you talk about their future, you still want them to aspire to be a pro athlete, and many of them it is a passion and goal of theirs. So you have to support their dreams and let them 
know that they should have other attainable goals they should also be striving towards.

\section{Customized Programming}

Many teams may have had travel schedule conflicts, and at times throughout their season the teams may not have been able to participate in some of the Life Skills Programming. Many participants indicated each team customized their programming based on their respective needs throughout the year. Participants 2, 4, and 6 provided thoughts about non-mandatory programming.

Life Skills Director \#2:

We also want to make sure we provide them with options, making choices. We want them to give thought on what they think they need, so we can have balance to our programming. We do have some mandatory programming and we bring two speakers in a year for all student-athletes. We offer 30-40 workshops a year on topics to mirror the NCAA 5 Commitments. They student-athletes buy into our programming because they have a choice in what seminars they can choose from. The student-athletes have can choose the number of seminars they attend, it is mandatory they choose one in every category and many actually attend more than the required amount.

\section{Life Skills Director \#4:}

The programs are not mandatory. For example we had a bowling social, and over 300 of the student-athletes attended to benefit one of the local shelters since many are community oriented. We had a graduate and professional school fair had over 100 student-athletes that participated.

Only three participants reported having mandatory programming throughout the year.

The student-athletes were given a choice on what programs they wanted to attend during the year. Participant \#6 provided his thoughts about mandatory programming.

Life Skills Director \#6:

The specific workshops that are mandatory that we do are drugs and alcohol, violence prevention, and social media. I try not to make outreach mandatory, but when I ask them to do it, they do it. We try not to force things, I get enough involvement from all the student-athletes throughout the year. 
When asked survey question \#3, "what new programs or initiatives would you create that your program does not currently offer and would make a positive impact on your studentathletes?" participants expressed there is a need for growth and improvement. Their responses varied from funding to improving career planning for student-athletes. There are many unique initiatives programs looking to explore to implement in the future or the immediate future. Participant \#1 described a new initiative their school is introducing in December of 2015.

\section{Life Skills Director \#1:}

We are going to rollout a post-eligibility opportunity program. I feel this is going to be really important. Any student-athlete letter winner graduate ... If you letter and graduate, starting with the graduating class in December 2015, we will fund 1 for one semester one of three options: internship, study abroad, or semester of graduate/professional school. The reason we wanted to do this, sometimes while that athlete is in school, even though you may be preaching the importance of internship, global experience, leadership, they still may be in denial. Some may think "I may not need it," "I am going to the show and play pro ball" . . . so it might be a year or two after they graduate and maybe pro sports does not work out and what we see is they come back to school and say, "Can you help me? What are you able to do for me?"

It is nice we will have this program, and so for a three-year window after they graduate, if they want to come back and take advantage of one of those opportunities, we will fund it. You are looking at a \$7,000-\$10,000 commitment that we are making available to every letter winner graduate. ... Once studentathletes exhausted their eligibility and graduated ... that is when most schools say, "Thank you for what you have done, good luck." They cut them off. We are not doing that. We are making that pledge to 100 athletes a year; that is pretty significant financially. But I think it will be more significant with that real world experience, when they are current student-athlete, it is really difficult for a current student-athlete to get an internship, study abroad because of the time constraints of their sport. We are pleased that we are able to offer these values, we think it can be a game changer for the student-athlete.

It just shows that the Life Skills program is not just while you are here, it can also mean beyond graduation. It is strong commitment but we are in a position to do this. Those are things that parents enjoy hearing and it differentiates us over another school. 
The most common response for improvement was career development. Participants \#2, 6, 8 , and 9 provided comments about the need to improve career programming for their studentathletes.

\section{Life Skills Director \#2:}

The one area that I would like to explore is the career area. We do have an excellent careers services office and we work with them. We encourage our athletes to utilize their services. We can do a better job and do more. For example, the career center talks about time management and resume workshops, sports nutrition, and a workshop on healthy eating.

\section{Life Skills Director \#6:}

A lot of our attention is now being focused on career development. We feel we have the community service component down, and we feel this is a unique opportunity for us to improve in this arena.

\section{Life Skills Director \#8:}

We just partnered with career services, and they will be coming in one day a week. We are taking stronger steps in ensuring our student-athletes get more opportunities to be able to get internships and job shadowing opportunities.

\section{Life Skills Director \#9:}

The one area we would like to enhance our career development: the mental health aspect and retiring from their sport. We provide workshops that can help our student-athletes.

\section{New Initiatives}

A few of the participants spoke passionately about new initiatives that were going to be unique to their already diverse menu of programming. They ranged from adding mandatory freshman seminars and a women's symposium to providing studying abroad opportunities for their student-athletes.

Life Skills Director \#3: 
Starting this fall 2015 , every freshman will be required to take a one-credit course. We are excited about that, it will be pass/fail, and we have an outside academic department and will have a chair person in that area managing this.

Life Skills Director \#10:

This upcoming March 2015, we will have our first ever Women's Symposium. The symposium is focused for our female student-athletes as they transition from being a student-athlete to being a young professional, understanding the communications essentials, and understanding personal choices. We will focus on the worth and value for female athletes and will bring experienced women in various industries to speak to our female athletes. The following year we will do the same for the male student-athletes, giving them an opportunity for them to hear professionals on the personal side and learn about barriers that may or may not exist in society and the work force.

\section{Life Skills Director \#4:}

We are looking to partner with the campus travel abroad programming so our student-athletes can do international traveling and study abroad. We encourage our student-athletes to participate in Coach for College: Student athletes from across the country can go to Vietnam and coach and work with kids in those communities. We also want to teach the student-athletes more practical skill sets for their preparation for life after college such as how to purchase a home, how to create a budget for yourself, how to purchase a car, how to obtain a loan.

There were some participants who felt their Life Skills department was moving in the right

direction. Participant \#3 provided his thoughts.

Life Skills Director \#3:

I feel we are in a really great place right now; I am doing a better job with reaching out to our advisors, coaching staff, administrators by getting the buy in. I feel like we are making some great strides, we are in the best position since I have been part of this. I feel the next few years we are going to be incredible.

Interview question four asked, "what concerns do you have about your schools Life Skills Program?" Of the ten administrators who responded to the survey, seven expressed concerns about their Life Skills Program. From the responses of the ten administrators, two major themes developed from four of the schools: career development and hiring more staff. The most 
frequently mentioned concern about the Life Skills Program was having more programming for career development.

While many respondents expressed the overall support from some coaches was great. Almost all stated they wanted to get the support from all coaches. Since one of the respondents was new to his position, he was adamant of ensuring he earned the trust of the coaches and other administrators in the athletic department. One respondent expressed, "some coaches wished there was not as much programming, but they get it." Participants \#2, 6, and 8 felt they needed to improve in the area of career development.

Life Skills Director \#2:

I think the career area [needs improvement]. I would like to see that grow. I am pretty please what we put forth, and the students think highly of what we do. We never want to get too comfortable.

Life Skills Director \#6:

Hiring more staff to assist with developing the area of career development. More workshops, we currently do one career fair and perhaps add another fair, one for each semester. We are adding some GA positions, so this will be helpful.

Life Skills Director \#8:

We can improve on getting the student-athletes with internships and helping them find real work experience while they are still enrolled in schools. Part of issue is that we are in a small town, compared to some of the other Big Ten schools that are in urban areas.

\section{Unique Findings}

The two most unique findings were participants who stated their concern about leadership among their African-American student-athletes. The other participant reported his was the only school in the conference with leadership academy with an outside organization that provides services for them over eleven years. When the researcher examined the literature, the findings were very consistent with the literature regarding African-American male student-athletes 
interacting outside of their sports. The importance of engaging student-athletes in educationally purposeful activities and enriching educational experiences, both inside and outside the classroom, has been well established in the literature (Comeaux, Speer, Taustine, \& Harrison, 2011; Gayles \& Hu, 2009; Martin, 2010). Notwithstanding, Black male student-athletes rarely accrue benefits and developmental outcomes associated with high levels of purposeful engagement beyond athletics. This has serious implications for faculty-student interaction, an important form of engagement.

Comeaux and Harrison (2007) found that engagement with faculty was essential to academic achievement for Black and White male student-athletes, yet professors spent significantly more out-of-class time with Whites. Furthermore, high-achieving Black male student-athletes in Martin, Harrison, and Bukstein's (2010) study reported that coaches prioritized athletic accomplishment over academic engagement, and discouraged participation in activities beyond their sport.

Leadership among African American student-athletes. One $(n=1)$ of the administrators who was African American introduced the importance of leadership among the African American student-athletes. Participant \#7 eloquently provided context about this issue.

\section{Life Skills Director \#7:}

The area we would like to improve on is to get our student-athletes of color to participate more in the programming we do for them. At the end of the day, it comes down to the leadership among the African American athletes and if they feel it is important to them. Most of the student-athletes of color for some reason ostracize themselves, and sit separately. Many don't see the importance of celebrating their culture. We have struggled to get them to see why it is important and vital. We feel confident that we will have a break through. At times it is like pulling teeth for many of the student-athletes to see the importance of Black History month. We have engaged many of the African American community to help us better engage with your student-athletes. 


\section{Unique Leadership Programming}

Participant \#2 reported his school was the only school in the Big Ten with an academy from an outside agency:

100 student-athletes are chosen to participate in the academy per year. It consists of three levels: (1) Emerging leader level. These student-athletes are not leaders yet but seeking to be leaders. (2) Veteran leader level: At this level they are starting to assume some leadership responsibilities, as a senior they participate in Leadership 360. At this level, seniors gather around a table setting and talk about their team and better ways to better lead their team. We have a 360 evaluation form for where the coaches and athletes on their team will evaluate their leadership skills. (3) Coaches' session: At this level, coaches learn about their students and sit down with their student-athletes to talk about the direction of their program. Been doing this programming for 11 years. In addition we have a group called career athletes that come to do a career night—-they also speak to the freshman and sophomores as well.

The fifth interview question asked "what is the 'buy in' (i.e., support) from the following university officials? Athletic directors, coaches, and academic administrators." The subjects described "buy-in" as financial support from the athletic director and program support from the coaches. Nine of the respondents specified the athletic directors from their institution's teams did have a great deal of buy in for their Life Skills Program. One proudly stated, "our AD and coaches are phenomenal!" Participants \#1, 6, and 8 stated their pleasure of the buy-in from the administration.

Life Skills Director \#8:

I can't say enough about our senior executive leadership. They really see this as being vital to the success within our mission of being a student-athlete. It is at the forefront and that definitely comes through from our office student-athlete development. "Many stated the area they needed to work on to continue to get $100 \%$ "buy in" was with the coaches. For the most part most of the coached have bought into the programs, some just feel "there is too much programming" but the overall consensus is most coaches have bought into the Life Skills Program. Another stated "It is 100\% amazing, I can't complain.

Life Skills Director \#10: 
"100\% buy in! We are one of unique programs across the country that is $100 \%$ privately funded, through donors and support. That allows them to be invested in all that we are doing. The internal support is suburb, the upper administration understands and knowing the value of the student-athlete development program that allows us provide qualitative/quantitative show the overall value of the work we are doing to prepare our student-athletes for life after they finish college."

\section{Life Skills Director \#1:}

"From our AD, it is VERY STRONG. He has allowed us to grow our program. We now have 3 full time coordinators including myself. Resource wise as it pertains to budget, as long as we can justify the value of a program, he never denied anything we asked for. From the administration it is VERY strong, the coaches are pretty good. There are some coaches that are guarded of their time, some may look at Life Skills a time absorber. Fortunately we have convinced them it is part of the student-athlete experience. It is school, your sport it is your life and all three should be fully valued."

\section{Life Skills Director \#6:}

"We get tremendous by in from the administration. There are some coaches that think we over program, and wish they were more educated on what we do, some get it, and others may not want to participate. For the most part they all are supportive and I can call them at any time."

\section{Life Skills Director \#5:}

"Our AD sets the tone, he is a strong proponent in ensuring all the student-athletes are leaders on and off the field. I am honored and grateful to work with such a dynamic and forward thinking human being."

\section{Program Effectiveness}

The third and final part of this study examined the effectiveness of the schools' Life

Skills Program. Murdock’s (2010) instrument measured levels of program effectiveness based on Life Skills’ five Commitment Statements.

The levels of effectiveness measured were based on the NCAA's Life Skills Commitments (Academic Commitment, Career Development Commitment, Athletics 
Commitment, Development Commitment and Service Commitment). Each respondent provided the appropriate rating concerning the level of effectiveness of their school's Life Skills Program.

\section{Academic Commitment}

The respondents were asked to evaluate the effectiveness of the Life Skills for Academic Commitment. The respondents $(n=10)$ chose from: study skills; goal setting; time management; tutorial program; supervised study hall; orientation program; academic assessment program; academic advising; student-athletes finishing their school curricula; academic counseling program; student-athletes completing scholarship applications; academic awards; and honors. The respondents were asked to rank the effectiveness of each item with values between zero and five. Zero indicated the respondent did not address the question, one was "very ineffective," two was "somewhat effective," three was "effective," four was "very effective" and five was "totally effective."

Six $(n=6)$ of the respondents rated study skills totally effective, two respondents effective, and one did not address the item.

Two of the respondents rated goal setting totally effective, four respondents very effective, two respondents effective, and one did not address the item.

Two of the respondents rated time management totally effective, four respondents very effective, three respondents effective and one did not address the item.

Six of the respondents rated tutoring program very effective, one respondent effective, and one did not address the item.

Five rated supervised study hall totally effective, two respondents effective, and two did not address the item. 
Three respondents rated the orientation program totally effective, five respondents very effective and one respondent effective.

Five of the respondents rated the academic assessment program a totally effective, one respondent very effective, one respondent effective and one did not address the item.

Four of the respondents rated the academic advising totally effective, one respondent very effective, one respondent effective, and three did not address the item.

Six of the respondents rated the student-athletes finishing their college curricula a totally effective, one respondent very effective, and two did not answer the item.

Five of the respondents rated academic counseling program totally effective, one respondent very effective, one respondent effective, and two did not answer the item.

Three of the respondents rated student-athletes completing scholarship applications totally effective, four respondents very effective, one respondent effective, and one did not address the item.

Five of the respondents rated the academic awards honors totally effective, three respondents very effective, and one respondent effective. See Table 4 for a summary of Effectiveness of Academic Commitment.

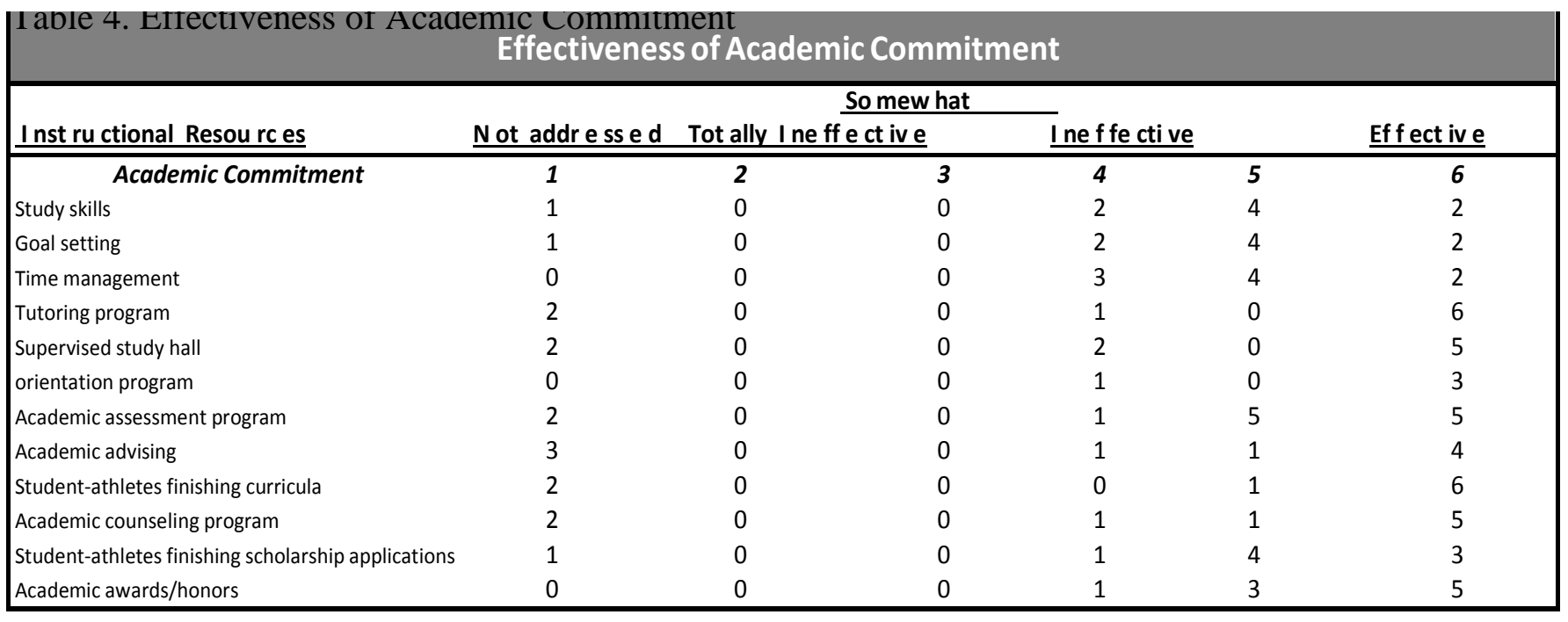




\section{Career Development Commitment}

The subjects were asked to evaluate the effectiveness of the Life Skills for Career

Development Commitment. This category included job search process, addressing

developmental concerns during freshman-senior years in college, post-college career preparation, interactions with agents, and student-athlete participation in alumni career networking. Four of the respondents rated job search totally effective, three respondents very effective, and one respondent effective. Two respondents rated addressing developmental concerns during freshman-senior years of college totally effective, six respondents very effective, and two respondents effective. Four of the respondents rated post-college career preparation totally effective, four respondents very effective, and one respondent effective. Four of the respondents rated interactions with agents very effective, three respondents effective, and two did not answer the item. Six of the respondents rated student-athlete participation in alumni career networking totally effective, two respondents very effective, and one respondent effective. See Table 5 for a summary of Effectiveness of Career Commitment.

Table 5. Effectiveness of Career Development Commitment

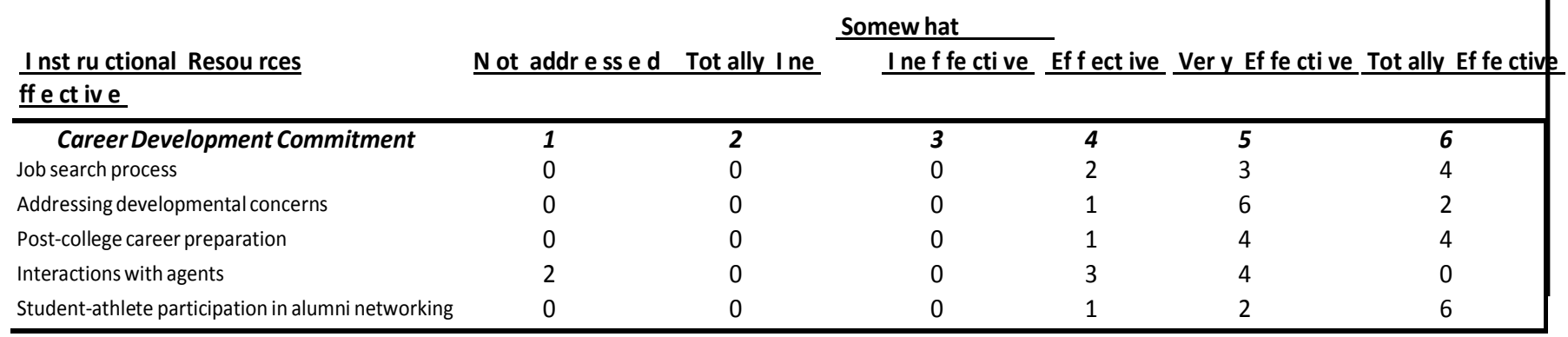

\section{Athletics Commitment}

The subjects were asked to evaluate the effectiveness of the Life Skills for Athletics Commitment. This category included athletic coaching, athletic department operations, support programs for athletics-related issues, student-athlete interviews, and student-athlete leadership 
development training. Four of the respondents rated athletic coaching very effective, two respondents totally effective, one respondent effective, and two did not address the item. Five respondents rated athletic department operations very effective, two respondents totally effective, one respondent effective, and one did not address the item. Four respondents rated support programs for athletics-related issues totally effective, four respondents very effective, and one did not address the item. Five respondents rated student-athletes interviews very effective, two respondents totally effective, one respondent effective, and one did not address the item. Four respondents rated student-athlete leadership development training very effective, three respondents totally effective, and two respondents effective. See Table 9 for a summary of Effectiveness of Athletics Commitment.

\begin{tabular}{|c|c|c|c|c|c|c|}
\hline \multirow[b]{2}{*}{ I nst ru ctional Resou rces } & \multicolumn{5}{|c|}{ Somew hat } & \multirow[b]{2}{*}{ Ef f ect iv e } \\
\hline & N ot addr e ss e d & Tot ally I ne ff e ct iv e & & Ine f fe cti ve & & \\
\hline Athletics Commitment & 1 & 2 & 3 & 4 & 5 & 6 \\
\hline Athletic coaching & 2 & 0 & 0 & 1 & 4 & 2 \\
\hline Athletic department operations & 1 & 0 & 0 & 1 & 5 & 2 \\
\hline Support programs for athletic issues & 1 & 0 & 0 & 0 & 4 & 4 \\
\hline Student-athlete interviews & 1 & 0 & 0 & 1 & 5 & 2 \\
\hline Student-athlete leadership development & 0 & 0 & 0 & 2 & 4 & 3 \\
\hline
\end{tabular}

\section{Personal Development Commitment}

The subjects were asked to evaluate the effectiveness of the Life Skills for Personal Development Commitment. This category included nutrition programs, eating disorder prevention education, personal relationship management, sexual responsibility, developing selfesteem, academic assessment program, student-athletes finishing their school curricula, academic counseling program, student-athletes competing scholarship applications, Academic awards and honors, social development, social etiquette, dealing with authority, understanding diversity, celebrating diversity, fiscal responsibility, violence prevention. Five of the subjects rated 
nutrition program totally effective, three respondents rated effective and one very effective. Five subjects rated eating disorder prevention education very effective, three respondents effective, and one very effective.

Four subjects rated personal relationship management effective, three respondents rated very effective, and two respondents rated very effective. Five subjects rated sexual responsibility effective, two respondents rated very effective, and two totally effective. Six respondents rated developing self-esteem effective, two respondents totally effective, and one did not address the item. Six respondents rated academic assessment program effective, two respondents totally effective, and one did not address the item. Three respondents rated academic advising totally effective, two respondents very effective, one respondent effective, and three did not address the item. Six respondents rated student-athletes finishing their school curricula totally effective, one respondent effective, and two did not address the item.

Five respondents rated academic counseling program totally effective, one respondent rated very effective, one respondent effective, and one did not address the item. Four respondents rated student-athletes completing scholarship applications totally effective, three respondent rated very effective, one respondent effective, and one respondent did not address the item. Four respondents rated academic awards and honors totally effective, two respondents effective, one respondent very effective, and one respondent did not address the item. Four respondents rated social development very effective, four respondents effective, and one respondent totally effective.

Four respondents rated social etiquette very effective, three respondents rated effective, one respondent ineffective, and one respondent totally effective. Six respondents rated dealing with authority effective and three respondents very effective. Four respondents rated 
understanding diversity very effective, three respondents totally effective, and two respondents effective. Five respondents rated celebrating with diversity very effective, three respondents totally effective, and one respondent effective. Four respondents rated fiscal responsibility effective, two respondents totally effective, two respondents very effective, and one respondent somewhat effective. Four respondents rated violence prevention totally effective, three respondents very effective, one respondent effective, and one respondent somewhat effective (see Table 7 for a summary of effectiveness of Personal Development Commitment).

\begin{tabular}{|c|c|c|c|c|c|c|c|}
\hline \multirow[b]{2}{*}{ I nst ru ctional Resou rc es } & \multirow[b]{2}{*}{ N ot addr e ss e d } & \multicolumn{2}{|r|}{ So mew hat } & \multirow{2}{*}{\multicolumn{2}{|c|}{ Ine f fe cti ve }} & \multirow[b]{2}{*}{ Ef f ect iv e } & \multirow[b]{2}{*}{$\underline{\mathrm{v}}$} \\
\hline & & Tot ally & I ne ff e ct iv e & & & & \\
\hline Personal Development Commitment & 1 & 2 & 3 & 4 & 5 & 6 & \\
\hline Nutrition program & 0 & 0 & 0 & 3 & 1 & 5 & \\
\hline Eating disorder prevention & 0 & 0 & 0 & 2 & 5 & 2 & \\
\hline Personal relationship management & 0 & 0 & 0 & 4 & 3 & 2 & \\
\hline Sexual responsibility & 0 & 0 & 0 & 5 & 2 & 2 & \\
\hline Developing self-esteem & 1 & 0 & 0 & 6 & 0 & 2 & \\
\hline Academic assessment program & 1 & 0 & 0 & 6 & 0 & 2 & \\
\hline Academic advising & 3 & 0 & 0 & 1 & 2 & 3 & \\
\hline Student-athletes finishing curricula & 2 & 0 & 0 & 1 & 0 & 6 & \\
\hline Academic counseling program & 2 & 0 & 0 & 1 & 1 & 5 & \\
\hline Student-athletes finishing scholarship applications & 1 & 0 & 0 & 1 & 3 & 4 & \\
\hline Academic awards/honors & 1 & 0 & 0 & 2 & 1 & 4 & \\
\hline Social Development & 0 & 0 & 0 & 4 & 4 & 1 & \\
\hline Social Etiquette & 0 & 0 & 1 & 3 & 4 & 1 & \\
\hline Dealing with authority & 0 & 0 & 0 & 6 & 3 & 0 & \\
\hline Understanding diversity & 0 & 0 & 0 & 2 & 4 & 3 & \\
\hline Celebrating diversity & 0 & 0 & 0 & 1 & 5 & 3 & \\
\hline Fiscal responsibility & 0 & 0 & 1 & 4 & 2 & 2 & \\
\hline Violence prevention & 0 & 0 & 1 & 1 & 3 & 4 & \\
\hline
\end{tabular}

\section{Service Commitment}

The respondents were asked to evaluate the effectiveness of Life Skills for Service Commitment. This category included mentoring, peer education, peer counseling, student-athlete assistance program, and working in the community. Four of the respondents rated mentoring very effective, three respondents rated totally effective, one respondent effective, and one did not address the item. Four of the respondents rated peer education effective, three respondents totally 
effective, and two respondents effective. Four respondents rated peer counseling effective, three respondents very effective, one respondent effective, and one somewhat effective. Three respondents rated student-assistance program effective, three respondents somewhat effective, two respondents very effective, and one respondent totally effective. Four respondents rated working in the community very effective, two respondents totally effective, two respondents somewhat effective, and one respondent effective (see Table 8 for a summary of effectiveness of Service Commitment.

\begin{tabular}{|c|c|c|c|c|c|c|}
\hline Inst ru ctional Resou rces & $\mathrm{N}$ ot addr e ss e d & Tot ally I ne ff & $\begin{array}{l}\text { Somew hat } \\
\text { Ine ffe cti }\end{array}$ & Ef f ect iv & Ver y Ef fe cti & Tot ally Ef fe \\
\hline Service Commitment & 1 & 2 & 3 & 4 & 5 & 6 \\
\hline Mentoring & 1 & 0 & 0 & 1 & 4 & 3 \\
\hline Peer Education & 0 & 0 & 0 & 4 & 2 & 3 \\
\hline Peer Counseling & 0 & 0 & 1 & 4 & 3 & 1 \\
\hline Student-athlete assistance program & 0 & 0 & 3 & 3 & 2 & 1 \\
\hline Working in the community & 0 & 0 & 2 & 1 & 4 & 2 \\
\hline
\end{tabular}




\section{CHAPTER V—CONCLUSIONS AND RECOMMENDATIONS}

Findings from this study contribute to the growing body of literature in the area of Life Skills Programming for student-athletes within Big Ten NCAA Division I institutions.

\section{Statement of the Problem}

The purposes of this study were:

1. To determine if Life Skills Programs exist in all of the 14 Big Ten Schools.

2. To determine if the NCAA Division I Life Skills Commitment Statements were utilized at all the Big Ten Schools.

3. To determine how Big Ten administrators perceived Life Skills Programs across all 14 Big Ten Universities.

It was anticipated that all Big Ten colleges would have a Life Skills Program on their campus. It was anticipated that Big Ten Life Skills administrators would perceive their programs to be effective.

Descriptive statistics were used to analyze demographic data for the first part of the study. The data analyzed in regards to administrators included job title; program budget; race; gender; graduation success rate; reporting structure, and the highest level of education attained. In the second part, the questionnaire examined the perceived effectiveness of the schools' Life Skills Programs. Murdock’s (2010) research instrument assessed levels of effectiveness based on Life Skills’ five Commitment Statements.

Five interview questions were also asked to gain a more in-depth perspective about the Life Skills Programs:

1. What do you feel are the strengths of your Life Skills Program?

2. What is the participation of your revenue generating sports in your Life Skills Program? 
3. What new programs or initiatives would you add that your program does not currently offer that would make a positive impact on your student-athletes?

4. What concerns, if any, do you have about your school's Life Skills Program?

5. What is the "buy in" (i.e., support) from the following University officials?

Based on the literature and results of the pilot study, the following research questions were generated:

1. Research Question One: Do NCAA Life Skills Programs exist at all Big Ten schools?

2. Research Question Two: Are the five NCAA Life Skills Commitment Statements being enforced at all Big Ten schools?

3. Research Question Three: Are NCAA Life Skills Programming perceived effective at all Big Ten schools?

In response to research question one, the researcher found that each Big Ten school $(n=10)$ delivered all of the five Commitment Statements the NCAA required as part of the Life Skills Program. All Big Ten schools NCAA Life Skills Commitment Statements were reported to have been enforced by each Life Skills Program.

In response to research question two, the researcher found each Big Ten school utilized the NCAA Life Skills Commitment Statements by assessing the Life Skills effectiveness at each school. There were two ways the researcher assessed Life Skills effectiveness. The first was through question \#24 on the questionnaire, "what is the overall effectiveness of their Life Skills Program?" The second was through interview questions \#1 and \#4, "what do you feel are the strengths of your Life Skills Program?” and "what concerns, if any, do you have about your school's Life Skills Program?" 
Research question \#3 was designed to measure perceived effectiveness of the Life Skills Program. The researcher anticipated that all Life Skills administrators would perceive their programs as effective. The most common themes from responses to that question described the strengths of a Life Skills Programs. The strengths described were service, athletic director support, part of the athletic director administrative team, geographic location, diversity, fully comprehensive programming, budget, and large staff.

The most frequently identified strength by the participating institutions' athletic department administrators related to involvement in community service. This was an interesting finding because Murdock (2010) concluded it might be advisable for athletic departments to have student-athletes involved more in on-campus service activities over primarily being sent out into the community.

All of the athletic administrators made comments concerning their program's Academic Commitment. The majority $(n=10)$ of this sub-group of respondents specifically mentioned study skills. For example, several athletic department administrators noted the high amount of activity displayed by their community service program. Other administrators mentioned the priority and focus they had on community service activities. Another respondent indicated their school completed community service hours through a community service competition between sports teams in the athletic department; which resulted in more community service hours being completed at that particular university than ever before. One administrator used "stellar" to describe their community service program. Some respondents identified community outreach, community involvement, or community/campus connections as particular strengths of their Life Skills Program. 
The primary components mentioned by respondents for an effective program included academic counseling, advising, and resources. For instance, one administrator reported they had counselors who were very skilled in providing academic guidance to their student-athletes. Two administrators indicated they had over ten academic counselors and close to 80 tutors to help student-athletes achieve great academic support. One administrator added that in their athletic department, they had a great deal of personal contact with their student-athletes. Some of the schools' administrators highlighted the general emphasis on academics at their institution. Responses $(n=8)$ included acknowledgement of their strong commitment to academics and reporting that academics was their program's biggest strength. One administrator specifically outlined the academic achievements and awards earned by their student-athletes in which they were a national leader for the past 20 years in producing academic All Americans.

The third research question examined the perceived effectiveness of Big Ten schools Life Skills Program. Murdock’s (2010) research instrument assessed levels of effectiveness based on Life Skills five Commitment Statements. The levels of effectiveness measured were based on the NCAA's Life Skills Commitments (Academic Commitment, Career Development Commitment, Athletics Commitment, Development Commitment and Service Commitment). Each respondent provided the appropriate rating concerning the level of effectiveness of his or her school's Life Skills Program.

\section{Academic Commitment}

The respondents were asked to evaluate the effectiveness of the Life Skills for Academic Commitment. Respondents ( $n=10)$ chose from the following variables: study skills; goal setting; time management; tutorial program; supervised study hall; orientation program; academic assessment program; academic advising; student-athletes finishing their school curricula; 
academic counseling program; student-athletes completing scholarship applications; academic awards and honors. The respondents were asked to rank the effectiveness of each variable between the numbers zero and five. Zero meant the respondent did not address the question, one meant very ineffective, two meant somewhat effective, three meant effective, four meant very effective, and five meant totally effective.

Respondents rated study skills; goal setting; time management; tutoring program; supervised study hall; orientation program; academic assessment program; academic advising; student-athletes finishing their college curricula, and academic awards honors as effective.

\section{Career Development Commitment}

The respondents were asked to evaluate the effectiveness of Life Skills in the following areas within Career Development Commitment: job search process; addressing developmental concerns freshman-senior years in college; post-college career preparation; interactions with agents, and student-athlete participation in alumni career networking. Respondents rated job search, addressing developmental concerns freshman-senior years of college, post-college career preparation, interactions with agents, and student-athlete participation in alumni career networking as indicators of program effectiveness.

\section{Athletics Commitment}

The subjects were asked to evaluate the effectiveness of the Life Skills for Athletics Commitment. This included athletic coaching; athletic department operations; support programs for athletics-related issues; student-athlete interviews; student-athlete leadership development training. Respondents rated all items as effective. 


\section{Personal Development Commitment}

The respondents were asked to evaluate the effectiveness of the Life Skills for Personal Development Commitment. This category included nutrition program; eating disorder prevention education; personal relationship management; sexual responsibility; developing self-esteem; academic assessment program; student-athletes finishing their school curricula; academic counseling program; student-athletes competing scholarship applications; academic awards and honors; social development; social etiquette; dealing with authority; understanding diversity; celebrating diversity; fiscal responsibility; and violence prevention. Respondents rated nutrition program; eating disorder prevention education; personal relationship management; studentathletes finishing their school curricula; academic counseling program; student-athletes completing scholarship applications; academic awards and honors; social development; and celebrating with diversity as very effective.

\section{Service Commitment}

The respondents were asked to evaluate the effectiveness of the Life Skills for Service Commitment. This included mentoring, peer education, peer counseling, student-athlete assistance program, working in the community. Respondents rated working in the community very effective.

The respondents were also asked five interview questions so researchers could gain a more in-depth perspective about the Life Skills Programs.

\section{Interview Questions}

Interview question one asked respondents about the strengths of their Life Skills Program. Many of the respondents attributed many things as strengths to their Life Skills program. The most common responses among respondents were: (a) having a fully 
comprehensive program; (b) support from their athletic director; (c) the commitment of providing service projects for their student-athletes; (d) a sustainable budget; (e) the influence of being on the senior management team; (f) the geographic location of the school; (g) programming in career development; (h) diversity. Interview question two probed respondents about the participation of revenue generating sports in in the Life Skills Programs. There were varying responses to this question. Responses ranged from getting " $100 \%$ support from those revenue generating sports" to the programs not being mandatory.

One of the recurring themes administrators faced with some of their coaches was the importance for their student-athletes to attend all of the Life Skills Programs. The responses ranged from "only a few Big Ten programs made it mandatory for student-athletes to attend," to "none of the Big Ten programs made it mandatory for student-athletes to attend." The programs that with mandatory attendance for all student-athletes were Big Ten schools that offered mandatory seminars for incoming freshmen and transfer students, and were designed to get that population acclimated to the university. Only $30 \%$ reported having mandatory programming throughout the year. Student athletes were given a choice on what programs they wanted to attend during the year.

The Big Ten programs with mandatory programming received full support from the student-athletes and coaches. There was no punishment administered to teams or student-athletes if they did not attend Life Skills Programs.

Interview question three queried respondents about any new programs or initiatives they wished for their Life Skills Program to have, did not currently offer, and could make an impact on the student-athletes. The most common initiatives were focused on career development, time management, resume writing, and partnerships with the campus community. Over $75 \%$ of the 
administrators stated a need to also focus on the mental and physical well-being of studentathletes. Over half of the respondents stated because of their geographic locations that they were challenged to successfully place student-athletes in adequate internships or provide job shadowing experiences.

Some Big Ten schools reported about new programs and initiatives they feel would make an impact on student-athletes. One of the most unique programs offered by a school was the post eligibility opportunity program. The post eligibility program provided any student-athlete letter winner that graduates from the university, starting December 2015, funding for one semester for an internship, studying abroad, or a semester of graduate or professional school. The school makes a $\$ 7,000-\$ 10,000$ commitment per student-athlete and has up to three years after they graduate to take advantage of this initiative.

A finding reported by one Big Ten institution was the establishment of a Women's Symposium. The program was be designed for female student-athletes and their transition from being a student-athlete to being a young professional. The program will focus on the worth and value of female athletes, and will bring experienced women in various industries to speak to female athletes.

Interview question four probed respondents about any concerns regarding their Life Skills Programs. 70\% of the administrators expressed concerns about their Life Skills Program. Two major themes emerged. One was career development and the other was hiring more staff. The most frequently mentioned concern about the Life Skills Program was having more programming around career development. Many administrators expressed the overall support from coaches was great, but almost all stated they wanted to get full support from all coaches. Since one of the respondents was new to the position, the respondent ensured earning the trust 
from the coaches and other administrators in the athletic department. Perhaps one of the most surprising concerns from an administrator was his interest in improving in the area of getting the student-athletes of color more engaged with the minority community at their institution, as well as improving the diversity programming the athletic department offered.

Interview question five asked respondents about the "buy-in" from university officials. The respondents described "buy-in" as financial support from the athletic director and program support from the coaches. Over $90 \%$ of the respondents specified the athletic directors or coaches from their institution's teams did have a great deal of "buy-in" for their Life Skills Program.

\section{Additional Findings}

Some additional findings revealed $50 \%$ of the respondents reported budgets for their Life Skills programs were under $\$ 100,000$. It is important to note that Wright (2002) reported 50\% of the Life Skills coordinators acknowledged that funding was never or rarely sufficient. $90 \%$ of the administrators in the current study felt that overall Life Skills Program was adequate, and 50\% felt their programs were not sufficiently funded. Researchers consistently reported a lack of adequate funding to support Life Skills programs. Wright (2002), found that $42.9 \%$ of the Life Skills coordinators felt their programs were sufficiently funded, and $32 \%$ felt their programs were not funded. However, Goddard (2004) reported that some institutions have budgets of $\$ 25,000$, but most must work within a budget of $\$ 2,500$ or less. The current study support revealed half $(n=5)$ of the respondents had budgets over $\$ 100,000$ and half $(n=5)$ had budgets under $\$ 100,000$. There were two schools that had budgets ranging from $\$ 21,000-\$ 50,000$.

The Knight Commission (1991) suggested that the costs of running athletic programs must be reduced. However cost reduction should not occur among any Life Skills programs. 
Interestingly, small private schools with relatively lower total endowments have been able to achieve more success in nearly every category of school success-even more than larger schools with greater endowments - by keeping costs down and looking for ways to enhance services (Ekman, 2006). One measure of success achieved by small private schools, compared to larger institutions, was that their students generally took less time to graduate (American Federation of Teachers, 2003). Therefore, increasing sources of revenue, reducing costs, or both, and looking at ways to best provide services to student-athletes are recommended ways to run a fiscallyefficient Life Skills Program (Murdock, 2010). Having a Life Skills Program for student-athletes that provides them diversity in programming and providing them with many options to choose from is important.

Pascarella \&Terenzini (1991) found that college students tend to learn more when they are engaged in a variety of educational activities. Student engagement encompasses not only activities such as interacting with instructors on a variety of issues, but also involves other activities considered important for college, like working together in community service activities (Kuh, 2001). The Life Skills Program's instructional resource, considered by the participating athletic department administrators to be the area most effectively applied, was working in the community. Therefore, student-athletes at these institutions were very likely actively encouraged, if not mandated, to regularly participate in ongoing community service events. The current study indicated that administrators cited working in the community was "very effective." In addition, the current study revealed $90 \%$ had a graduation success rate between $80 \%-100 \%$. The current study revealed the schools that produced a high graduation success rate were employed in their department over nine years. 
Murdock (2010) concluded those administrators with the most job experience considered their institution's Life Skills Program to be more effective in implementing the instructional resources, as compared to administrators with less experience (Murdock, 2010). Murdock’s study suggested when administrators had more job experience in Life Skills, the athletic director, coaches and student-athletes supported the seminars offered. In the current study more than half of the administrators with more experience on the job cited they had a larger budget, more "buy in" from administrators, and the Life Skills Program did not have budget or financial concerns. Wright (2002) found both men and women program coordinators appeared to be leaving the position of Life Skills only after one to three years of service. Wright (2002) found both men and women program coordinators appeared to be leaving the position of Life Skills after only one to three years of service. In the current study the average number of years for a Life Skills administrator is 8.2 (range: 1 years to 32 years), and two administrators have been in their role over 28 years.

Wisdom (2006) reported those institutions that provided the most comprehensive programming for their student athletes had the most successful programs. Similarly, Murdock (2010) reported highly experienced administrators were perhaps more of a crucial component in contributing to a program's success than less experienced administrators. It could have been that at the time they completed the survey, administrators with more job experience at their school may have had comparatively more time developing needed campus-specific skills within the framework and mission of their school.

The NCAA (2009h) has recommended that individuals who wish to become administrators with the Life Skills Program contact schools in their geographic region and gain experience through volunteering, shadowing, and otherwise seeking ways to gain experience 
with a specific institution. Based on the current study's findings, and findings from Murdock (2010) study, it seemed that staff members with a significant amount of experience of over eight years would be proficient in implementing an effective program. In addition, many of the respondents would like for other experienced Life Skills Directors to provide a blue print of how to effectively create Life Skills Programs at their school.

Murdock (2010) found athletic department administrators who had been employed in their current jobs for two years or less, as well as those with three to five years of job experience, judged their school's Life Skills Program to be less effective at implementing the program's instructional resources than those who had six or more years of job experience. In this current study all of the Life Skills Directors judged their school's Life Skills Program to be very effective. In addition, there were only three directors with over eight years of experience, and each of them had been very effective of creating programming. In fact, some of the most comprehensive and robust programming came from those directors who had under eight years of experience. In the current study, all of the schools had high profiles and prominent service programming which were widely known and praised nationally by the NCAA. Most of the schools had diversity programming that addressed the needs of their African American, minority, and International populations.

One of the major suggested findings of this study was that respondents received one hundred percent support from their senior team. Four $(n=4)$ of the respondents were members of their senior teams. This new phenomenon created the support from the senior administrative teams, coaches, and other administrators.

Wright (2002) concluded based on the titles of the Life Skills administrators that the professionals were very descriptive of their job duties. In the current study, all respondents had at 
least one person in charge of Life Skills, and only four of the ten had "Life Skills" in their official titles. The current study revealed the average number of a Life Skills staff department was three, and the largest staff was five. Four schools reported there was just one person on their Life Skills staff. One of the unique aspects with the staff which had four to five employees is that they were each able to have an employee in charge programming for one of the five NCAA Life Skills Commitment Statements: Personal Development, Career Development, Service, Academics and Athletics.

This was very important because the roles and responsibilities of a Life Skills Director expanded since the inception of the Life Skills Program in 1991. Additionally, the employees in charge of one of the NCAA Life Skills Commitment Statements were able to plan programming for the student-athlete. Wright (2002) also concluded a Life Skills Director may be responsible for compliance with the NCAA rules. In this current study, none of the administrators had dual roles in compliance. However, it is important that the Life Skills Director, along with all of the units in athletics, work closely with compliance to ensure that the student-athletes and the administrators abide by NCAA rules. For example, if a student-athlete participates in a community service project with a company, she is not allowed to accept gifts or monetary compensation for her participation. Since the role and responsibility of a Life Skills Director has changed over time, the primary responsibility of a Life Skills Director is to have a fully functioning staff providing programming for the five NCAA Commitment Statements.

Some major concerns expressed by Life Skills Program administrators related to the lack of career development for the program by four of the respondents $(n=4)$. In this current study, $90 \%$ of the respondents stated they received support from their athletic director, coaches, and senior staff. Murdock (2010) reported that administrators suggested that a greater awareness and 
interest in their Life Skills Program should be demonstrated by those in a position to provide potential support, especially coaches. Sharp and Sheilly (2008) noted that coaches and athletic department personnel should engage in healthy communication so that student athletes' academic well-being can be properly supported, since the goal is to help student athletes experience a proper education, not to just maintain eligibility for competition. In the current study, five were members of the athletic department senior team.

\section{Recommendations for Practice}

Based on the limitations of the study, the reader cautions the interpretations. The results are not generalizable of all Life Skills Programs. The researcher has worked with NCAA Division I athletic departments for 19 years, based on his experience and knowledge he provided the following five recommendations for the future of Life Skills Programs:

1. It is widely recommended that student athletes should be an integral part of the University/College student body. Tinto (1987) posited that involvement in college life was a strong predictor of academic success for student athletes, including reaching graduation. Hence, student engagement appeared to be an important factor for student athletes achieving success in school. Murdock (2010) concluded it might be advisable for athletic departments to have student-athletes more involved in on-campus service activities rather than primarily being sent out into the community (Murdock, 2010). Evidence suggests student-athletes should be integrated into the community.

Having the student-athletes integrated in the community provides them accountability, empathy, and leadership skills essential to their overall personal and professional development. If schools want the community to support their teams, their teams need to support the community. However, Potts (2003) suggested as time- 
management issues are scrutinized, activities such as community service might be subtracted from a bigger equation to reduce student-athlete time commitments outside the 20 countable hours of athletic activities each week. The issue for coaches and student athletes dealing with the 20 -hour rule boils down to voluntary vs. mandatory participation (Potts). When the student-athlete does not feel community service is mandatory and a chore, they are more than likely to enjoy the experience of providing the service versus them feeling forced to perform the community service.

2. Findings supported a need to further educate the athletic director and administrators about the benefits of a Life Skills Program, and to provide necessary budget support and a detailed reporting structure. Half of the respondents $(n=5)$ in this study had budgets of over $\$ 100,000$. Schools with budgets over $\$ 50,000$ appeared to have full support of the administrators, students, and coaches. Half of the schools' budgets exceeded $\$ 100,000$. Those schools also had Life Skills departments with an average number of four individuals on staff. In comparison, schools with budgets of under $\$ 50,000$ did not have more than one staff employee for the Life Skills Program. Secondly, those schools with lower budgets needed to articulate to administrators and coaches the benefits and role of Life Skills on a more regular basis than those with larger budgets exceeding $\$ 100,000$.

3. The Knight Commission (1991) concluded that a school's first priority should be academics over any other considerations. Off-campus service activities had benefits for student-athletes that helped them to be successful in school. These events may be worthwhile. Murdock (2010) concluded student-athletes typically had very demanding time schedules, and/or their coursework should be closely evaluated and monitored by administrators at the institution. The researcher in this study concluded that each team 
should monitor what service projects their student-athletes participate in throughout an academic year based on their time commitments.

4. In this current study, the respondents $(n=10)$ made suggestions about improvements needed in their Life Skills Program regarding staff. The respondents wanted consideration in hiring more full-time coordinators who could concentrate on one of the five NCAA Life Skills Commitment Statements as it related to programming in that area. Three of the schools had four to five full time people in their Life Skills division and receive tremendous support from the senior administration. Participants in the current study expressed the need to have additional people in their department, and suggested the athletic director would provide additional funding to support the school's Life Skills Program. They also felt resources available outside the athletic department may reduce at least some of the need for expanding the athletic department's capabilities by increasing the number of campus-wide staff available to help. Even though student-athletes are a unique population, campus personnel and other sources of support could be trained on how to address and manage student-athletes' specific needs (Murdock, 2010). This training could reduce the need for spending more money within the athletic department on personnel, would increase student-athletes' engagement in the campus environment, and could be a relatively simple way to infuse more supportive personnel into the athletic department's Life Skills Program and who can help student-athletes succeed.

5. In this current study four $(n=4)$ of the ten schools reported that diversity programming was one component of the pillars in their Life Skills Programming. All of the Big Ten schools had less than $10 \%$ minorities on their campus, and they should look to creating more defined programming for the underrepresented populations. In this study, student- 
athletes at four of the schools reported that, by the end of the school year, when they were involved in diverse programming they had a better understanding about diverse populations on campus and in society. The Life Skills Directors described "diverse" as including women, people of color, LGBT community members, and people of different religions.

\section{Conclusion}

The study results and the literature presented offered the following conclusions.

Unsurprisingly, all Big Ten schools offer a Life Skills Program. In 1994, the Life Skills Program was launched to the NCAA membership. Over 50 NCAA institutions participated in the inaugural orientation session for administrators from around the country. Since then, approximately 50 member institutions have joined the Life Skills Program each year. Life Skills focus on five basic areas: academic excellence, athletics excellence, personal development, career development, and service. Schools tailor the program to fit the specific needs of the student-athletes on their campuses. In this recently conducted study all ten schools focused on the five basic Life Skills Commitment Statements, and based on the needs of the student-athlete and teams, many schools enhanced their programming or tailored it to the student-athletes' needs.

To date, few scholars have researched perceived effectiveness of Life Skills Programs. Farrell (1996) was one of the first to do research on the topic. Farrell (1996) examined the perceptions of student services by athletic administrators at NCAA Division I Life Skills schools. In this current study many of the respondents were on the senior athletic administration, and the perceptions from the senior teams and coaches were positive because of the immediate influence the Life Skills Director had on his colleagues and coaches. 
$100 \%$ of the administrators in the department of athletics participated. Seven of the participants were female and three were male. Seven of the participants were Caucasian and three were African American. Nine subjects reported an 80-100\% graduation success rate. Only one reported 51-79\%. Three of the female respondents held a doctorate. Job titles of the Life Skills administrators varied among the participants. The Life Skills role has expanded since its inception in 1991. In this current study it was revealed that all but two schools had the same titles for the directors of the Life Skills Program.

Wright (2002) examined NCAA Division I-A program coordinators' perceptions of cooperation and support of the program by head coaches and athletic administrator regarding football and basketball teams. The current study, similar to Wright's (2002), revealed respondents were asked about their interactions with student-athletes. Respondents were asked about the frequency of interactions with student-athletes. All ten respondents $(n=10)$ indicated they always interacted with student-athletes. Respondents were asked how frequently they attended student-athletes' practices. Two indicated twice a week, seven said several times a month, one said rarely. Respondents were asked if they attended student-athletes' home games. Four indicated always, and two indicated sometimes. Lastly, respondents were asked if they attended student-athletes' away games. Three indicated sometimes, two indicated seldom, and one indicated never.

The researcher concluded when Life Skills administrators attended the student-athletes' practices and games and interacted with them on a consistent basis, the greater the support the student-athlete had for the Life Skills Program. In this study the researcher found that when the Life Skills administrator did not interact with the student-athletes daily the attendance and support of the Life Skills Program was low. 
Unlike previous studies where Life Skills administrators held their positions for less than five years, in this study three of the Life Skills administrators held their current positions for four years to nine years. Three of them held there position two years, two of them held their position four months to a year, and two of them held their current positions for twenty eight years to more than thirty years.

Half of the respondents made attended schools with budgets under $\$ 100,000$ and made suggestions concerning financial support. Wright (2002) reported 50\% of the Life Skills coordinators claimed funding was never or rarely sufficient. $50 \%$ of the administrators in the current study felt that overall Life Skills Program was adequately funded, and $50 \%$ felt their programs were not sufficiently funded. Wright (2002) found that $42.9 \%$ of the Life Skills coordinators felt their programs were sufficiently funded, and 32\% felt their programs were not funded. Goddard (2004) reported that some institutions had budgets of $\$ 25,000$, but most had to work with a budget of $\$ 2,500$ or less.

The current study support revealed half $(n=5)$ of the respondents had budgets over $\$ 100,000$ and half $(n=5)$ had budgets under $\$ 100,000$. There were two schools with budgets ranging from $\$ 21,000-\$ 50,000$. All ten subjects $(n=10)$ were asked to identify the Life Skills budget. Only one respondent reported they had no budget because at the time of this study he was just hired and the Athletic Director had not yet decided what the Life Skills budget would be. Subjects were asked if the budget increased or decreased over the past two years. Five indicated their budgets increased, four indicated the budget stayed the same, and one indicated they did not have a budget because they just started their position. Subjects were asked where the Life Skills offices were located. All ten $(n=10)$ reported the Life Skills offices were located in the athletic department. Subjects were asked who was responsible for the Life Skills Program. 
Ten of the respondents indicated they responsible, and one of the respondents indicated the Life Skills coordinator was responsible.

This current study revealed that $50 \%$ of Life Skills Directors felt their programs were underfunded, which is almost $10 \%$ greater than what previous literature had revealed. In addition, contrary to previous literature on the average budget for Life Skill programs, this study revealed the budgets increased by $50 \%$. Overall, this study did not support previous literature regarding funding the budget for Life Skills programs. In this study the budgets were much higher, and the programs had more funding than what previous literature reported.

In this study, effectiveness was assessed by inquiring about the Life Skills Commitment Statements and implementing Murdock’s (2010) instrument based on Life Skills' five Commitment Statements. Effectiveness was also assessed by asking Big Ten athletic administrators open ended questions inquiring about the strengths of their institution's Life Skills Program.

\section{Practical Implications}

The NCAA Life Skills office - a well-known collaboration between the NCAA national office, the 1,200 member institutions, and conference offices — was committed to the total development of student-athletes, preparing them with "life skills" that are useful throughout the college experience and after graduation. Previously known as Life Skills, the student-athlete development program was modeled after the "Total Person Project" established by Dr. Homer Rice, longtime athletics director at Georgia Institute of Technology. The project stemmed from Dr. Rice's belief that excellence is a result of a balanced life-including academic achievement, athletic success, and personal wellbeing — core values which Life Skills administrators across the NCAA membership bring to their everyday interaction with student-athletes (NCAA, 2009). 
The Life Skills five distinct commitments are: (a) Commitment to Academic Excellence; (b) Commitment to Athletic Excellence; (c) Commitment to Personal Development; (d) Commitment to Career Development; (e) Commitment to Service.

Currently, the leadership development department of the NCAA coordinates and facilitates cutting-edge education and training for student-athletes, coaches and athletics administrators from NCAA membership institutions, conference offices, and the national office. The staff hosts more than 20 programs annually, at little or no cost to the membership. The NCAA also provides on-going education and topical training to athletic professionals who identify and serve student-athlete needs. The leadership development programming includes practical and relevant subjects such as academics, athletics, service, personal development, career development, engagement, communication, wellness, social networking, and coaching.

In 2014, the NCAA reached out to the membership with a collaboration initiative to reinvigorate the Life Skills mission. The association sought dedicated administrators willing to make a commitment to three actions teams These teams were charged with defining the profession, bettering the emerging lives of NCAA student-athletes, supporting membership professionals, as well as providing both student-athletes and administrators with tools to be successful. The action teams formed were Yearly Initiatives, Life Skills Academy and Mental Health. The mission and purpose changed tremendously since the inception of the Life Skills Program. The following section briefly describes each of the action teams:

\section{Yearly Initiatives Action Team}

The Yearly Initiatives Action Team is charged with addressing the growing needs of Life Skills administrators, bettering student-athlete opportunities, and increasing welfare initiatives across all three divisions. The team is leading the effort to rebrand the profession's current Life 
Skills name and logo, reevaluate the intent and goals of the mission, create an accessible curriculum that will parallel the newly renovated brand, and enhance the current Life Skills Symposium.

\section{NCAA Life Skills Academy Action Team}

The Life Skills Academy action team is developing a cutting-edge academy for studentathlete development administrators. The selected participants periodically gathered over a twoyear (2014-2016) period for topical continuing education programming, expertly-designed training to better serve student-athletes; as well as skill development workshops specific to job responsibilities. Vetted topics will be immediately transferable to work on campus or in the conference office. These topics could include budget management, strategic planning, communication, fundraising, emotional intelligence, and technology. The Academy will also connect engaged athletics professionals committed to supporting each other throughout the twoyear education process.

\section{Mental Health Action Team}

The Mental Health action team, in collaboration with the NCAA Sport Science Institute, is developing expert methods to best educate student-athlete development administrators on campus about prevalent wellness issues such as mood disorders, substance abuse, and anxiety disorders. Life Skills administrators typically do not handle specific mental health cases, yet it is crucial they understand how to manage sometimes difficult situations and incorporate best practices to appropriately refer student-athletes to the necessary help.

The action team, comprised of athletics professionals and clinical psychologists, is crafting efficient tools and application-oriented resources that address a variety of mental health 
issues. This approach will provide direction and empower administrators to best serve the needs of the student-athletes.

\section{Recommendations to College Athletic Administrators}

Based on the literature and current research findings, the following recommendations are made for future of Life Skills Programs:

1. The development of a focus group of Life Skills administrators examining the needs of Life Skills Programs at NCAA institutions. This group of highly skilled experts will set standards and measure outcomes. Once this is accomplished, a curriculum can be administered and implemented for all Division I schools. The ultimate purpose of the Life Skills focus group would consist of the following:

a. Develop a matrix of Life Skills Programming initiatives.

b. Advocate for the establishment of Life Skills Programming across all NCAA divisions (I, II and III).

c. Develop a reporting structure with all Life Skills Programs across all NCAA divisions (I, II and III). The structure would have the Life Skills Director provide annual reports to the athletic director, president, board of trustees and to the NCAA focus group.

d. Develop a central reporting agency for Life Skills administrators at all NCAA institutions in all divisions (I, II and III) to provide Life Skills administrators accountability of the programming they initiated throughout the academic year. 
2. The development of a Life Skills academy for high school student athletes. The purpose for this academy is to prepare high school student-athletes - mentally, emotionally, and spiritually_-for the rigors of college life.

3. The development of a fully comprehensive career, academic and personal development enrichment plan. In addition to preparing the student-athlete in the classroom and on the field, all of the respondents in this study indicated that preparing student-athletes for life beyond college was very important. There should be a curriculum that is tailored for students in their freshman, sophomore, junior, and senior years.

4. The establishment of permanent partnerships with alumni. Each school can incorporate alumni within all of the three commitment areas: provide career opportunities for alumni to have access to alumni networks; participate in career fairs; provide mentorship to current student-athletes; provide internships and shadowing opportunities for student-athletes. More importantly, allow student-athletes to participate in all of the programming for them. In this study more than half of the schools had their alumni base integrated into the Life Skills Programming.

5. Create a mandatory orientation program for freshman and transfer students based on the findings of this study.

6. Restructure coaches' contracts similar to those who have incentives for their graduation rate or APR score. The researcher recommends the coach makes it mandatory for the student-athletes to attend and participate in the Life Skills seminars offered throughout the year by the athletic department. Whereas graduation rates and APR scores are very important, it is also important to address issues related to 
coaches being held to a standard to ensure student athlete attends mandatory Life Skills Programs. The researcher feels such contracts should contain clauses that monetarily penalize coaches because the mental, emotional and professional development of the student-athlete is just as important as if the student-athlete is academically eligible. Clauses that carry penalties should also be extended to assistant coaches' contracts (Gragg, 2004).

7. Increase the number of African American staff members. In this study, there were three African American administrators. Historically, the number of African American faculty and staff members at predominantly white institutions (PWIs) have been extremely low (Gragg, 2004). In this study, an African American administrator reported he was frustrated with the apathy and leadership of the African American student-athletes.

8. Develop diversity initiatives for minorities. In this study, four of the ten respondents reported diversity programming for minorities (i.e., women, LBGT, and international students) was a major strength. One of the unique aspects of the Big Ten is that each school in the conference designates a diversity intern to represent the Big Ten. It is mandatory that each team has a representative. Four of the ten schools reported diversity initiatives were a major strength in their Life Skills Programs.

9. Hire outside Life Skills companies whose mission is to empower student-athletes. Established companies such as Jensen Leadership Academy, Career Athletes, and Scholar Baller have each offered programming during the past twenty years that assists Division I schools with leadership skills. Jensen Leadership Academy works closely with two Big Ten schools. In one of their specialized leadership programs 
they choose 100 student-athletes to participate in the academy per year. It consists of three levels. At the Emerging Leader level student-athletes are not leaders yet, but are seeking to become leaders. At the Veteran Leader level they are starting to assume some leadership responsibilities. As seniors they participate in Leadership 360. At this level, seniors gather around a table to talk about their team and ways to better lead their team.

10. Develop a mentorship program. In this study, one program created a mentorship initiative for "at-risk" student-athletes by providing them an objectives-based study hall staffed with professional educators who can address the students' study skills, academic needs, and provide homework support.

11. Enhance programming for African American and minority student-athletes. In this study the percentage of African American student-athletes was less than $6 \%$.

12. Develop specific programming for female and male student-athletes. As a former student-athlete, and having the unique opportunity to work with many NCAA Division I student-athletes, it was alarming to witness the number of social and personal issues many of the female and male student-athletes face. In this current study, three administrators reported providing programming for their female and male student-athletes. Some of the student-athletes stated they felt more comfortable discussing issues like domestic violence, rape, abortion, gender identity, and isolation with members of their own gender. One administrator created an annual program designed to empower women in various careers, and the female student-athletes reported that it was one of their favorite program throughout the year. 
13. Develop a Life Skills Programming guide for 2015-2016 and beyond. The programming guide will serve as a matrix for all athletic directors at the Division I level, regardless of conference or school size. The NCAA could use this study to evaluate effectiveness at smaller NCAA member institutions in Divisions II and III.

Based on the findings of this study and extant literature, these variables are relevant to college presidents, athletic administrators, college coaches, and potential readers. The following variables must be taken into consideration when an athletic director is selecting an individual to manage a the Life Skills division of an NCAA Division I athletic department: title of the Life Skills program; job title of the Life Skills program administrator; budget for the Life Skills program; organizational structure; and Life Skill Commitments statements.

\section{The Future of Life Skills Programs}

Based on the current research, the titles of the Life Skills Program varied. When the Life Skills Program was introduced in 1991, each school was encouraged to use the title on their campuses. Over the past twenty-four years, many schools have changed the name of their program and just utilized the five Commitment Statements. In this study, six of the ten schools utilized the name "Life Skills" in their program name. Three of the schools used the names "Leadership," "Student Athlete Development," and "Excellence" in their titles. I would recommend the name have some derivation of "Life Skills" and "Student Athlete Leadership" in the title of the program because the majority of NCAA Division I schools considered to have stellar Life Skills Programs have moved in that direction. In addition, many of the Life Skills Directors that are considered to be experts among their peers across the country the researcher spoke with feel this is the direction the profession is heading. 


\section{Job Title of the Life Skills Program Administrator}

Since the inception of the Life Skills Program, the title of the program administrator has also evolved. Many had "coordinator" in the title while having to perform other roles in the athletic department such as: compliance director, tutor, academic counselor and many others. As athletic departments grew, so did the demands of providing programming for student-athletes to meet the five Life Skills Commitment Statements. Athletic directors began hiring administrators who focused only on Life Skills. In this study, the job titles of the Life Skills administrators varied among the participants.

Based on the findings of this study, it is important that the administrator's title include some variation of the term "student athlete development." Globally, universities are working to develop students who are able to function mentally, spiritually and holistically. The studentathletes should also have the opportunity to develop in the same capacity as the regular student population. In this study, six of the administrators had "student athlete development" in the title. Moreover, there were other variations of the word "development" in the title such as: "career development." After speaking to some of the senior leadership of the NCAA and seven members of the NCAA action team, the researcher recommends using the terms "Life Skills" and "student athlete development" in selecting an appropriate title for the administrator.

\section{Budget for Future Life Skills Programs}

Perhaps one of the biggest needs for improvement identified by the findings of this study was the need to increase the budget for the Life Skills program at many of the institutions. Suggestions concerning financial support were recommended by schools with budgets under $\$ 100,000$ (half of the respondents). According to Wright (2002), 50\% of the Life Skills coordinators reported that funding was never or rarely sufficient. Wright (2002) found that 
$42.9 \%$ of the Life Skills coordinators felt their programs were sufficiently funded, and $32 \%$ felt their programs were not sufficiently funded. Goddard (2004) reported that some institutions had budgets of $\$ 25,000$, but most must worked within a budget of $\$ 2,500$ or less. The current study revealed half of the respondents had budgets over $\$ 100,000$. There were two schools with budgets ranging from $\$ 21,000-\$ 50,000$. When subjects were asked if their budgets changed in the last two years five indicated their budgets increased, four indicated the budget stayed the same, and one indicated they did not have a budget because they just took on their position.

Based on the current research and interviews that were conducted with NCAA Division I Life Skills program administrators and athletic directors across the country, it is important the average budget should not be under $\$ 150,000$. In this study, the researcher found schools with budgets of $\$ 100,000$ or above tended to have the most effective programming. Those schools also had larger staffs and received the most support from the administration and coaches.

\section{Organizational Structure of the Life Skills Program}

It is imperative that all program administrators be on the senior athletic administrative team. In this study, only four administrators were on the athletic senior leadership team and reported to the athletic director. The remaining six administrators reported to senior leadership. This was consistent with previous research by Farrell (1996), Wright (2002), Goddard (2004), and Murdock (2010). None of those studies reported that program administrators were on the senior leadership team. In this study, three respondents reported that being on the senior athletic leadership team helped influence the importance of Life Skills, provided the staff a better understanding, and emerged as a common theme. Administrators on the senior leadership team expressed the following: 
Being on the senior administrative team carries a lot of weight, the executive staff values the work we are doing means a lot helps to foster consistency in what we do with the student-athletes.

Program administrators should have the title of "director." The researcher found from speaking to athletic administrators in this study — as well as other NCAA Division I athletic administrators - that they felt they received more respect and were taken more seriously from their peers with this title. See Appendix Page 146 for Recommended Life Skills Organizational Chart.

Each year the NCAA sponsors the Life Skills Symposium. It is a three-day program for athletics professionals whose job responsibilities include student-athlete development. Attendees receive relevant, effective, and practical training through various workshops, breakouts, and general sessions equipping them with a toolkit to best serve the continuously-changing needs of student-athletes. Based on findings from this study the researcher commends commitments each conference should:

1. Provide campus and conference resources year-round. In addition to the annual NCAA Life Skills Symposium, most (if not all) NCAA Division I conferences have an annual conference with athletic administrators assisting athletics professionals in translating lessons learned through leadership and becoming a better administrator. In addition to the yearly conference, they should also create platforms for all the Life Skills administrators to meet collectively and discuss best practices. Currently, the Big Ten has an annual conference meeting, but it does not have a Life Skills component or meeting focusing on Life Skill Programming and initiatives. 
2. Each Life Skills administrator in the conference should have mandatory monthly calls and participate in discussions with other Life Skills administrators at conference member schools.

3. The leadership of development unit of the NCAA annually distributes over $\$ 2.5$ million in grants to institutions and conference offices. In addition, the conference should provide financial resources for the athletic directors, Life Skills administrators and their staff to attend the mandatory conference meeting on Life Skills.

\section{Commitment Statements for Life Skills}

When the CHAMPS/Life Skills Program was introduced to NCAA member schools, there were five distinct commitments: (a) Commitment to Academic Excellence; (b) Commitment to Athletic Excellence; (c) Commitment to Personal Development; (d) Commitment to Career Development; (e) Commitment to Service. It was the belief of the NCAA leadership and governing boards that the implementation of the five commitment areas of emphasis would assist student-athletes during their tenure on and off campus, and would assist in their transition from college to life after school (NCAA, 2005).

Based on the extant literature and the findings of this study, the researcher recommends the Commitment Statements contain the following: Commitment to Academic Excellence, Commitment to Athletic Excellence, and Commitment to Personal Development (i.e., Service, Career Development, and Mental Health).

\section{Additional Recommendations for Athletic Directors}

Based on the dearth of research of Life Skills, investigating the effectiveness of Life Skills, and the findings of this study and existing literature, the following recommendations are 
offered: athletic directors are (a) encouraged to continue to be supportive of a Life Skills Program in their department, and (b) to encourage the director of Life Skills to develop and enhance the program each year. In addition, the researcher recommends Life Skill programs should have a holistic approach to encouraging academic integrity, increasing the APR for all sports, and educating student-athletes on societal issues such as exploitation and drop-out rates.

\section{Recommendations for Further Research}

Recommendations for Further Research include:

1. Analyze Life Skills Program effectiveness with athletic directors, student athletes, coaches, and college presidents in the Big Ten Conference, and eventually to all NCAA conferences (Divisions I, II and III). The purpose would be to assess whether results vary among the different conferences. Such a study could help Life Skills Directors create programming that fits the specific needs of their student-athletes. The study would also assist administrators and athletic directors with understanding the needs of their studentathletes.

Goddard (2004) found students who have been in school less than two years believed the Life Skills Programs are less effective than those engaged in the Life Skills Program for a longer period. Adding to the debate, Goddard (2004) found that developing a needs assessment of the transfer student-athletes would help lead to greater effectiveness in the Life Skills Program for the transfer student-athletes. The data from this study indicated that in the most successful programs the athletic directors, student athletes, college presidents, and coaches all had positive perceptions of their Life Skills Program. 
2. Conduct research to see if there are Life Skills Programs at historically black colleges and universities (HBCUs). If so, examine the effectiveness of the programs. Since the NCAA's inception of the Life Skills Program in 1991, there has not been any research done on Life Skills at HBCUs. Another major issue regarding Life Skills at HBCUs is the implementation of the APR and its tough sanctions on HBCUs. This has affected many HBCU's academically and athletically. Sanctions have also impacted the psyche of many student-athletes attending HBCUs. To affect change with the APR and HBCU's there has to be a directive from the president or chancellor (Fairbank, 2011).

Future research should examine the broader scope of these issues related to Life Skills in all aspects of intercollegiate and interscholastic athletics. Investigating high schools, community colleges, and other collegiate levels such as Divisions II and III and the National Intercollegiate Athletic Association can only enhance our understanding of these important decisions in college sports. Data using various theoretical models with objective and subjective measurements can inform us about the emerging patterns in Life Skills for student-athletes. 


\section{REFERENCES}

Baez, B. (2002). Affirmative action, hate speech, and tenure: Narratives about race, law, and the academy. New York: Routledge Falmer.

Bartlett, A. (2012). The NCAA academic progress rate educational. Retrieved from http://www.academia.edu/2231151/The_NCAA_Academic_Progress_Rate

Beamon, K. (2008). Used goods: Former African American college student-athletes' perceptions of exploitation by Division I universities. Journal of Negro Education, 77(4), 352-364. Retrieved from EBSCOhost.

Bell, E. A. (2005). A comparison of academic assistance programs provided for student-athletes among Division I-A colleges and universities. ProQuest Dissertations and Theses. Retrieved from http://search.proquest.com/docview/305349364? accountid=2837. (305349364).

Berry, R. D. (2001). Athletic commodities: The African American male student-athlete in higher education. ProQuest Dissertations and Theses. Retrieved from http://search.proquest.com/docview/251696542?accountid=2837. (251696542).

Branch, T. (2011, September 7). The shame of college sports. The Atlantic. Retrieved from http://www.theatlantic.com/magazine/archive/2011/10/the-shame-of-collegesports/308643/?single_page=true

Brown, C., \& Hartley, D. (1998). Athletic identity and career maturity of male college studentathletes. International Journal of Sport Psychology, 29, 17-26.

Brown, G. (1999, Nov. 22). NCAA answers call to reform the 'Sanity Code' leads association down path to enforcement program. Retrieved from http://fs.ncaa.org/Docs/NCAANewsArchive/1999/19991122/active/3624n24.html 
Brown, G. (2012, Aug. 3). Executive Committee funds pilot to help limited-resource schools boost APR. Retrieved from http://www.ncaa.org/about/resources/media-center/news/executive-committee-fundspilot-help-limited-resource-schools

Busenberg, B., and Smith, D. (1997). Affirmative action and beyond: The woman's perspective. In M. Garcia (ed.), Affirmative action's testament of hope: Strategies for a new era in higher education (pp. 149-180). Albany, NY: SUNY Press.

Clow, C. T. (2000). Student athletes' perceived value of education: Effects of a career exploration intervention. ProQuest Dissertations and Theses. Retrieved from http://search.proquest.com/docview/304583783?accountid=2837. (304583783).

Collegiate Athletic Association. (2005). NCAA CHAMPS/Life Skills Program pamphlet. Shawnee Mission, KS: NCAA Publishing.

Comeaux, E., Speer, L., Taustine, M., \& Harrison, C. K. (2011). Purposeful engagement of firstyear Division I student-athletes. Journal of the First Year Experience \& Students in Transition, 23, 35-52.

Cooper, J., Kane, K., and Gisselquist, J. (2001). Forces eroding affirmative action in higher education: The California-Hawaii’s distinction.” In B. Lindsay \& M. J. Justiz (eds.), The quest for equity in higher education: Toward new paradigms in an evolving affirmative action era (pp. 163-182). Albany, NY: State University of New York Press.

Dodd, R. (2014, August 3). Even as college athletic department revenues rise, student subsidies remain. Retrieved from http://www.kansascity.com/sports/college/article984117.html

Donnor, J.K. (2005). Towards an interest-convergence in the education of African American football student-athletes in major college sports. Race Ethnicity and Education, 8(1), 45- 
67. doi: 10.1080/1361332052000340999

Edwards, H. (1983). Educating Black athletes. The Atlantic Monthly, 252(2), 31-38.

Fairbank, D. (2011, May, 27). HBCUs disproportionately penalized by academic criteria. Daily Press. Retrieved from http://articles.dailypress.com/2011-05-27/sports/dp-spt-columnfairbank-0528-20110527_1_hbcus-academic-progress-rate-ncaa

Farrell, R. J., II. (1996). Perceptions of student services held by staff at national collegiate athletic association institutions participating in the life skills program. ProQuest Dissertations and Theses. Retrieved from http://search.proquest.com/docview/304297136?accountid=2837. (304297136).

Gayles, J. G., \& Hu, S. (2009). The influence of student engagement and sport participation on college outcomes among Division I student-athletes. Journal of Higher Education, 80(3), 315-333.

Goddard, M. (2004). An assessment of the effectiveness of the CHAMPS/Life skills program at the University of North Texas: A pilot study. ProQuest Dissertations and Theses. Retrieved from http://search.proquest.com/docview/305167870?accountid=2837. (305167870).

Gragg, D. L. (2004). Factors that positively affect academic performance of African American football student-athletes who graduate from southeastern conference institutions. ProQuest Dissertations and Theses. Retrieved from http://search.proquest.com/docview/305217597? accountid=2837. (305217597).

Grasgreen, A. (2013, June 17). Uphill battle for HBCU athletics. Inside Higher Ed. Retrieved from https://www.insidehighered.com/news/2013/06/17/hbcus-get-some-help-stillstruggle-meet-ncaa-academic-standards 
Gray, M. (Sep 9, 2014) HBCUs cut from NCAA post-season over academics foul. They're right. News One. Retrieved from http://newsone.com/3010651/hbcus-cut-from-ncaapostseason-over-academics-cry-foul-theyre-right/

Harper, S. R. (2012). Black male student success in higher education: A report from the national Black male college achievement study. Philadelphia: University of Pennsylvania, Center for the Study of Race and Equity in Education.

Harper, S. R., Williams, C. D., \& Blackman, H.W. (2013). Black male student-athletes and racial inequities in NCAA Division I college sports. Philadelphia: University of Pennsylvania, Center for the Study of Race and Equity in Education.

Harrison, C.K. (1999). Perceptions of African American male student-athletes in higher education. ProQuest Dissertations and Theses. Retrieved from http://search.proquest.com.www.libproxy.wvu.edu/docview/304526112 accountid=2837. (304526112).

Harrison, C.K., Lapchck, R., and Neza, Janson. (2009). Decision making in hiring: intercollegiate athletics coaches and staff. New Directions for Institutional Research, 144, 93-101.

Harrison, C.K., \& Lawrence, S.M. (2003). African American student-athletes' perceptions of career transition in sport: A qualitative and visual elicitation. Race, Ethnicity and Education, 6(4), 373-394. Retrieved from EBSCOhost.

Harrison, C.K., \& Lawrence, S.M. (2004). College students' perceptions, myths, and stereotypes about African American athleticism: A qualitative investigation. Sport, Education \& Society, 9(1), 33-52. doi: 10.1080/1357332042000175809 
Knight Foundation Commission on Intercollegiate Athletics. (1991). Keeping faith with studentathletes: A new model for intercollegiate athletics. Charlotte, NC: Knight Foundation Commission on Intercollegiate Athletics.

Lapchick, R. E. Sense of urgency to address colleges' lack of diversity. Street and Smith's Sport Business Journal, 2008b, 11(41), 34.

Martin, B. E., Harrison, C. K., \& Bukstein, S. (2009). "It takes a village" for African American male scholar-athletes: Mentorship by parents, faculty, and coaches. Journal for the Study of Sports and Athletes in Education, 4(3), 277-295.

Madsen, R. M. (2010). Female student-athletes intentions to pursue careers in college athletics leadership: The impact of gender socialization. (Order No. 3451391, University of Connecticut). ProQuest Dissertations and Theses. Retrieved from http://search. proquest.com/docview/862847685?accountid=2837. (862847685).

Murdock, S. C. (2010). Identification of best practices of the CHAMPS/Life Skills program: Perspectives of Division I college and university athletic department administrators. (Order No. 3480813, Lamar University-Beaumont). ProQuest, UMI Dissertations Publishing. Retrieved from http://search.proquest.com.www.libproxy.wvu.edu/docview/899807083 accountid=2837. (899807083).

National Collegiate Athletic Association. (n.d.). 2006-07 revenue distribution plan. Retrieved from http://www1.ncaa.org/finance/revenue_distribution_plan National

NCAA Research Report Series 01. (1990-1997). Retrieved from http://www.ncaa.org/library/research/01Series/index.html 
NCES. (1995). Who can play? An examination of NCAA's Proposition 16. National Center for Education Statistics. 95-763.

Northcutt, Jamil. (2013). The dilemma: Career transition of African American male football players at Division I institutions. ProQuest Dissertations and Theses. Retrieved from http://search.proquest.com.www.libproxy.wvu.edu/docview/1507868051 ?accountid=283 7. (1507868051).

Patton, M. Q. (2002). Qualitative research and evaluation methods. Thousand Oaks, CA: Sage Publications.

Rosen, L. J. (2001). Proposition 16 and the NCAA initial-eligibility standards: Putting the student back in student-athlete, Cath. UL Rev. 50, 175. Retrieved from http://scholarship.law.edu/lawreview/vol50iss 1/11

Satterfield, J. W., Croft, C., Godfrey, M., \& Flint, A. (2010). Academic progress reports: Leadership implications for college basketball coaches. Academic Leadership Journal, $8(2), 43-45$.

Smith, Chris. (2014, April 15). The most valuable conferences in college sports 2014. Retrieved from http://www.forbes.com/sites/chrissmith/2014/04/15/the-most-valuable-conferencesin-college-sports-2014/

Smith, R. A. (2001). Play-by-play: Radio, television, and big time college sport. Baltimore, MD: Johns Hopkins University Press.

Splitt, F. (2009, December 2). The Knight Commission on Intercollegiate Athletics: Why it needs fixing. Retrieved from http://thedrakegroup.org/

U.S. Department of Education, National Center for Education Statistics. (2013). Digest of Education Statistics, 2012 (NCES 2014-015), Chapter 3. 
Williams, S. (2011). Sports and economics: Examination of college sports and big business. Learning Culture through Sports. Washington DC: Rowman and Litman Publishers.

Wisdom, T. (2006). Assessing the effectiveness of the NCAA CHAMPS/Life Skills Program model at meeting the developmental and psychological needs of Division I studentathletes. (Unpublished doctoral dissertation). University of Northern Colorado, Greeley.

Woverton, B. (2014, October 27). NCAA's graduation rates don't necessarily prove success. Retrieved from http://chronicle.com/article/NCAAs-Graduation-RatesDont/149627/?cid=at\&utm_source=at\&utm_medium=en

Wright, O. L. (2002). The administration of the NCAA Division I-A CHAMPS/Life Skills Program and the perception of support by program coordinators. (Unpublished doctoral dissertation). Yale University. Retrieved from http://www.yalebulldogs.com/sports/mcrewhvy/2011-12/releases/201208030hj2yi 


\section{APPENDICES \\ Appendix A-IRB Approval

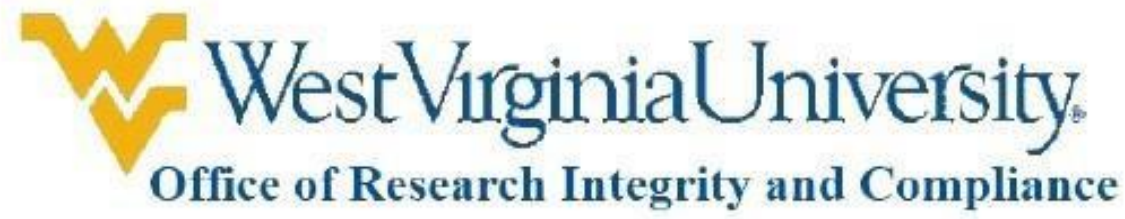

\section{Acknowledgement Letter Exempt Initial Protocol Review}

To

From

Action Date

Approval Period

Subject

Protocol Number

Title
Luisa Velez-Colon

WVU Office of Research Integrity and Compliance

$12 / 15 / 2014$

12/15/2014 Expiration Date 12/14/2017

Acknowledgement Letter Exempt Initial Protocol Review

1411494172

CHAMPS Life Skills Dissertation Proposal

The above-referenced study was reviewed by the West Virginia University Institutional Review Board IRB and was granted exemption in accordance with 45 CFR 46.101. Documents for use in this study have been acknowledged and are available in the WVUkc system in the Notes and Attachments section of your protocol. The Office of Research Integrity and Compliance is here to provide assistance to you from the initial submission of an IRB protocol and all subsequent activity. Please feel free to contact us by phone at 304.293.7073 with any question you may have. Thank you.

WVU Office of Research Integrity and Compliance

Date: $12 / 15 / 2014$

Signed:

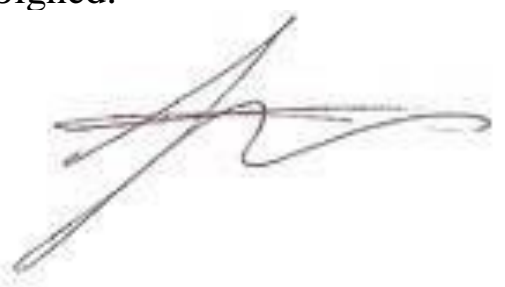

Jonathan Young

Program Administrator 
Appendix B-Participant Cover Letter

Subject: Survey Request Participation

Dear Participant:

My name is Marc Williams; I am a doctoral student at West Virginia University in Morgantown, West Virginia in the college of Education and Human Resources under the supervision of Dr. Sam Stack, a Professor in the College of Education and Human Resources. This letter is a request for you to take part in a descriptive analysis of CHAMPS/Life Skills Programs at selected Division I NCAA institutions. I am very interested in your perspective since you are an administrator over a CHAMPS/Life Skills Program. The West Virginia University Institutional Review Board (IRB) has acknowledgement of this study on file.

Your participation in this study is greatly appreciated and should take approximately 20 minutes to complete the following research packet.

Please note that your participation in this study is totally voluntary. There are no foreseeable risks associated with your participation in this study. If you find that you feel uncomfortable with any of the questions you encounter, you may withdraw at any time. The survey responses you provide with be kept strictly confidential and will be destroyed after the study concludes. All data will be reported in the aggregate. I will not ask any information that should lead back to your identity as a participant. You may skip any question that you do not wish to answer and you may discontinue at any time. Please contact me at mwilli66@mix.wvu.edu if you would like a copy of the summary of the results, or if you have any other questions.

Thank you for your time and help with this study.

Sincerely,

Marc Williams, Ed.D. Candidate

West Virginia University 
Appendix C-Questionnaire

\section{CHAMPS/Life Skills Survey}

Demographics

1. What is the name of your College or University?

2. What is your gender?

Male

Female

3. Please indicate your institution's 2013 Graduation Success Rate.

$1-50 \%$

$51-79 \%$

$80-100 \%$

4. What is your Race/Ethnicity?

African American

Asian

Caucasian/White

Latin American

Native American

Other (Specify)

5. What is your current job title?

6. How many years have you been employed in your current role?

7. Does your athletic department have a CHAMPS/Life Skills Program? Yes

No

8. How many years have you been involved as an administrator in the CHAMPS/Life Skills Program at your institution?

1 month to 1 year

2 years

3 years

4 years

5 or more years

9. How many years has your current institution been involved in the CHAMPS/Life Skills Program?

1 month to 1 year

2 years

3 years

4 years

5 or more years 
10. Please indicate student size of enrollment at your institution.

1,000 to 10,000

10,001 to 15,000

15,001 to 25,000

25,001 to 35,000

35,001 and more

11. What is your highest level of education attained?

High School___ Associates___ Bachelors__ Masters__ Doctorate_
Other (Specify) __

12. Were you a former College Student Athlete? Yes__ No _ _

13. If yes, what position(s) and/or event did you play?

College Sport (List)

14. Academic College Major?

Academic Minor?

15. How many Student Athletes by gender are at your current institution? Male _Female_

16. On a weekly basis, how often do you have face to face interactions from your studentathletes? Once a day Twice a week Three times a week__ Never__ Other (Specify)

17. Do you attend Student Athletes' practices? Once a day Twice a week Three times a week_ Never Other (Specify) ___

18. Do you attend Student Athletes' home games? Never Seldom Sometimes Always

19. Do you attend Student Athletes' away games? Never Seldom Sometimes Always

20. Does your CHAPMS/Life Skills Program include each of the five components listed below?

Commitment to Academic Excellence

Commitment to Personal Development

Commitment to Career Development

$\begin{array}{ll}\text { Yes__ } & \text { No } \\ \text { Yes__ } & \text { No__ } \\ \text { Yes__ No } & \text { No } \\ \text { Yes__ No_ } & \text { No } \\ \text { Yes__ } & \text { No }\end{array}$

Commitment to Athletic Excellence

Commitment to Service

Yes

No

21. Is it mandatory for your student-athletes to attend the CHAMPS/Life Skills seminars? Yes___No___ If no, why not? 
22. Which sports attend Life Skills seminars regularly?

23. Which sports are NOT required or tend to attend Life Skills Programming?

24. How would you assess the overall effectiveness of your CHAMPS/Life Skills Program? Very effective

Somewhat effective

Effective

Ineffective

Very ineffective

25. What is the annual budget for your CHAMPS /Life Skills Program?
Less than $\$ 20,000$
b. $21,000-\$ 50,000$
c. $\$ 51,000-\$ 99,000$

d. $\$ 100,000$ and above

26. Has the budget for the program increased or decreased over the past two years? Increased Decreased

27. Where are the CHAMPS /Life Skills administrative offices located on your campus? Student Affairs Athletic Department Other

28. What are the incentives for student-athletes to attend the CHAMPS/Life Skills Seminars?

29. What is the overall effectiveness of your Life Skills Program? 


\section{Appendix D-Open-Ended Questions}

1. What do you feel are the strengths of your CHAMPS/Life Skills Program?

2. What is the participation of your revenue generating sports in your CHAMPS/Life Skills Program?

3. What new programs or initiatives would you add that your program does not currently offer that would make a positive impact on your student-athletes?

4. What concerns, if any, do you have about your school's CHAMPS/Life Skills Program?

5. What is the "buy in" (i.e., support) from the following University officials? 


\section{Appendix E-Best Practices Questionnaire}

Best Practices These items are based on the NCAA's instructional resources dusters of the CHAMPS/Life Skills (i.e., Academic Commitment, Career Development Commitment, Athletics Commitment, Development Commitment and Service Commitment),

Please check the most appropriate rating concerning the level of effectiveness of your school's CHAMPS/Life Skills Program relative to each italicized instructional resource area with 1 - Totally Ineffective through 5 - Totally Effective for each item. If your program does not address an item check "N/A" on the survey form.

\begin{tabular}{|c|c|c|c|c|c|c|}
\hline Instructional Resources & $\begin{array}{c}\text { Totally } \\
\text { Ineffective }\end{array}$ & & & & $\begin{array}{l}\text { Totally } \\
\text { Effective }\end{array}$ & $\begin{array}{c}\text { Not } \\
\text { Addressed }\end{array}$ \\
\hline $\begin{array}{l}\text { Please rate your program's } \\
\text { effectiveness in addressing the } \\
\text { ACADEMIC COMMITMENT with } \\
\text { respect to: }\end{array}$ & 1 & 2 & 3 & 4 & 5 & 0 \\
\hline Study Skills & & & & & & \\
\hline Goal setting & & & & & & \\
\hline $\begin{array}{ll}\text { Time } & \\
\text { management }\end{array}$ & & & & & & \\
\hline $\begin{array}{ll}\text { program } & \text { Tutoring } \\
\end{array}$ & & & & & & \\
\hline $\begin{array}{l}\text { Supervised } \\
\text { study hall }\end{array}$ & & & & & & \\
\hline $\begin{array}{ll}\text { Orogram } & \text { Orientation }\end{array}$ & & & & & & \\
\hline $\begin{array}{l}\text { Academic } \\
\text { assessment program }\end{array}$ & & & & & & \\
\hline $\begin{array}{ll} & \text { Academic } \\
\text { Advising } & \end{array}$ & & & & & & \\
\hline \begin{tabular}{l}
\multicolumn{1}{c}{ Student } \\
athletes finishing their school \\
curricula
\end{tabular} & & & & & & \\
\hline $\begin{array}{l}\text { Academic } \\
\text { counseling program }\end{array}$ & & & & & & \\
\hline $\begin{array}{l}\text { Student } \\
\text { athletes completing scholarship } \\
\text { applications }\end{array}$ & & & & & & \\
\hline $\begin{array}{l}\text { Academic } \\
\text { awards and honors }\end{array}$ & & & & & & \\
\hline & $\begin{array}{c}\text { Totally } \\
\text { Ineffective }\end{array}$ & & & & $\begin{array}{l}\text { Totally } \\
\text { Effective }\end{array}$ & $\begin{array}{c}\text { Not } \\
\text { Addressed }\end{array}$ \\
\hline
\end{tabular}




\begin{tabular}{|c|c|c|c|c|c|}
\hline $\begin{array}{l}\text { Please rate your program's } \\
\text { effectiveness in addressing Its } \\
\text { CAREER DEVELOPMENT } \\
\text { COMMITMENT component with } \\
\text { respect to the following: }\end{array}$ & 1 & 2 & 3 & 4 & 0 \\
\hline 13. Job search Process & & & & & \\
\hline $\begin{array}{l}\text { 14. Addressing developmental } \\
\text { concerns-Freshman-senior } \\
\text { years of college }\end{array}$ & & & & & \\
\hline $\begin{array}{l}\text { 15. Post-College career } \\
\text { preparation }\end{array}$ & & & & & \\
\hline 16. interactions with agents & & & & & \\
\hline $\begin{array}{l}\text { 17. Student athlete } \\
\text { participation in alumni career } \\
\text { networking }\end{array}$ & & & & & \\
\hline
\end{tabular}




\begin{tabular}{|c|c|c|c|c|c|c|}
\hline & $\begin{array}{c}\text { Totally } \\
\text { Ineffective }\end{array}$ & & & & $\begin{array}{l}\text { Totally } \\
\text { Effective }\end{array}$ & $\begin{array}{c}\text { Not } \\
\text { Addressed }\end{array}$ \\
\hline $\begin{array}{l}\text { Please rate your program's } \\
\text { effectiveness in addressing } \\
\text { its ATHLETICS COMMITMENT } \\
\text { component with respect to } \\
\text { the following: }\end{array}$ & 1 & 2 & 3 & 4 & 5 & 0 \\
\hline \multicolumn{7}{|l|}{ 18. Athletic coaching } \\
\hline \multicolumn{7}{|l|}{$\begin{array}{l}\text { 19. Athletic department } \\
\text { operations }\end{array}$} \\
\hline \multicolumn{7}{|l|}{$\begin{array}{l}\text { 20. Support programs for } \\
\text { athletics-related issues }\end{array}$} \\
\hline \multicolumn{7}{|l|}{$\begin{array}{l}\text { 21. Student athlete } \\
\text { interviews }\end{array}$} \\
\hline \multicolumn{7}{|l|}{$\begin{array}{l}\text { 22. Student athlete } \\
\text { leadership development } \\
\text { training }\end{array}$} \\
\hline & $\begin{array}{c}\text { Totally } \\
\text { Ineffective }\end{array}$ & & & & $\begin{array}{l}\text { Totally } \\
\text { Effective }\end{array}$ & $\begin{array}{c}\text { Not } \\
\text { Addressed }\end{array}$ \\
\hline $\begin{array}{l}\text { Please rate your program's } \\
\text { effectiveness In addressing } \\
\text { its PERSONAL } \\
\text { DEVELOPMENT } \\
\text { COMMITMENT component } \\
\text { with respect to the } \\
\text { following: }\end{array}$ & 1 & 2 & 3 & 4 & 5 & 0 \\
\hline \multicolumn{7}{|l|}{ program Nutrition } \\
\hline \multicolumn{7}{|l|}{$\begin{array}{l}\text { Eating } \\
\text { disorder prevention } \\
\text { education }\end{array}$} \\
\hline \multicolumn{7}{|l|}{$\begin{array}{c}\text { Personal } \\
\text { relationship management }\end{array}$} \\
\hline \multicolumn{7}{|l|}{$\begin{array}{l}\text { Sexual } \\
\text { responsibility }\end{array}$} \\
\hline \multicolumn{7}{|l|}{$\begin{array}{ll} & \text { Developing } \\
\text { self-esteem } & \end{array}$} \\
\hline \multicolumn{7}{|l|}{$\begin{array}{l}\text { Academic } \\
\text { assessment program }\end{array}$} \\
\hline \multicolumn{7}{|l|}{ Advising Academic } \\
\hline $\begin{array}{l}\text { Student } \\
\text { athletes finishing their } \\
\text { school curricula }\end{array}$ & & & & & & \\
\hline
\end{tabular}




\begin{tabular}{|c|c|c|c|c|c|c|}
\hline $\begin{array}{c}\text { Academic } \\
\text { counseling program }\end{array}$ & & & & & & \\
\hline $\begin{array}{l}\text { Student } \\
\text { athletes completing } \\
\text { scholarship applications }\end{array}$ & & & & & & \\
\hline $\begin{array}{l}\text { Academic } \\
\text { awards and honors }\end{array}$ & & & & & & \\
\hline \begin{tabular}{ll} 
Social & \multicolumn{1}{c}{ Sovelopment }
\end{tabular} & & & & & & \\
\hline $\begin{array}{ll} & \text { Social } \\
\text { etiquette } & \end{array}$ & & & & & & \\
\hline $\begin{array}{ll}\text { Dealing with } \\
\text { authority }\end{array}$ & & & & & & \\
\hline ng diversity Understand & & & & & & \\
\hline $\begin{array}{l}\text { Celebrating } \\
\text { diversity }\end{array}$ & & & & & & \\
\hline $\begin{array}{ll} & \text { Fiscal } \\
\text { responsibility } & \end{array}$ & & & & & & \\
\hline $\begin{array}{ll} & \text { Violence } \\
\text { prevention } & \\
\end{array}$ & & & & & & \\
\hline & $\begin{array}{c}\text { Totally } \\
\text { Ineffective }\end{array}$ & & & & $\begin{array}{l}\text { Totally } \\
\text { Effective }\end{array}$ & $\begin{array}{c}\text { Not } \\
\text { Addressed }\end{array}$ \\
\hline $\begin{array}{l}\text { Please rate your program's } \\
\text { effectiveness in addressing } \\
\text { its SERVICE } \\
\text { COMMITMENT component } \\
\text { with respect to the } \\
\text { following: Totally Effective, } \\
\text { Totally Ineffective: }\end{array}$ & 1 & 2 & 3 & 4 & 5 & 0 \\
\hline Mentoring & & & & & & \\
\hline education Peer & & & & & & \\
\hline $\begin{array}{ll} & \text { Peer } \\
\text { counseling } & \end{array}$ & & & & & & \\
\hline $\begin{array}{c}\text { Student } \\
\text { athlete assistance program }\end{array}$ & & & & & & \\
\hline $\begin{array}{l}\text { Working in } \\
\text { the community }\end{array}$ & & & & & & \\
\hline
\end{tabular}




\section{Appendix F-Life Skills Survey Results}

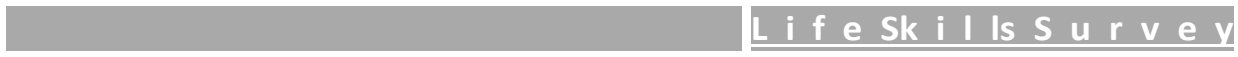

1. What is the name of your College or University?

Answer

2. What is your gender?

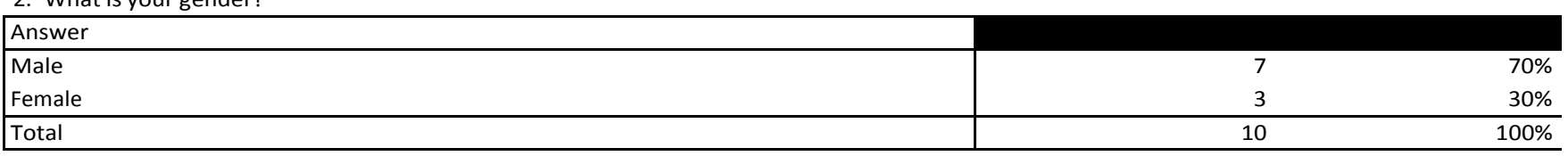

3. Please indicate your institution's 2013 Graduation Success Rate

\begin{tabular}{|l|r|}
\hline Answer & \\
$0-50 \%$ & 0 \\
$51-79 \%$ & 1 \\
$80-100 \%$ & $10 \%$ \\
\hline Total & $90 \%$ \\
\hline
\end{tabular}

4. What is your Race/Ethnicity?

\begin{tabular}{|lr|}
\hline Answer & \\
\hline African American & 3 \\
Asian & 0 \\
Caucasian/White & $0 \%$ \\
Latin American & $70 \%$ \\
Native American & 0 \\
Other (Specify) & 0 \\
\hline Total & $0 \%$ \\
\hline
\end{tabular}

5. What is your current job title?

\begin{tabular}{|l|c|}
\hline Answer & \\
\hline Associate Athletic Director for Student-Athlete Development & 1 \\
Associate Athletic Director - Academic Services & 1 \\
Associate Athletic Director for Life Skills & 1 \\
Assistant Athletic Director, Student-Athlete Development & $10 \%$ \\
Director of Leadership and Life Skills & $10 \%$ \\
Associate Director For Athletic Academic Support and Life Skills Coordinator & 1 \\
Assistant Athletics Director - Life Skills and Career Development & 1 \\
Assistant Director of Academic Services, Student-Athlete Development & $10 \%$ \\
Director of Student-Athlete Development & $10 \%$ \\
\hline Total: & $10 \%$ \\
\hline
\end{tabular}

6. How many years have you been employed in your current role?

\begin{tabular}{|c|c|c|}
\hline Answer & & \\
\hline Less than a year & 2 & $20 \%$ \\
\hline 1 - 2 years & 3 & $30 \%$ \\
\hline $3-5$ years & 2 & $20 \%$ \\
\hline $6-10$ years & 1 & $10 \%$ \\
\hline $11-20$ years & 0 & $0 \%$ \\
\hline $21-30$ years & 2 & $20 \%$ \\
\hline Total: & 10 & $100 \%$ \\
\hline
\end{tabular}

7. Does your athletic department have a CHAMPS/Life Skills Program?

\begin{tabular}{|l|r|}
\hline Answer & 10 \\
\hline Yes & $100 \%$ \\
No & 0 \\
\hline Total: & $10 \%$ \\
\hline
\end{tabular}


8. Please indicate student size of enrollment at your institution

\begin{tabular}{|l|r|}
\hline Answer & $0 \%$ \\
\hline 1,000 to 10,000 & $0 \%$ \\
10,001 to 15,000 & $10 \%$ \\
15,001 to 25,000 & $20 \%$ \\
25,001 to 35,000 & 1 \\
35,001 and more & 2 \\
\hline Total & $70 \%$ \\
\hline
\end{tabular}

9. What is your highest level of education attained?

\begin{tabular}{|l|r|}
\hline Answer & $0 \%$ \\
\hline High School & $0 \%$ \\
Associates & 0 \\
Bachelors & 0 \\
Masters & $10 \%$ \\
Doctorate & $60 \%$ \\
\hline Total & $30 \%$ \\
\hline
\end{tabular}

10. Were you a former College Student-Athlete?

\begin{tabular}{|l|r|}
\hline Answer & $50 \%$ \\
\hline Yes & 5 \\
No & $50 \%$ \\
\hline Total & $10 \%$ \\
\hline
\end{tabular}

11. If yes to Q10, what sport did you play?

\begin{tabular}{|l|r|}
\hline Answer & $20 \%$ \\
\hline Tennis & $20 \%$ \\
Gymnastics & 1 \\
Swimming & 1 \\
Football & $20 \%$ \\
Multi-sport (Volleyball, Basketball, Softball) & 1 \\
\hline Total & $20 \%$ \\
\hline
\end{tabular}

12. How many Student-Athletes by gender are at your current insitution?

\begin{tabular}{|l|r|}
\hline Answer & \\
\hline Male & $52 \%$ \\
Female & 337 \\
\hline Total & $48 \%$ \\
\hline
\end{tabular}

13. On a weekly basis, how often do you have face to face interaction with your student-athletes?

\begin{tabular}{|l|r|}
\hline Answer & \\
\hline Once a day & $70 \%$ \\
Twice a week & $10 \%$ \\
Three times a week & $20 \%$ \\
Never & $0 \%$ \\
\hline Total & 1 \\
\hline
\end{tabular}

14. Do you attend student-athletes home games?

\begin{tabular}{|l|r|}
\hline Answer & \\
\hline Never & $0 \%$ \\
Seldom & $0 \%$ \\
Sometimes & 0 \\
Always & $70 \%$ \\
\hline Total & $30 \%$ \\
\hline
\end{tabular}

15. Do you attend student-athletes away games?

\begin{tabular}{|l|r|}
\hline Answer & \\
\hline Never & $0 \%$ \\
Seldom & $90 \%$ \\
Sometimes & $10 \%$ \\
Always & $9 \%$ \\
\hline Total & 1 \\
\hline
\end{tabular}


16. Is it mandatory for your student-athletes to attend the CHAMPS/Life Skills seminars?

\begin{tabular}{|l|rr|}
\hline Answer & & 2 \\
\hline Yes & $20 \%$ \\
No & 8 & $80 \%$ \\
\hline Total & 10 & $100 \%$ \\
\hline
\end{tabular}

17. How would you assess the overall effectiveness of your CHAMPS/Life Skills program?

\begin{tabular}{|c|c|c|}
\hline Answer & & \\
\hline Very effective & 4 & $40 \%$ \\
\hline Somewhat effective & 4 & $40 \%$ \\
\hline Effective & 1 & $10 \%$ \\
\hline Ineffective & 0 & $0 \%$ \\
\hline Very Ineffective & 0 & $0 \%$ \\
\hline N/A & 1 & $10 \%$ \\
\hline Total & 10 & $100 \%$ \\
\hline
\end{tabular}

18. What is the annual budget for your CHAMPS/Life Skills program?

\begin{tabular}{|l|rr|}
\hline Answer & & \\
\hline Less than $\$ 20,000$ & 0 & $0 \%$ \\
$\$ 21,000-\$ 50,000$ & 2 & $20 \%$ \\
$\$ 51,000-\$ 99,000$ & 2 & $20 \%$ \\
$\$ 100,000$ and above & 5 & $50 \%$ \\
N/A & 1 & $10 \%$ \\
\hline Total & 10 \\
\hline
\end{tabular}

19. Has the budget for the program increased or decreased over the past two years?

\begin{tabular}{|c|c|c|}
\hline Answer & & \\
\hline Increased & 5 & $50 \%$ \\
\hline Decreased & 0 & $0 \%$ \\
\hline Stayed the Same & 4 & $40 \%$ \\
\hline $\mathrm{N} / \mathrm{A}$ & 1 & $10 \%$ \\
\hline Total & 10 & $100 \%$ \\
\hline
\end{tabular}

20. Where are the CHAMPS/Life Skills administrative offices located on your campus?

\begin{tabular}{|l|rr|}
\hline Answer & \multicolumn{2}{c|}{} \\
\hline Student Affairs & 0 & $0 \%$ \\
Athletic Department & 10 & $100 \%$ \\
Other & 0 & $0 \%$ \\
\hline Total & 10 & $100 \%$ \\
\hline
\end{tabular}


16. Is it mandatory for your student-athletes to attend the CHAMPS/Life Skills seminars?

\begin{tabular}{|l|r|}
\hline Answer & $20 \%$ \\
\hline Yes & 2 \\
No & $80 \%$ \\
\hline Total & $100 \%$ \\
\hline
\end{tabular}

17. How would you assess the overall effectiveness of your CHAMPS/Life Skills program? Answer

\begin{tabular}{l|r} 
Very effective & $40 \%$ \\
Somewhat effective & $40 \%$ \\
Effective & 4 \\
Ineffective & $10 \%$ \\
Very Ineffective & $0 \%$ \\
N/A & $0 \%$ \\
\hline Total & 0 \\
\hline
\end{tabular}

18. What is the annual budget for your CHAMPS/Life Skills program?

\begin{tabular}{|l|r|}
\hline Answer & $0 \%$ \\
\hline Less than \$20,000 & 0 \\
$\$ 21,000-\$ 50,000$ & $20 \%$ \\
$\$ 51,000-\$ 99,000$ & $20 \%$ \\
$\$ 100,000$ and above & $50 \%$ \\
N/A & $10 \%$ \\
\hline Total & 5 \\
\hline
\end{tabular}

19. Has the budget for the program increased or decreased over the past two years?

\begin{tabular}{|l|r|}
\hline Answer & $50 \%$ \\
\hline Increased & $0 \%$ \\
Decreased & 0 \\
Stayed the Same & $40 \%$ \\
N/A & $10 \%$ \\
\hline Total & 1 \\
\hline
\end{tabular}

20. Where are the CHAMPS/Life Skills administrative offices located on your campus?

\begin{tabular}{|l|r|}
\hline Answer & \\
\hline Student Affairs & $0 \%$ \\
Athletic Department & 0 \\
Other & 10 \\
\hline Total & $0 \%$ \\
\hline
\end{tabular}


Appendix G-Recommended Life Skills Organizational Chart

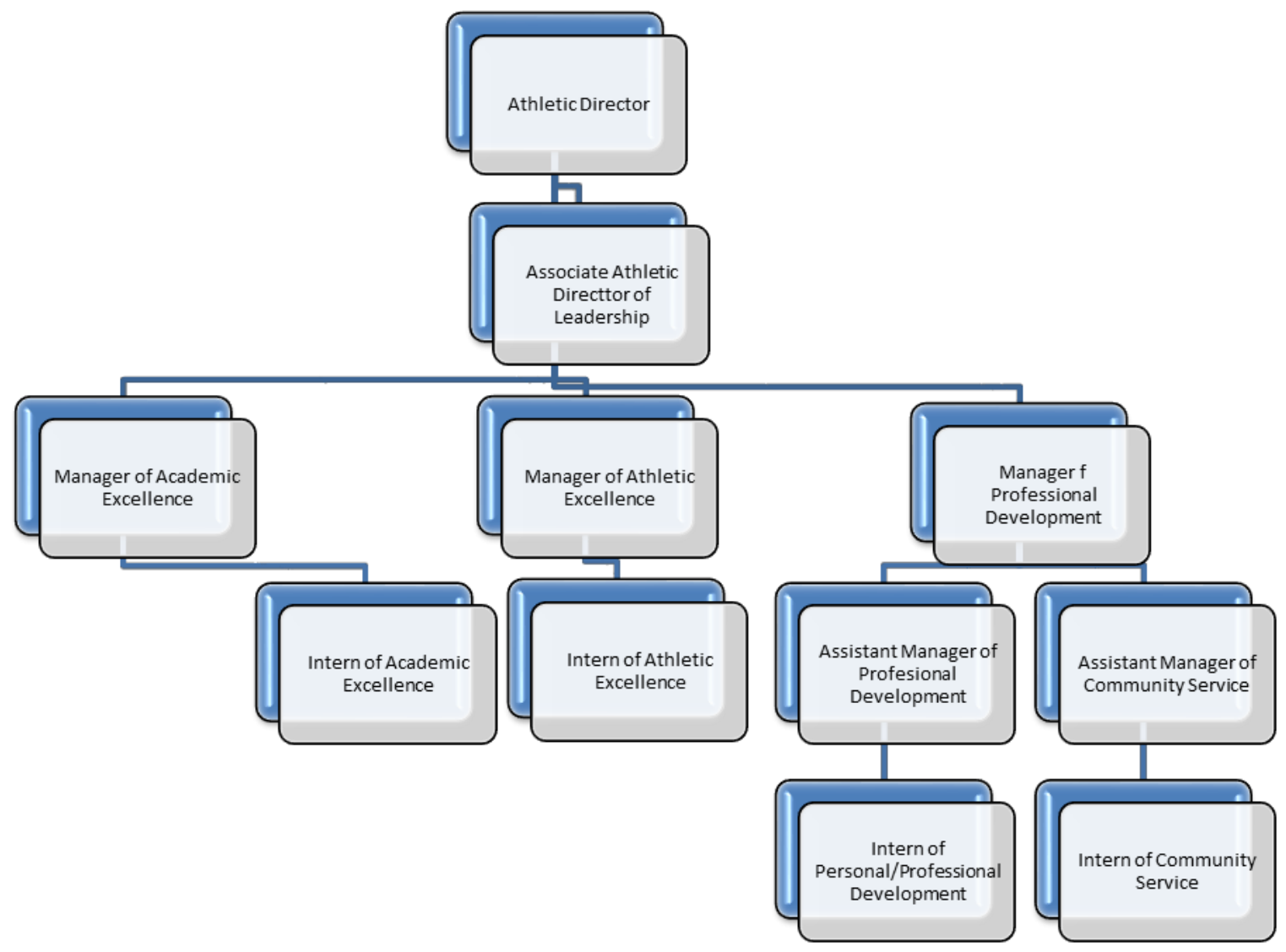

